UNIVERSIDADE DE BRASÍLIA

FACULDADE DE CEILÂNDIA

PROGRAMA DE PÓS-GRADUAÇÃO EM

CIÊNCIAS E TECNOLOGIAS EM SAÚDE

ACESSO A MEDICAMENTOS PARA HIPERTENSÃO ARTERIAL SISTÊMICA EM CEILÂNDIA: COMPONENTE DA PROMOÇÃO DO

USO RACIONAL DE MEDICAMENTOS

FABIANA XAVIER CARTAXO SALGADO

BRASÍLIA

2015 

FABIANA XAVIER CARTAXO SALGADO

\section{ACESSO A MEDICAMENTOS PARA HIPERTENSÃO ARTERIAL SISTÊMICA EM CEILÂNDIA: COMPONENTE DA PROMOÇÃO DO USO RACIONAL DE MEDICAMENTOS}

Tese apresentada ao Programa de Pós-Graduação em Ciências e Tecnologias em Saúde como requisito parcial para a defesa de tese de doutorado

Área de concentração: Promoção, Prevenção e Intervenção em Saúde

Linha de Pesquisa: Estratégias Interdisciplinares em Promoção, Prevenção e Intervenção em Saúde

Orientadora: Profa. Dra. Margô Gomes de Oliveira Karnikowski

BRASÍLIA 
Ficha catalográfica elaborada automaticamente, com os dados fornecidos pelo(a) autor(a)

Salgado, Fabiana Xavier Cartaxo

ACESSO A MEDICAMENTOS PARA HIPERTENSÃO ARTERIAL

a SISTÊMICA EM CEILÂNDIA: COMPONENTE DA PROMOÇÃO DO USO RACIONAL DE MEDICAMENTOS / Fabiana Xavier Cartaxo Salgado; orientador Margô Gomes de Oliveira Karnikowski. -- Brasilia, 2015.

$$
125 \mathrm{p} \text {. }
$$

Tese (Doutorado - Doutorado em Ciências $e$ Tecnologias em Saúde) -- Universidade de Brasilia, 2015.

1. Hipertensão Arterial Sistêmica. 2. Acesso a medicamentos. 3. Indicadores de acesso a medicamentos. I. Karnikowski, Margô Gomes de Oliveira, orient. II. Título. 
FABIANA XAVIER CARTAXO SALGADO

\section{ACESSO A MEDICAMENTOS PARA HIPERTENSÃO ARTERIAL SISTÊMICA EM CEILÂNDIA: COMPONENTE DA PROMOÇÃO DO USO RACIONAL DE MEDICAMENTOS}

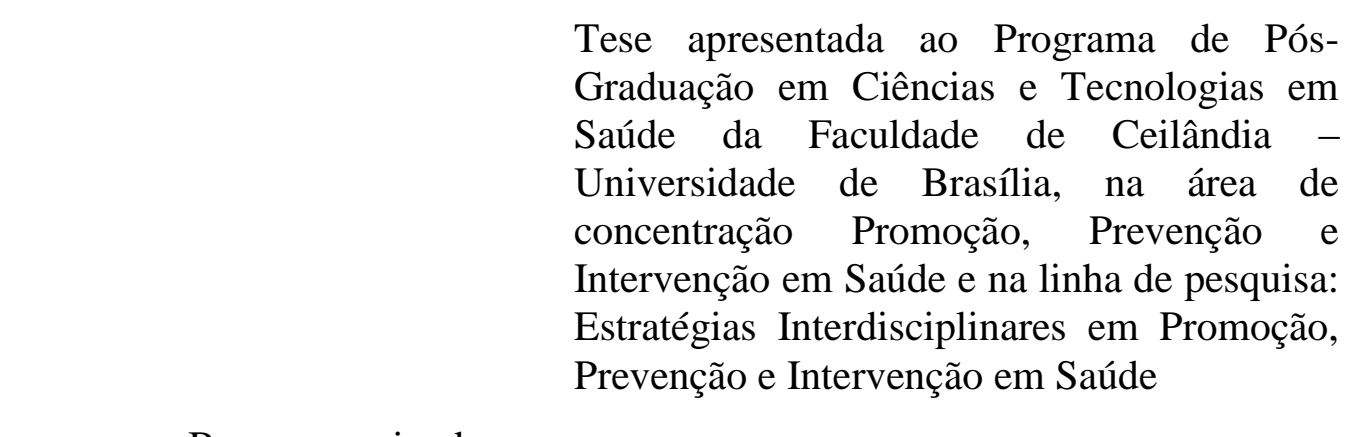

Banca examinadora

Profa Dra Margô Gomes de Oliveira Karnikowski (presidente)

Universidade de Brasília

Prof Dr Luiz Sinésio Silva Neto

Universidade Federal do Tocantins

Profa Dra Marileusa D.Chiarello

Universidade Católica de Brasília

Profa Dra Marina Morato Stival

Universidade de Brasília

Profa Dra Dayani Galato

Universidade de Brasília

Profa Dra Silvana Schwarz Funghetto (Suplente)

Universidade de Brasília 

"Talvez não tenha conseguido fazer o melhor, mas lutei para que o melhor fosse feito. Não sou o que deveria ser, mas Graças a Deus, não sou o que era antes". (Martin Luther King) 

Dedico este trabalho a minha mãe, Maria do Socorro Xavier Crispim, (in memoriam), que estava comigo no início... e meu pai, Vicente de Paulo Cartaxo Salgado (in memoriam), exemplos de amor e dedicação. 



\section{AGRADECIMENTOS}

À Deus, inicialmente à Deus... sempre à Deus... principalmente à Deus...

Ao meu amado companheiro Noriberto Barbosa da Silva, pelo amor, incentivo, cumplicidade, e paciência nos meus momentos mais difíceis;

Aos meus amados filhos Priscilla Cartaxo, Patrícia Cartaxo e Gabriel Cartaxo, porque são os meus maiores tesouros, espero sinceramente que sejam infinitamente melhores que eu;

Aos meus irmãos e toda minha grande família, herança preciosa deixada pelos meus pais;

A minha orientadora, Dra Margô, pela amizade, orientação, carinho, experiência e sabedoria nos meus momentos mais difíceis. Você é um exemplo para mim, principalmente como ser humano;

A professora Dra Noemia Urruth L. Tavares, que me ajudou imensamente no treinamento dos alunos para a coleta de dados;

Aos alunos da Iniciação Científica do curso de farmácia que me ajudaram na coleta e se dedicaram com afinco;

Aos moradores de Ceilândia que aceitaram participar do inquérito e receberam com gentileza nosso grupo do inquérito domiciliar;

Aos professores da banca examinadora, pela análise crítica e contribuições valorosas para o melhor deste trabalho;

Ao Programa de Pós-Graduação Ciências e Tecnologias em Saúde e aos cidadãos brasileiros que financiaram essa trajetória, espero poder retribuir à sociedade todo esse investimento;

Aos colegas de trabalho do Hospital Regional da Asa Norte, obrigada pela imensa compreensão e incentivo;

A todos que direta ou indiretamente me ajudaram;

À Deus, sempre à Deus... principalmente à Deus... finalmente à Deus. 



\section{SUMÁRIO}

1. INTRODUÇÃO 23

$\begin{array}{ll}\text { 1.1. Objetivos } & 27\end{array}$

1.1.1. Objetivo geral 27

1.1.2. Objetivos específicos 27

2. ARTIGO 29

2.1. Dimensões of access to antihypertensive medications in Ceilândia, Distrito Federal, Brazil 31

3. DISCUSSÃO GERAL E CONCLUSÕES 33

3.1. Construindo o caminho: Detalhes do Inquérito Domiciliar 35

3.2. Reflexões e perspectivas $\quad 37$

REFERÊNCIAS BIBLIOGRÁFICAS 43

$\begin{array}{lll}\text { ANEXOS } & 47\end{array}$ 



\section{LISTA DE TABELAS}

\section{DISCUSSÃO GERAL E CONCLUSÕES}

Tabela 1 Classe farmacêutica e principais medicamentos anti-hipertensivos 38 Prescritos e faltosos nas farmácias do SUS e popular

Tabela 2 Variáveis comportamentais de fumo, bebida alcoólica, dieta e exercício $\mathbf{4 0}$ físico 



\section{LISTA DE ABREVIATURAS E SIGLAS}

CNEFE Cadastro Nacional de Endereços para Fins Estatísticos

DCNT Doenças Crônicas Não Transmissíveis

DCV Doenças Cardiovasculares

DF Distrito Federal

DM Diabetes mellitus

HAS Hipertensão Arterial Sistêmica

IBGE Instituto Brasileiro de Geografia Estatística

IMC Índice de Massa Corporal

OMS Organização Mundial da Saúde

PNAUM Pesquisa Nacional sobre Acesso, Utilização e Uso Racional de Medicamentos

RA Regional Administrativa

RENAME Relação Nacional de Medicamentos Essenciais

SUS Sistema Único de Saúde

URM Uso Racional do Medicamento 

SALGADO, F X C. Acesso a medicamentos para Hipertensão Arterial Sistêmica em Ceilândia: componente da promoção do Uso Racional de Medicamentos. 2015. Tese de doutorado. (Programa de Pós-Graduação em Ciências e Tecnologias em Saúde) - Universidade de Brasília - Faculdade de Ceilândia, Ceilândia, Brasília, 2015.

\section{RESUMO}

Introdução: As Doenças Crônicas Não-Transmissíveis (DCNT) representam as principais causas de morte no mundo. A Hipertensão Arterial Sistêmica (HAS) é a mais prevalente. O medicamento anti-hipertensivo constitui-se um importante meio de controle da doença e seu acesso deve ser assegurado. Este trabalho busca avaliar o acesso da população de Ceilândia a medicamentos para o tratamento da Hipertensão Arterial Sistêmica. Métodos: Estudo epidemiológico realizado por Inquérito domiciliar com delineamento transversal. Foram investigados perfil epidemiológico e socioeconômico, hábitos comportamentais, DCNT e a idade em que foram diagnosticadas. Verificou-se as dimensões de acesso a medicamentos antihipertensivos referentes a disponibilidade física, monetária, geográfica e de aceitabilidade encontradas pelos usuários hipertensos de Ceilândia. Resultados: $\mathrm{O}$ universo amostral foi de 400 indivíduos e a amostra de hipertensos de 140 (35\%). A primeira morbidade a ser diagnosticada foi a HAS (43,08 $\pm 12,3$ anos), seguida da Diabetes Mellitus (DM) $(50,0 \pm 12,9$ anos), Dislipidemias (DLP) (50,3 $\pm 14,9$ anos) e a Artrite Reumatoide (AR) (51,5 $\pm 14,4$ anos). A avaliação do acesso aos medicamentos anti-hipertensivos sob a dimensão da disponibilidade física, revelou que os usuários encontraram dificuldades para aquisição em quase um terço das oportunidades e em alguns casos não obtiveram acesso gratuito a nenhum desses produtos, o que reverberou na aquisição dos medicamentos através de recursos financeiros próprios. A maior dificuldade de acesso foi verificada nas farmácias do Sistema Único de Saúde e farmácias populares. A população hipertensa apresentou um perfil de obesidade, baixa escolaridade, menor renda per capita e a atitude de reduzir o sal na dieta de forma significativa, bem como uma maior associação com outras morbidades, quando comparado aos não hipertensos. Conclusão: $O$ acesso aos medicamentos essenciais ao tratamento da HAS encontra-se comprometido, devido ao desabastecimento da rede pública de saúde, o que tem onerado o usuário. Trata-se de uma população que apresenta morbidades associadas, aliadas a hábitos de vida considerados de risco para o agravamento da doença. Estes resultados revelam a necessidade de implementação de políticas públicas eficazes, que assegurem o acesso aos medicamentos anti-hipertensivos e envolvam a participação do usuário na mudança de hábitos e comportamentos, a fim de promover o controle adequado e sustentado da Hipertensão Arterial Sistêmica.

Palavras-chave: Acesso a saúde, Hipertensão Arterial Sistêmica, tratamento medicamentoso 

SALGADO, F X C. Access to medicines for Hypertension in Ceilândia: promotion component of Rational Use of Drugs. 2015. Doctoral thesis. (Post Graduate Program in Sciences and Technologies in Health) - University of Brasília - Faculty of Ceilândia, Ceilândia, Brasília, 2015.

\begin{abstract}
Objective: The chronic non-communicable diseases (CNCD) is the leading cause of death worldwide. Systemic arterial hypertension $(\mathrm{SAH})$ is the most prevalent. The antihypertensive drug constitutes an important means of controlling the disease and its access should be ensured. This work aims to assess the access of the population of Ceilândia drug for the treatment of Hypertension. Methods: Epidemiological study carried out by household survey with crosssectional design. They were investigated epidemiological and socioeconomic profile, behavioral habits, NCDs and the age they were diagnosed. There was the dimensions of access to antihypertensive drugs regarding the physical availability, monetary, geographic and acceptability encountered by users of hypertensive Ceilândia. Results: The sample universe was 400 subjects and hypertensive sample of 140 (35\%). The first to be diagnosed morbidity was hypertension (43.08 \pm 12.3 years), followed Diabetes Mellitus (DM) $(50.0 \pm 12.9$ years), dyslipidemia (DLP) $(50.3 \pm 14.9$ years) and Rheumatoid Arthritis (RA) $(51.5 \pm 14.4$ years). The evaluation of access to anti-hypertensive drugs on the size of physical availability, revealed that users found it difficult to acquire in nearly a third of opportunities and in some cases did not obtain free access to any of these products, which reverberated in the purchase of medicines through its own financial resources. The more difficult access was found in pharmacies of the Unified Health System and drugstores. The hypertensive population showed an obesity profile, low education, lower per capita income and the attitude of reducing salt in the diet significantly and a higher association with other diseases compared to non-hypertensive. Conclusion: Access to essential medicines for treatment of hypertension is impaired due to the shortage of public health system, which has burdened the user. It is a population that has associated morbidities, combined with lifestyle at risk for the disease from worsening. These results reveal the need to implement effective public policies that ensure access to antihypertensive medications and involve user participation in changing habits and behaviors in order to promote proper and sustained control of hypertension.
\end{abstract}

Keywords: Health Care Access, Systemic Arterial Hypertension, Drugs treatments 



\section{INTRODUÇÃO}

A saúde é assegurada na legislação brasileira enquanto um direito de cidadania a ser garantido pelo Estado e a universalidade da atenção implica, necessariamente, na formulação de um modelo social, ético e equânime.

A Constituição da República Federativa do Brasil, de 1988 em seu Art. 196 dita: “A saúde é direito de todos e dever do Estado, garantido mediante políticas sociais e econômicas que visem à redução do risco de doenças e de outros agravos e ao acesso universal, igualitário às ações e serviços para sua promoção, proteção e recuperação".

Conforme a Lei Complementar no 8080 do 19 de setembro de 1990 no Art. 2 - "A saúde é um direito fundamental do ser humano, devendo o Estado prover as condições indispensáveis ao seu pleno exercício".

A criação do Sistema Único de Saúde (SUS) foi um avanço decisivo na consolidação deste direito fundamental do cidadão, baseados em três princípios básicos de Universalidade, Integralidade e Equidade.

No entanto, o princípio da Universalidade é um desafio relevante e se não implementado compromete a efetiva consolidação do SUS, na medida em que o cidadão encontra dificuldades no acesso aos serviços e aos demais recursos em saúde, incluindo aqueles que constituem a assistência farmacêutica. Surge, portanto, a necessidade de identificação das questões referentes aos problemas encontrados pelo usuário na busca por estes serviços.

"É na unidade de relação do usuário com os serviços que devem
ser centradas as análises que busquem conhecer como o direito à
saúde se expressa concretamente no cotidiano das pessoas. A
categoria central para análise dessas inter-relações é o acesso"”
(GIOVANELLA e FLEURY, 1996). ${ }^{1}$

Nesse sentido, o impasse vivenciado com a concretização do acesso universal aos serviços de saúde e a disponibilidade de todos os recursos necessários para atender as necessidades da população na área, requer o fortalecimento constante da saúde como um bem público, e como direito individual e coletivo. ${ }^{1}$ Esta leitura da realidade implica práticas construídas a partir de uma gestão democrática e participativa que se reflete em todos os níveis de atenção à saúde, tanto no setor público quanto privado.

Assim sendo, o acesso não se restringe a disponibilidade ao produto ou recursos, pois se insere em complexa rede e inclui diferentes aspectos e constructos relacionados entre si. ${ }^{2}$ Acesso a assistência de saúde inclui o fornecimento de medicamentos para garantir o direito à saúde, e, por consequência, o direito fundamental à vida, requer do Estado uma ação positiva, 
uma ação em que o Estado garanta ao cidadão, o fornecimento do medicamento indispensável para o seu tratamento. ${ }^{3}$

Neste contexto, o acesso aos medicamentos essenciais ganha relevância, uma vez que tem por princípio contribuir com o tratamento das doenças mais prevalentes, que acometem a população. ${ }^{4}$ A realização deste direito envolve várias combinações de provisão de serviços e financiamentos públicos e privados. ${ }^{5}$

$\mathrm{O}$ acesso aos medicamentos sumariza um conjunto de áreas mais específicas de ajuste entre o paciente e o sistema de saúde. Desta forma, algumas dimensões específicas foram relatadas na literatura, na questão do acesso a medicamentos e serviços de saúde, ampliando a compreensão do que se entende por acesso. ${ }^{6}$

A primeira dimensão refere-se à disponibilidade física do produto, definida pela relação entre o tipo e quantidade do produto ou serviço requerido e fornecido. A segunda trata da capacidade aquisitiva, relaciona-se ao aspecto da dimensão do custo, aos preços dos serviços e à capacidade das pessoas em efetuar o pagamento dos medicamentos requeridos. A terceira faz menção a acessibilidade geográfica, que se refere à existência dos serviços no lugar e no momento em que é requerido pelas pessoas e, portanto, retrata à relação entre a localização de produtos e serviços e a localização do eventual usuário, de modo a considerar os recursos do usuário no transporte, tempo de viagem e distância. A última é a dimensão da aceitabilidade ou satisfação que refere a relação entre atitudes e expectativas dos usuários sobre os produtos e serviços e características reais dos mesmos. ${ }^{6}$

Cabe ressaltar que as quatro dimensões se encontram intimamente relacionadas à Assistência Farmacêutica, que é entendida como parte do cuidado à saúde individual ou coletiva, tendo no medicamento o insumo essencial, cujo acesso deve ser garantido, na prerrogativa do uso racional. ${ }^{7}$ Sendo assim, a Assistência Farmacêutica se concretiza mediante o acesso aos medicamentos pelos usuários, nas quantidades adequadas e no momento necessário. Em vista disso, o Estado gestor orienta-se para a provisão de medicamentos considerados essenciais ou que tratam as doenças de grande impacto para a saúde pública.

No Brasil, o acesso a medicamentos essenciais considerando o Uso Racional do Medicamento (URM), se inscreve no marco doutrinário do Sistema Único de Saúde. ${ }^{4}$ Sendo assim, a assistência farmacêutica, e, portanto, a garantia de acesso aos medicamentos, devem atender aos princípios da universalidade, integralidade e equidade. ${ }^{8-9-10-11}$ Esta garantia é um indicador da qualidade e resolutividade do sistema de saúde e um determinante importante no cumprimento da terapia medicamentosa prescrita. 
A literatura indica que a ausência de acesso é uma causa frequente de retorno de pacientes aos serviços de saúde. ${ }^{12}$ Ainda em 1970, uma lista de medicamentos que atendesse a resolução das doenças mais prevalentes em uma determinada população foi recomendada pela Organização Mundial da Saúde (OMS). Em 1989, o Brasil cria a Relação Nacional de Medicamentos Essenciais (RENAME), prioridade na política farmacêutica do País. Os critérios de seleção dos medicamentos contidos na RENAME obedecem aos princípios de eficácia, segurança e custo-efetividade, o que favorece aos ditames do Uso Racional de Medicamentos. ${ }^{7} \mathrm{O}$ URM se estabelece quando há uma prescrição apropriada à necessidade clínica, na dose e posologia correta, por um período de tempo adequado a eficácia e ao menor custo para si e para a comunidade. ${ }^{13}$

No entanto, a adoção de tais estratégias não pareceu refletir avanços significativos no que se refere ao acesso e o URM. Nas áreas mais pobres do Brasil, a exemplo de outros países da América Latina, África e Ásia, os medicamentos se encontraram inacessíveis para mais de $50 \%$ da população, demonstrando que boa parcela de pessoas não possuía acesso regular aos medicamentos essenciais. ${ }^{14-15}$ Pesquisas regionais realizadas no Brasil têm relatado um índice elevado de desabastecimento de medicamentos essenciais no âmbito do SUS. 16-17-18

Na década de 90 o usuário brasileiro, no tocante ao perfil de consumo de medicamentos, foi dividido em três grupos: os que possuíam renda acima de 10 salários mínimos (15\% da população) consumiam $48 \%$ da produção total de medicamentos; o grupo com renda entre quatro e 10 salários mínimos (34\%) consumiam 36\% da produção e os que tinham renda entre zero e quatro salários mínimos ( $51 \%$ da população) consumiam $16 \%$ da produção. ${ }^{8}$ Este fato evidenciou claramente que, por razões socioeconômicas, o acesso à terapia medicamentosa não ocorreu de forma igual na população, ficando comprometido para os milhões de brasileiros que tinham baixa renda.

Contudo, estes dados precedem a formulação e implantação da Política Nacional de Medicamentos e da Política Nacional de Assistência Farmacêutica, bem como dos programas de governo que priorizaram o acesso a medicamentos, contemplando seu uso racional ao promover a continuidade do tratamento. ${ }^{19-20}$

Um dos programas lançados pelo Governo Federal em 2004 foi o Programa Farmácia Popular do Brasil, que surgiu como estratégia de ampliação do acesso aos medicamentos essenciais, de modo a enfocar aqueles utilizados para o tratamento da Hipertensão Arterial Sistêmica (HAS) e Diabetes mellitus (DM). No âmbito do Programa, os medicamentos para o tratamento destas doenças eram disponibilizados a baixo custo para a população que fazia uso de serviços privados, mas possuía dificuldade de acesso a medicamentos. ${ }^{21}$ 
No ano de 2011 o governo lançou o Programa Saúde Não Tem Preço, o qual visa garantir o acesso gratuito aos medicamentos para o tratamento da HAS e DM. A oferta de medicamentos gratuitos ocorre por intermédio da rede "Aqui Tem Farmácia Popular" e se propõem a beneficiar 33 milhões de brasileiros hipertensos e 7,5 milhões de diabéticos, podendo assim colaborar para a continuidade do tratamento e para o URM. ${ }^{22}$

A implementação de Programas desta ordem contribui para a disponibilidade dos medicamentos, porém não garante necessariamente o acesso aos mesmos, uma vez que existem outras dimensões determinantes para a questão, conforme descrito anteriormente. O acesso a medicamentos essenciais permanece sendo um importante desafio para a saúde pública, sobretudo no caso de Doenças Crônicas Não Transmissíveis (DCNT), que necessitam de terapia medicamentosa de uso contínuo.

Entre as DCNT destaca-se a Hipertensão Arterial Sistêmica que representa importante problema de saúde pública em todos os países, e assume ônus crescente e preocupante, independentemente de seu grau de desenvolvimento. ${ }^{23-24-25-26}$

A hipertensão arterial sistêmica é uma condição clínica multifatorial caracterizada por níveis elevados e sustentados de pressão arterial, associados frequentemente ao aumento do risco de eventos cardiovasculares fatais e não-fatais ${ }^{27}$. A hipertensão tem alta prevalência e baixas taxas de controle, é considerada um dos principais fatores de risco modificáveis. Inquéritos populacionais em cidades brasileiras nos últimos 20 anos apontaram uma prevalência de HAS acima de $30 \%$. $^{28-29}$

A instituição do tratamento medicamentoso visa à proteção dos órgãos-alvos; redução do impacto causado pela elevação da Pressão Arterial, redução do impacto causado pela presença de fatores de risco associados e na progressão do processo aterosclerótico. ${ }^{30}$ São inúmeras as consequências advindas da ausência do medicamento para o tratamento da HAS tanto em termos individuais quanto coletivos, uma vez que recai sobre o sujeito e sociedade o ônus social e econômico das possíveis sequelas e mortalidade resultantes das barreiras de acesso a esses produtos. Neste sentido é que o medicamento se fundamenta enquanto bem público cujo acesso deve ser garantido ao cidadão como parte integrante do direito à saúde.

A Ceilândia, Regional Administrativa (RA) do Distrito Federal onde se investigou o acesso da população aos medicamentos utilizados para HAS, apresenta uma história singular de movimentos sociais e culturais de visibilidade nacional e com grande potencial de mobilização, identificadas diretamente com as necessidades de sua população e que se reflete inclusive na área de saúde. Da população de Ceilândia 88,85\% utiliza o serviço público de saúde e deste total $87,55 \%$ utilizam os serviços da própria Região. ${ }^{31}$ 
A realização da presente pesquisa na Região Administrativa de Ceilândia acontece num contexto de valorização e reconhecimento da importância da produção técnica de estudos e informações como subsídio ao planejamento estratégico de políticas públicas, na promoção da saúde e na melhoria da qualidade de vida da população de Ceilândia.

A ausência de investigações epidemiológicas que revelem o atual cenário de acesso da população de Ceilândia ao tratamento medicamentoso para HAS, proposto nas políticas e programas vigentes no Brasil, pode comprometer o redirecionamento e formulação de políticas, assim como o planejamento de estratégias em saúde. Estes fatos, adicionados a necessidade de se criar indicadores para melhor compreender e avaliar as dimensões do acesso a medicamentos para o tratamento de HAS justificaram a realização da presente Tese de Doutorado.

Ao avaliar o acesso a medicamentos utilizados para tratamento da hipertensão, pode-se contribuir para o entendimento da influência das políticas públicas de assistência farmacêutica, da produção do setor industrial farmacêutico, e da qualidade dos serviços de saúde, identificada a partir do acesso da população a medicamentos essenciais.

A realização dessa pesquisa de doutorado contribui para construção de conhecimento inovador junto a literatura científica, ao apresentar indicadores para as dimensões do acesso a medicamentos anti-hipertensivos, que subsidiará a avaliação mais criteriosa do acesso a esses produtos na perspectiva do uso racional.

Para tanto, elenca-se os seguintes objetivos:

\subsection{Objetivos}

\subsubsection{Objetivo geral}

Avaliar o acesso da população de Ceilândia a medicamentos para o tratamento de Hipertensão Arterial Sistêmica, enquanto estratégia basilar para o Uso Racional de Medicamentos.

\subsubsection{Objetivos específicos:}

a) caracterizar a população hipertensa de Ceilândia quanto a aspectos socioeconômicos;

b) elaborar indicadores de avaliação das dimensões física, monetária, geográfica e de aceitabilidade dos medicamentos anti-hipertensivos;

c) investigar a disponibilidade dos medicamentos, quanto às especificidades do produto e quantidade requerida pelo usuário para tratamento da HAS;

d) investigar as dificuldades e formas de aquisição ou pagamento do medicamento requerido pelo usuário; 
e) investigar o acesso geográfico aos locais que disponibilizam medicamentos para o tratamento da HAS;

f) verificar a aceitabilidade e satisfação do usuário com relação às características dos medicamentos utilizados para o tratamento da HAS. 
2. ARTIGO 


\title{
Dimensions of Access to Antihypertensive Medications in Ceilândia, Distrito Federal, Brazil
}

Fabiana Xavier Cartaxo Salgado1, Dayani Galato1, Gislane Ferreira de Melo², Marileusa Dosolina Chiarello², Aline Gomes de Oliveira1, Letícia Farias Gerlack1, Micheline Marie Milward de Azevedo Meiners' ${ }^{3}$, Margô Gomes de Oliveira Karnikowski1

\author{
${ }^{1}$ Graduate Program in Health Sciences and Technology, Campus of Ceilândia, University of Brasília (FCE/UnB), \\ Brasília, Brazil \\ ${ }^{2}$ Graduate Program in Gerontology, Catholic University of Brasília (UCB), Brasília, Brazil \\ ${ }^{3}$ Graduate Program in Public Health, University of Brasília (UnB), Brasília, Brazil \\ Email: fabianacartaxo@yahoo.com.br, dayanigalato@unb.br, gmelo@ucb.br, mdc@pos.ucb.br, \\ alinegoma1@gmail.com, leticiafg@yahoo.com.br, michelinemeiners@gmail.com, margo@unb.br \\ Received 20 October 2015; accepted 14 November 2015; published 17 November 2015
}

Copyright (C) 2015 by authors and Scientific Research Publishing Inc.

This work is licensed under the Creative Commons Attribution International License (CC BY).

http://creativecommons.org/licenses/by/4.0/ (c) (1) Open Access

\section{Abstract}

Access can be understood as the sum of a number of elements of the interface between patients and the health care system. This study took a comprehensive approach to the dimensions of access to medications, employing indicators to evaluate the dimensions of access to antihypertensive medications in Ceilândia, DF, Brazil. This was a cross-sectional epidemiological study, administering questionnaires during home visits. The survey covered epidemiological and socioeconomic profiles, behavioral habits and the dimensions of access to antihypertensive medications comprising physical, financial, and geographic availability and accept ability according to the hypertensive population of Ceilândia. The total sample comprised $\mathbf{4 0 0}$ individuals and the hypertensive subset numbered $140(35 \%)$. Indicators of physical availability of medications revealed that users found it difficult to acquire their drugs on almost one third of occasions and in some cases were unable to access any of these products. The greatest barriers to access were reported by users of pharmacies belonging to the Brazilian National Health Service (SUS) and on the "People's Pharmacies" network. More than one third of the hypertensive sample spent their own money on medications they could not find at these pharmacies. The majority of the hypertensive subsets were overweight/obese, a minority engaged in physical activity and $40 \%$ were smokers/ex-smokers. More women reduced their salt intake. Men had higher incomes, educational level, and socioeconomic status. Failure to keep the public health care system supplied has prejudiced access to essential medications for hypertension treatment, transferring the costs onto users. This population has lifestyle habits that increase the risk of exacerbation of hypertension. These results reveal a

How to cite this paper: Salgado, F.X.C., Galato, D., Melo, G.F., Chiarello, M.D., Oliveira, A.G., Gerlack, L.F., Meiners, M.M.M.A. and Karnikowski, M.G.O. (2015) Dimensions of Access to Antihypertensive Medications in Ceilândia, Distrito Federal, Brazil. Health, 7, 1517-1526. http://dx.doi.org/10.4236/health.2015.711165

Íntegra do artigo encontra-se publicado na revista Health, no link abaixo:

http://www.scirp.org/journal/PaperInformation.aspx?PaperID=61183 
3. DISCUSSÃO GERAL E CONCLUSÕES 


\subsection{Construindo o caminho: Detalhes do Inquérito Domiciliar}

Para o desenvolvimento dessa tese foi inicialmente realizado um inquérito domiciliar na RA da Ceilândia, com instrumento de coleta de dados elaborado e adaptado a partir da Pesquisa Nacional sobre Acesso, Utilização e Uso Racional de Medicamentos (PNAUM), que investigou o acesso, utilização e Uso Racional de Medicamentos para diferentes enfermidades agudas e crônicas na população brasileira. Cabe ressaltar que a tese se encontra inserida no âmbito da PNAUM, estudo da qual a doutoranda participou das reuniões no Ministério da Saúde e reuniões satélites em outras capitais, colaborando na elaboração do inquérito nacional, na discussão de questões técnicas e operacionais. Enfatiza-se que na PNAUM nove Estabelecimentos de Educação Superior do país participaram, sendo estes a Faculdade de Ciências Médicas da Santa Casa de São Paulo, Universidade Federal de Santa Catarina, Universidade de São Paulo, Universidade Federal do Rio Grande do Sul, Universidade Federal da Bahia, Escola Nacional de Saúde Pública (FioCruz), Universidade Federal do Ceará, Universidade Federal de Minas Gerais e Universidade de Brasília

Com o objetivo principal de verificar o acesso a medicamentos anti-hipertensivos em suas diferentes dimensões, bem como a prevalência da HAS na população de Ceilândia foi realizado estudo epidemiológico com delineamento transversal, por entender-se que os Inquéritos domiciliares de base populacional representam oportunidades ímpares para a obtenção de informações sobre o uso de serviços e produtos em saúde.

Para tanto foi utilizado o processo de amostragem probabilístico em múltiplos estágios, conforme preconizado por autores de estudos nos quais é empregada a teoria probabilística da abordagem quantitativa de pesquisa, e descrita em detalhes no primeiro artigo.

Para a execução da entrevista domiciliar foram selecionados 15 entrevistadores entre alunos de Iniciação Científica da Universidade de Brasília, Faculdade de Ceilândia, do curso de Farmácia, ocasião em que foram eleitos alunos com o perfil mais apropriado a dinâmica do projeto, priorizando-se adjetivos como: responsabilidade, comprometimento, interesse no tema abordado pela pesquisa, disponibilidade, entre outros. Todas as etapas do projeto foram supervisionadas pela doutoranda e orientadora.

Os entrevistadores receberam um manual contendo informações das boas práticas de abordagem e treinamento, ocasião em que foram orientados a não influenciar a percepção que o respondente possui, assumindo, assim, uma postura neutra, além de registrar corretamente as respostas para posterior codificação. Foi realizado uma experiência de campo onde foram efetivados ajuste das questões, correções de falhas de linguagem e dificuldades de compreensão. 
Cada entrevistador recebeu um kit de coleta de dados composto pelos roteiros de viagens, pelos questionários, Termo de Consentimento Livre e Esclarecido, manuais, canetas, crachás, cartas de apresentação e relação de endereços a serem visitados.

Os dados coletados durante o inquérito domiciliar foram armazenados em arquivos eletrônicos do EpiData ${ }^{\circledR}$ versão 3.1 e comparados por dupla conferência com os originais a fim de checar possíveis erros de digitação. Foram geradas tabelas básicas de frequência para identificar valores discrepantes, os quais possibilitaram correções, juntamente com um controle de qualidade em relação as entrevistas em uma amostra de aproximadamente $10 \%$ dos indivíduos estudados.

A PNAUM, projeto no qual a presente proposta encontra-se inserida, foi submetida e aprovado pelo Comitê de Ética em Pesquisa da Universidade Federal do Rio Grande do Sul, sob protocolo $\mathrm{N}^{\mathrm{o}}$ 18947013.6.0000.0008. Esta pesquisa foi também submetida ao Comitê de Ética em Pesquisa/Faculdade de Saúde/Universidade de Brasília sob protocolo $\mathrm{N}^{\circ}$ 29298814.0.0000.0030. Consentimentos livres e esclarecidos foram obtidos dos participantes antes da entrevista, garantindo o sigilo quanto à identidade, confidencialidade das informações, bem como o direito de não participar ou suspender a participação a qualquer momento. 


\subsection{Reflexões e perspectivas}

A Constituição Federal de 1988 estabelece que o direito a saúde deve ser garantido mediante políticas sociais e econômicas que tenham o objetivo de reduzir o risco de doenças e de garantir o acesso universal e igualitário às ações e serviços voltados para a promoção, proteção e recuperação da saúde.

Os serviços de saúde devem expressar, portanto, as políticas públicas e sociais na garantia do direito a saúde em toda sua amplitude. $\mathrm{O}$ acesso aos medicamentos se encontra implícito neste direito, sendo um indicador da qualidade e resolutividade do sistema de saúde. O usuário deste serviço torna-se um interlocutor da concretude e efetividade das políticas públicas de saúde e os inquéritos populacionais são instrumentos que podem retratar as dificuldades cotidianamente enfrentadas pelos usuários, na busca pelos produtos e serviços.

Diferentemente dos estudos realizados em serviços de saúde, a abordagem populacional permite identificar dificuldades de acesso a medicamentos mesmo em indivíduos que não utilizam o serviço.

Os resultados dessa tese, a partir do inquérito domiciliar, revelam um comprometimento do acesso a medicamentos para tratamento da HAS, na população de Ceilândia. Neste sentido, os princípios de prestação de assistência universal, equânime e, acima de tudo, resolutiva à população, encontram-se comprometidos pela falta de medicamentos de fornecimento gratuito. Haja vista o desabastecimento da rede pública de saúde, representada nesta pesquisa, pelas farmácias do SUS e farmácias populares.

Cabe ressaltar que a situação encontrada ocorre em um país onde há políticas públicas bem definidas para a área, e programas de governo que se propõem manter a gratuidade para medicamentos essenciais, em especial aqueles para o tratamento de HAS.

A ausência do medicamento anti-hipertensivo no local e momento requerido compromete o uso racional do medicamento, convergindo assim para a descontinuidade do tratamento e/ou para a oneração financeira do usuário com consequências incomensuráveis, tanto do ponto de vista clínico, quanto da repercussão social. Ampliar o acesso e promover o uso racional de medicamentos se constitui, ainda, em um grande desafio para os serviços no SUS.

$\mathrm{Na}$ presente pesquisa, se verificou ainda, quais eram os principais medicamentos antihipertensivos prescritos, bem como os principais medicamentos que faltaram nas farmácias referidas neste trabalho. (Tabela 1 ). 
Tabela 1. Classe farmacêutica e principais medicamentos anti-hipertensivos prescritos e faltosos nas farmácias do SUS e popular

\begin{tabular}{|c|c|c|c|}
\hline Principais & & Principais & \\
\hline $\begin{array}{l}\text { medicamentos anti- } \\
\text { hipertensivos } \\
\text { prescritos }\end{array}$ & $\begin{array}{c}\text { Classe } \\
\text { Farmacêutica }\end{array}$ & $\begin{array}{c}\text { medicamentos anti- } \\
\text { hipertensivos que } \\
\text { faltaram nas farmácias }\end{array}$ & $\begin{array}{c}\text { Classe } \\
\text { Farmacêutica }\end{array}$ \\
\hline $\begin{array}{c}\text { Losartana } \\
16,8 \% \quad(n=38)\end{array}$ & $\begin{array}{l}\text { Antagonista da } \\
\text { angiotensina II }\end{array}$ & $\begin{array}{c}\text { Losartana } \\
(13 \%)\end{array}$ & $\begin{array}{l}\text { Antagonista da } \\
\text { angiotensina II }\end{array}$ \\
\hline $\begin{array}{l}\text { Hidroclorotiazida } \\
14,6 \% \quad(n=33)\end{array}$ & Diurético & $\begin{array}{l}\text { Atenolol } \\
(14 \%)\end{array}$ & Betabloqueantes \\
\hline $\begin{array}{c}\text { Atenolol } \\
12,8 \%(n=29)\end{array}$ & Betabloqueantes & $\begin{array}{l}\text { Anlodipino } \\
\qquad(11 \%)\end{array}$ & $\begin{array}{c}\text { Bloqueadores dos } \\
\text { canais de cálcio }\end{array}$ \\
\hline $\begin{array}{c}\text { Anlodipino } \\
11,9 \% \quad(n=27)\end{array}$ & $\begin{array}{l}\text { Bloqueadores } \\
\text { dos canais de } \\
\text { cálcio }\end{array}$ & $\begin{array}{c}\text { Captopril } \\
(30 \%)\end{array}$ & $\begin{array}{l}\text { Antagonista da } \\
\text { angiotensina }\end{array}$ \\
\hline $\begin{array}{c}\text { Enalapril } \\
10,6 \% \quad(n=24)\end{array}$ & $\begin{array}{l}\text { Antagonista da } \\
\text { angiotensina }\end{array}$ & $\begin{array}{l}\text { Enalapril } \\
(12,5 \%)\end{array}$ & $\begin{array}{l}\text { Antagonista da } \\
\text { angiotensina }\end{array}$ \\
\hline $\begin{array}{l}\text { Indapamida } \\
9,3 \%(n=21)\end{array}$ & Diurético & $\begin{array}{l}\text { Hidroclorotiazida } \\
\qquad(3 \%)\end{array}$ & Diurético \\
\hline $\begin{array}{c}\text { Captopril } \\
4,4 \%(n=10)\end{array}$ & $\begin{array}{l}\text { Antagonista da } \\
\text { angiotensina }\end{array}$ & $\begin{array}{c}\text { Indapamida } \\
\qquad(5 \%)\end{array}$ & Diurético \\
\hline
\end{tabular}

A constatação de que os principais medicamentos prescritos aos hipertensos também são os que mais faltaram endossa a evidência de uma descontinuidade no tratamento da HAS.

A VI Diretriz Brasileira de Hipertensão aponta que estudos de desfechos clinicamente relevantes demonstraram redução de morbidade e mortalidade em hipertensos tratados com diuréticos $^{32}$, betabloqueadores ${ }^{33,34}$, inibidores da enzima conversora da angiotensina (IECA) 32,35,36, bloqueadores do receptor AT1 da angiotensina II (BRA II) ${ }^{37,38}$ e com antagonistas dos 
canais de cálcio (ACC) $)^{32,35,36,39,40}$, classes farmacêuticas estas contempladas nos medicamentos utilizados pelos hipertensos da presente pesquisa.

A mortalidade por doença cardiovascular (DCV) aumenta progressivamente com a elevação da pressão arterial de forma linear, contínua e independente ${ }^{1}$. O tratamento antihipertensivo visa não só a redução da pressão arterial, mas também suas diversas repercussões sistêmicas. Entre os hipertensos investigados, observou-se uma prevalência de $40 \%$ com outro problema de saúde advindo da hipertensão.

No Brasil, as DCV têm sido a principal causa de morte e responsáveis por alta frequência de internações, ocasionando custos médicos e socioeconômicos elevados ${ }^{1,3}$. O ônus social e econômico da interrupção do tratamento de DCNT, sobretudo a HAS, apresenta-se nesse contexto potencializado, devido a cascata de eventos sistêmicos a que estão expostos, a população diretamente vulnerável e a sociedade como um todo, que financia uma administração de recursos mal administrados.

Sabemos que a hipertensão é uma doença multifatorial e seu tratamento envolvendo outros profissionais de saúde, as sociedades científicas e as agências governamentais, é fundamental para se atingir metas aceitáveis de tratamento e controle da HAS. Para tanto tornase necessário dirimir fatores de risco modificáveis tais como: excesso de peso e obesidade, ingestão excessiva de sal, abuso na ingestão de álcool, fumo e sedentarismo. Estas variáveis comportamentais foram exploradas em nossa pesquisa (Tabela 2).

Foi observado que a população hipertensa da Ceilândia apresenta elevados índices de sobrepeso e obesidade, aliados a baixa adesão de práticas de exercício físico, conforme descritos nos artigos resultantes da presente pesquisa. No entanto, torna-se relevante salientar que $62,1 \%$ dos usuários da pesquisa relataram que a cidade não oferece, de forma suficiente, áreas de lazer e de práticas esportivas para a população. Em adição, 74,1\% dos hipertensos acima do peso normal não se encontram em dieta visando redução de peso. 
Tabela 2 - Variáveis comportamentais de fumo, bebida alcoólica, dieta e exercício físico

\begin{tabular}{|c|c|c|c|}
\hline \multicolumn{4}{|c|}{ Hipertensos $=140(35 \%)$} \\
\hline \multirow{8}{*}{ Fumo } & \multicolumn{2}{|l|}{ Fumantes } & $(n=16)$ \\
\hline & \multicolumn{2}{|l|}{ Idade (média $\pm \mathrm{DP})$} & $56,9 \pm 10,8$ anos \\
\hline & \multicolumn{2}{|l|}{ Sexo Feminino } & $87,5 \%$ \\
\hline & \multicolumn{2}{|c|}{ Idade (média \pm DP) em que foi diagnosticada a HAS } & $22,4 \pm 14,2$ anos \\
\hline & \multicolumn{2}{|c|}{ Idade (média $\pm \mathrm{DP}$ ) em que iniciou o fumo } & $18,3 \pm 4,9$ anos \\
\hline & \multicolumn{2}{|c|}{ Tempo de fumo (média \pm DP) } & $36,9 \pm 12,1$ anos \\
\hline & \multicolumn{2}{|c|}{ Relataram fumar todos os dias } & $93,7 \%$ \\
\hline & \multicolumn{2}{|c|}{ Cigarros por dia (média $\pm \mathrm{DP})$} & $15,2 \pm 9,4$ \\
\hline \multirow{3}{*}{ Bebida alcoólica } & \multicolumn{2}{|c|}{ Consome bebida alcóolica uma vez ou mais por mês } & $(n=13)$ \\
\hline & \multicolumn{2}{|c|}{ Periodicidade de consumo por semana (média) } & 2,2 dias \\
\hline & \multicolumn{2}{|l|}{ Doses ao dia (média) } & 3,5 \\
\hline \multirow{3}{*}{ Dieta } & \multicolumn{2}{|l|}{ Reduz o consumo de sal } & $(n=127)$ \\
\hline & \multicolumn{2}{|c|}{ Reduz o sal por aconselhamento médico } & $(n=87)$ \\
\hline & \multicolumn{2}{|c|}{ Reduz o sal por decisão própria } & $(n=35)$ \\
\hline \multirow{7}{*}{ Exercício físico } & \multicolumn{2}{|c|}{ Praticam algum exercício físico regularmente } & $(n=30)$ \\
\hline & \multirow{3}{*}{$\begin{array}{l}\text { Praticante de exercício } \\
\text { físico intenso } 7,8 \% \\
(n=11)\end{array}$} & Acima do peso normal & $90,9 \%$ \\
\hline & & $\begin{array}{l}\text { Periodicidade do exercício } \\
\text { físico (média) }\end{array}$ & 3 dias/semana \\
\hline & & $\begin{array}{l}\text { Tempo do exercício físico } \\
\text { diário (mediana) }\end{array}$ & 60 minutos \\
\hline & \multirow{2}{*}{\multicolumn{2}{|c|}{\begin{tabular}{lrl} 
Praticante de exercício & & Acima do peso normal \\
\cline { 3 - 3 } físico de & Pédiodicidade do exercício & \\
& & físico (média)
\end{tabular}}} & $57,9 \%$ \\
\hline & & & 3,6 dias/semana \\
\hline & $(n=19)$ & $\begin{array}{l}\text { Tempo do exercício físico } \\
\text { diário (mediana) }\end{array}$ & 60 minutos \\
\hline
\end{tabular}

Nesse contexto observamos uma incipiência nas políticas públicas referentes ao tratamento multiprofissional da HAS, bem como a ausência de estrutura urbana e de segurança que incentive e permita a prática de atividade física nos espaços públicos. Ações governamentais de conscientização dos comportamentos promotores do desencadeamento e agravo de DCNT e campanhas educativas de incentivo a hábitos de vida saudável devem ser 
endossados pelo estado, a fim de alcançar e envolver a população na corresponsabilidade da manutenção de sua própria saúde.

Finalmente, a experiência vivenciada durante esta tese nos permitiu conhecer a população de Ceilândia quanto a sua caracterização socioeconômica, comportamentos e atitudes, suas morbidades, tratamento medicamentoso, condições de acesso aos produtos e serviços de saúde, entre tantos outros aspectos ainda não explorados que serão objetos de outros artigos e de outros estudos em grupo de pesquisa já constituído.

Cabe ressaltar que este trabalho, embora contribua para a importância da expansão do entendimento do acesso, não esgota todos os aspectos que ainda podem ser explorados. O tema acesso revela-se muito amplo e deve ser aferido em diferentes dimensões, afim de contribuir de forma mais efetiva para a legítima implementação de políticas de saúde pública.

Esta tese, em consonância com a proposta da assistência farmacêutica, que visa ações voltadas à promoção, à proteção, e à recuperação da saúde da população, pretende subsidiar o conhecimento em busca da promoção do melhor acesso e uso racional dos medicamentos. 


\section{REFERÊNCIAS BIBLIOGRÁFICAS}

1- Donabedian A. Models for organizing the delivery of personal health services and criteria for evaluating them. Milbank Mem Fund Quart, 1972; 50. apud

GIOVANELLA L., FLEURY S. - Universalidade da Atenção à Saúde: Acesso como Categoria de Análise. In: Eibenschutz Co, Ed. Política de Saúde: o público e o privado, Rio de Janeiro: FIOCRUZ, 1996.

2- CPM/MSH (Center for Pharmaceutical Management/Management Sciences for Health).2011. Center for Pharmaceutical Management: Technical Framework, Approaches, and Results. Arlington, Va.: CPM.

3- Lora AP. Acessibilidade aos serviços de saúde: estudo sobre o tema no enfoque da saúde da família no Município de Pedreira, São Paulo [Dissertação]. Campinas, SP: [s.n.], 2004.

4- Chaves G.C et al. Indicadores de uso racional de medicamentos e acesso a medicamentos: um estudo de caso. Rev. Bras. Farm. v.86, n. 3, p. 97-103, 2005.

5- MS. Ministério da Saúde. Secretaria Executiva. Sistema Único de Saúde. (SUS): Brasília: Ministério da Saúde, 1990.

6- Roy Penchansky DBA, J William T. The Concept of Access Definition and Relationship to Consumer Satisfaction. Medical Care February 1981, Vol. XIX, No. 2.

7- Vieira FS. Assistência farmacêutica no sistema público de saúde no Brasil. Rev Panam Salud Publica. V.27, n.2, p. 149-56, 2010.

8- MS/PNM - Ministério da Saúde. Política Nacional de Medicamentos. Brasília, 2001.

9- Araújo ALA et al. Perfil da assistência farmacêutica na atenção primária do Sistema Único de Saúde. Ciência \& Saúde Coletiva. v.13, (Sup 2), p.611-617, 2008.

10- Oliveira LCF, Assis MMA, Barboni AR. Assistência Farmacêutica no Sistema Único de Saúde: da Política Nacional de Medicamentos à Atenção Básica à Saúde. Ciência \& Saúde Coletiva, v. 15(Supl. 3), p. 3561-3567, 2010.

11- Barreto JL, Guimarães MCL. Avaliação da gestão descentralizada da assistência farmacêutica básica em municípios baianos, Brasil. Cad. Saúde Pública, Rio de Janeiro, v. 26, n.6, p.1207-1220, jun, 2010.

12- Paniz VMV et al. Acesso a medicamentos de uso contínuo em adultos e idosos nas regiões Sul e Nordeste do Brasil. Cad. Saúde Pública, Rio de Janeiro, v. 24, n. 2, p.267-280, fev, 2008.

13-WHO. WHO Expert Commite on National Drugs Policies. Contribution to updating the WHO guidelines for developing national drug policies. Geneva: WHO, 1995. 
14- Guerra JR AA et al. Disponibilidade de medicamentos essenciais em duas regiões de Minas Gerais, Brasil. Rev Panam Salud Publica/Pan Am J Public Health. v. 15, n. 3, 2004.

15- Figueiredo TA, Pepe VLE, Osorio-de-Castro CGS. Um enfoque sanitário sobre a demanda judicial de medicamentos. Physis Revista de Saúde Coletiva, Rio de Janeiro, v.20, n.1, p. 101-118,2010.

16- Luiza VL. Acesso a medicamentos essenciais no Estado do Rio de Janeiro [Tese de Doutorado]. Rio de Janeiro. Escola Nacional de Saúde Pública; 2003.

17- Karnikowski MGO et al. Access to Essential Drugs in II Brazilian Cities: A Community-based Evaluation and Action Method. In: Phyllis Freeman \& Anthony Robbins - Co-editor. USA. Journal of Public Health Policy. v. 25, n.3/4, p.288, 2004.

18- Serra CG, Rodrigues PHA. Avaliação da referência e contra referência no Programa Saúde da Família na Região Metropolitana do Rio de Janeiro (RJ, Brasil).Ciência\& Saúde Coletiva. v. 15,(Supl. 3), p. 3579-3586, 2010.

19-MS/PNM - BRASIL. Ministério da Saúde. Portaria ${ }^{\circ}$. 3.916, de 30 de outubro de 1998. Dispõe sobre a aprovação da Política Nacional de Medicamentos. Diário Oficial da União, 1 out 1998.

20-MS/PNAF - BRASIL. Conselho Nacional de Saúde. Resolução n. 338, de 6 de maio de 2004. Aprova a Política Nacional de Assistência Farmacêutica. Diário Oficial da União. Brasília: Ministério da Saúde. Poder Executivo, Seção 1 n. 96, 20 maio 2004.

21-Santos-Pinto CDB et al. Quem acessa o Programa Farmácia Popular do Brasil? Aspectos do fornecimento público de medicamentos. Ciência \& Saúde Coletiva. v. 16, n. 6, p. 2963-2973, 2011.

22- MS/SUS. Programa Saúde Não Tem Preço. Disponível em: $<$ http://www.saudenaotempreco.com/o_programa.php> Acesso em: 20 de Dezembro de 2011.

23- Toscano CM. As campanhas nacionais para detecção das doenças crônicas nãotransmissíveis: diabetes e hipertensão arterial. Ciência \& Saúde Coletiva, v. 9, n. 4, p.885-895, 2004.

24- Passos VMA, Assis TD, Barreto SM. Hipertensão arterial no Brasil: estimativa de prevalência a partir de estudos de base populacional. Epidemiologia e Serviços de Saúde. v.15, n.1, p. 35 - 45, 2006.

25- Paiva DCP, Bersusa AAS, Escuder MML. Avaliação da assistência ao paciente com diabetes e/ou hipertensão pelo Programa Saúde da Família do Município de Francisco Morato, São Paulo, Brasil. Cad. Saúde Pública, Rio de Janeiro, v. 22, n. 2, p.377-385, fev, 2006. 
26-Sairenchi T, Irie F, Izumi Y, Muto T. Age-Stratified Analysis of the Impact of Hypertension on National Health Insurance Medical Expenditures in Ibaraki, Japan. J Epidemiol. v.20, n.3, p.192-196, 2010.

27- Williams B. The year in hypertension. JACC 2010; 55(1): 66-73.

28- Cesarino CB et al. Prevalência e fatores sociodemográficos em hipertensos de São José do Rio Preto. Arq Bras Card 2008; 91(1): 31-35.

29- Rosário TM, Scala LCNS, França GVA, Pereira MRG, Jardim PCBV. Prevalência, controle e tratamento da hipertensão arterial sistêmica em Nobres, MT. Arq Bras Card 2009; 93(6): 672-678.

30- Andrade JP, Nobre F. VI Diretrizes Brasileiras de Hipertensão. ArqBrasCardiol [Internet]. 2010 [acesso em 2015 ago 25];95(1supl 1):1-51. Disponível em: http://publicacoes.cardiol.br/consenso/2010/Diretriz_hipertensao_associados.pdf

31- Codeplan - Pesquisa Distrital por Amostra de Domicílios - Brasília - PDAD 2013.

32- The ALLHAT Officers and Coordinators for the ALLHAT Collaborative Research Group. Major outcome in high-riskhypertensivepatientstoangiotensinconvertingenzymeinhibitororcalciumchannelblockervsdiuretic. The Antihypertensive and Lipid-Lowering Treatment to Prevent Heart Attack Trial (ALLHAT). JAMA. 2002;228:2981-97.

33- Wright JM, Lee C-H, Chamber GK. Systematic review of antihypertensive therapies: does the evidence assist in choosing a first-line drug. CMAJ. 1999;161:25-32

34- UK Prospective Diabetes Study Group. Efficacy of atenolol and captopril in reducing risk of macrovascular and microvascular complications in type 2 diabetes. UKPDS 39. BMJ. 1998;317:713-20.

35- Neal B, Mac Mahon S, Chapman N. Blood Pressure Lowering Trialist's Collaboration. Effects of ACE inhibitors, calcium antagonists and other blood -pressure lowering drugs: results of prospectively designed overviews of randomized trials. Lancet. 2000;356:1955-64.

36-Hansson L, Lindholm LH, Ekborn T, et al. Randomized trial of old and new antihypertensive drugs in elderly patients: cardiovascular mortality and morbidity. The Swedish Trial in Old Patients with Hypertension-2 study. Lancet. 1999;34:1129-33.

37-Dahlof B, Devereux R, Kjeldsen S, et al. Cardiovascular morbidity and mortality in the losartan intervention or end point reduction in hypertension study (LIFE): a randomized trial against atenolol. Lancet. 2002;359:995-1003.

38- Vidt DG. Telmisartan, Ramipril, or Both in Patients at High Risk for Vascular Events. N Engl J Med. 2008;358:1547-59. 
39-Stassen JA, Fagard R, Thijs L. Randomized double-blind comparison of placebo and active treatment for older patients with isolated systolic hypertension. The Systolic hypertension in Europe (SYST-EUR). Lancet. 1997;350:757-64.

40- Dahlof B, Sever PS, Poulter NR, Wedel H, Beevers DG, Caulfield M, et al.; ASCOT Investigators. Prevention of cardiovascular events with an antihypertensive regimen of amlodipine adding perindopril as required versus atenolol adding bendroflumethiazide as required, in the Anglo-Scandinavian Cardiac Outcomes Trial-Blood Pressure Lowering Arm (ASCOT-BPLA): a multicentre randomised controlled trial. Lancet. 2005;366:895-906. 


\section{ANEXOS}

\section{Normas de Publicação}

Artigo: Dimensions of Access to Antihypertensive Medications in Ceilândia, Distrito Federal, Brazil

Revista Health (Irvine) - Qualis 2014 - B2 (medicina I)

Manuscript Preparation -

To expedite the review process, please format the manuscript in ways as follow:

Article type:

One Column

Manuscript organization:

1.1 All manuscripts are expected to be prepared as a single PDF or MS Word document with the complete text, references, tables and figures included. Any revised manuscripts prepared for publication should be sent as a single editable Word document. LaTex paper is also acceptable for publication, but it should be in PDF for review first.

1.2 Manuscripts should be written in English. Title, author(s), and affiliations should all be included on a title page as the first page of the manuscript file, followed by a 100-300 word abstract and 3-5 keywords. The order they follow is: Title, Authors, Affiliations, Abstract, Keywords, Introduction.

Figure and table requirement:

1.3 All figures or photographs must be submitted as jpg or tif files with distinct characters and symbols at 500 dpi (dots per inch). Test your figures by printing them from a personal computer. The online version should look relatively similar to the personal-printer copy. Tables and equations should be in an editable rather than image version. Tables must be edited with Word/Excel. Equations must be edited with Equation Editor. Figures, tables and equations should be numbered and cited as Figure 1, Figure 2, Figure 3, etc. in sequence.

How to count page numbers:

1.4 Before submission or after acceptance, type your manuscript single spaced, and make all the characters in the text, tables, figure legends, footnotes and references in a single typeface and point size as 10 pt Times New Roman. This will save space, make it easier for reviewers and editors to process the submitted work, and contributes to slowing down global warming by using less paper.

References format:

1.5 All references should be numbered in square brackets in the text and listed in the REFERENCES section in the order they appear in the text. 


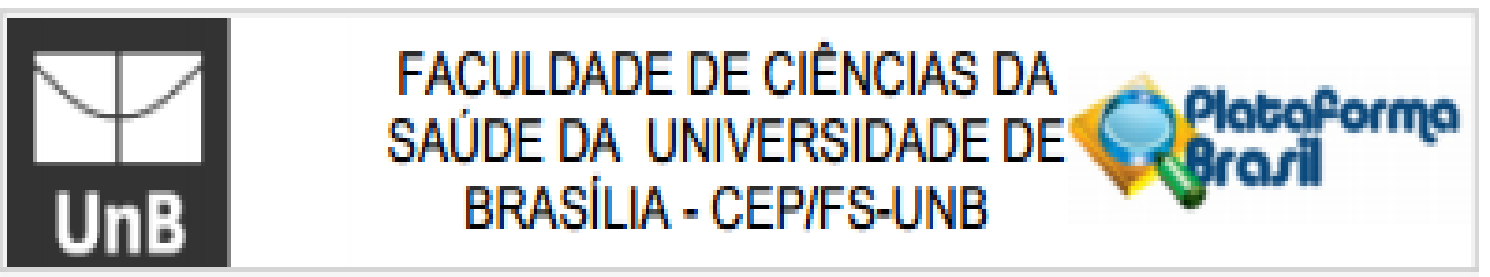

\section{PARECER CONSUBSTANCIADO DO CEP}

\section{DADOS DO PROJETO DE PESOUISA}

Titulo da Pesquisas Inquetrito domiciliar sobre Acesso a medicamentos Em Ceilandia:Componente da Promoça do Uso Racional de Medieamentos

Pesquisador: Margó Gomes de Olivera Kamikonski

Area Temótica:

Versio: 3

CAAE: 29298814.0000000030

Instituiçāo Proponente: Făeuldade de Ceilundia - FUNDACAO UNMERSIDADE DE ERASILIA

Patrocinador Principal: Financiamento Propiōo

\section{DADOS DO PARECER}

Nümero do Parecer: 714.445

Data da Relatoria: $0907 / 2014$

\section{Apresentação do Projato:}

A sajde é assegurada na legislaça brasileira enquanio um direibo de cidadania a ser garantido pelo Estado e a universalidade da atençlo implica, necessariamente, na formulaçăo de um modelo social, efico e equatrime. A Constituiça da Repüblica Federativa do Erasil, de 1986 em seu artigo 196 dita: "A sajde é freilo de lodos e dever do Estado, garantido mediante politieas sociais e economicas que visem à reduça do risco de doenças e de outros agravos e ao acesso universal igualiturio as actós e sencopos para sua promoçaso, proteçto e retiperaçbo". Conforme a Lei Complementar if 8080 do 19 de Selembro de 1990 nó Artigo $2^{\circ}$ " "A saude et um direilo fundamental do ser humano, devendo o Estado prover as condiçós indispensaveis ao seu pleno exercicio". A crisçto do Sistemb Úrico de SaĹde (SUS) foi um avanço decisivo na consolidaça deste direilo fundamental do cidadao, baseados em tras principios basicos de Universalidade, Initegralidade e Equidade. No entanibo o principio da Universalidade enconilra-se ameaçada e impede uma efeliva consolidaça do SUS, na medida que que o odad to enoonitra dificildades no acesso aos servopos de salde e ados demaiss fecursos incluindo aqueles que conslituem a assistencia farmaceufca. Surge portanio, a necessidade de identificaçbo das questbes referenles aos problemas enconitatos pelo usuario na busca por estes semiços. E na unidade de relaçço do 


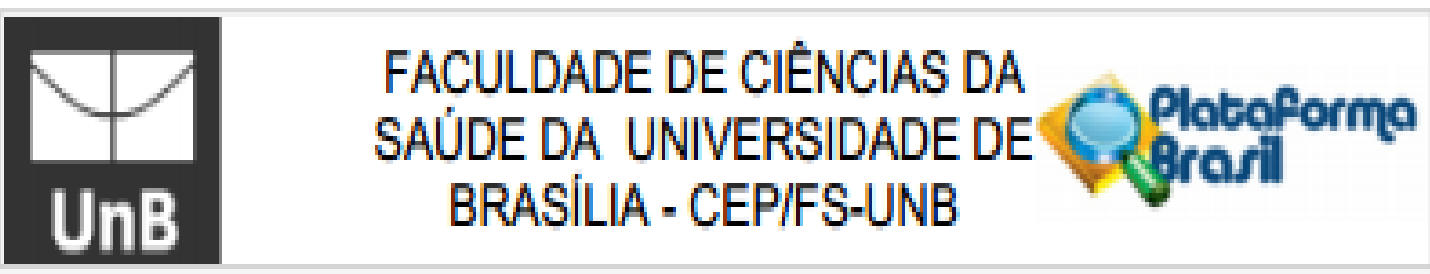

Conthuple de Pavar:714.44

usuatio com os serviços que devem ser ceniradas as antlises que busquem conhecer como o difeito th sabude se expressa concrelamente nó colidiano das pesscas. A caltegoria ceniral para analise dessas interrelaçónes to acasso (GIONANELLA E FLEURY, 1996). Nessese

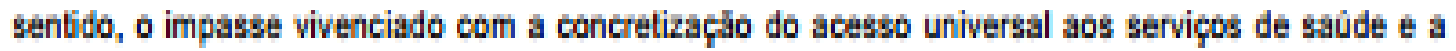
disponibilidade de lodos os reevisos necessatios para alender as necessidades da populaça na ares, requer o fortalecimento constarte da salde como um bem pủblico, e como dreilo individual e colelivo. Esta leiluta de realidade implica prablicas construidas a partir de uma gestub demoeratica e participaliva que se reflete em lodos os niveis de alençito a saude, tarto no selor publico quanto privado. No entianto, o acesso nâo se restringe a disponibilidade as produto ou recursos, pois se insere em complexa rede et inclui diferentes aspetós e consilructos félacionados entre si. 2 Acesso a assistencia de saúde inclui o fornecimento de medicamentos para gararitir o direilo a saủde, e por consequencia o direilo fundamential a

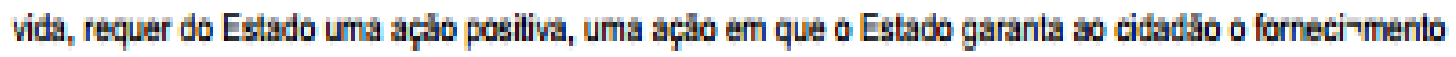
do medicamento indispenstuel para o seu tratamento. 3 Neste contexto o acesso abs medicamentos

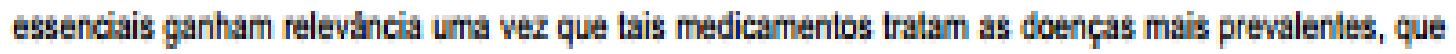
acomelem a populaçio. 4 A resalizaça desite direilo envolve varias combinaçdes de provisto de serviços e financiamentos publicos e privados. 0 acesso aos medicamentos sumariza um conjunib de areas mais especficas de ajuste entre o paciente e o sistema de saude. Desta forma algumas dimensós especticas

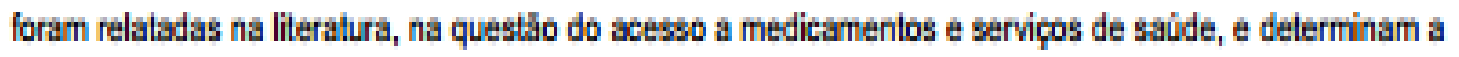
compreensaso do que se entende por acesso. A primeira refere-se al disporibilidade fisica do produto definido como uma retaç⿰彳亍o entre o lipo e quantidade do produlo ou servico requerido, assim como o lipo a quantidade do produto fomecido. A segunda trata da capacidade aquisitwa, relaciona-se ao aspecto da dimensabo do eusio, aos preços dos serviços e a capacidade de pagamento das pessosas. A terceira faz mencho a acessiblidade geografica, que se relere a existencich dos servicos no lugar è no momento em que é requerido pelos clientes, retrata à relaçâo entre a localizaça de produlos e e no momento em que é

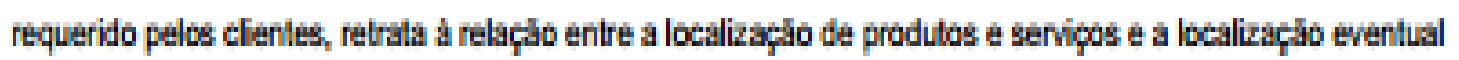
do usuario destes produlos e serviços, tendo em conta os recursos do usuabrio no transporte, tempo de viagem e distancia. Temos ainda a dimensado da aceiliabilidade ou salisfaça como umia relaçato entre

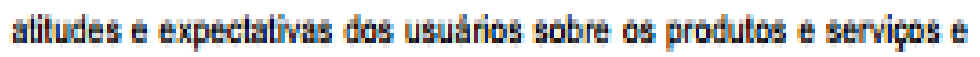
caracteristicas reasis dos mesmos. As dimensóes releridas se encontram intimamente retacionadas a Assistenoia Farmaceutica, que et entendida como parte do didado da saude individual ou coletiva, tendo nó medicamenio o insumo essendial, cujo acesso deve ser garantido, na prerrogativa do uso 


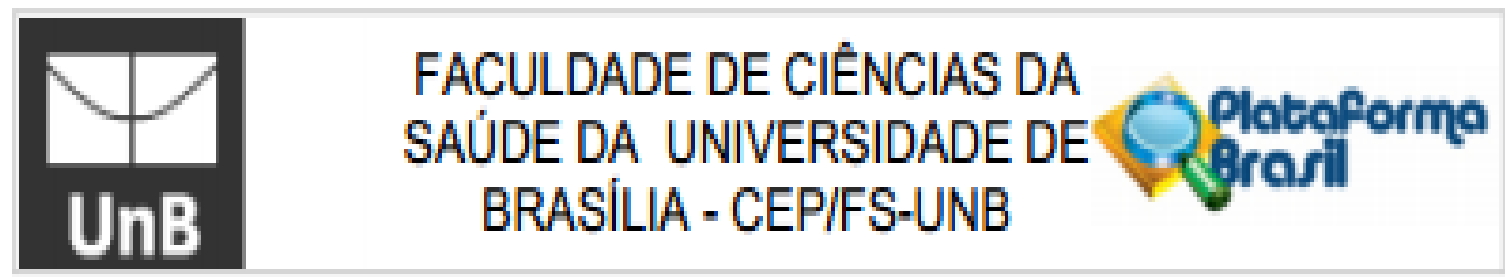

Corthukis de Pavar: 714.44s

racional. Sendo assin a Assistencia Farmacedulica se concrebiza mediante o acasso abs medicamenibs pelos pachentes, nas quantidades adequadas en momento necessario. Em vista disso, o Estado gestor onienta-se para a provisso de medicamentos congiderados essenciais ou que combatam as doenças de grande impacto para a sajde pública. No Brasil, o acesso a medicamentos essenciais considerando o Uso Rational do Medicamento (URM), se insereve no maroo doutrinario do Sistema Unico de Saude. 4 Sendo assim, a assistencia farmbetudica, e, portanto a garanilia de acesso aos medicamentos, devem alender aos principios da uriversalidade, integralidade e equidade. Esta garantia e um indicador da qualidade e resolutividade do sistema de saude e um delerminante

importante no cumprimenib do tratamento prescrib. A literatura indica que a ausencia de acasso te umba casusa frequente de relomo de pacientes aos serviços de sabude. Ainda em

1970, uma lisita de medicamenios que atendesse a resoluçato das doenças mais prevalentes em umia determinada populaça fó recomendadta pela Orgarizaça Mundial da SaLde (OMS). Em 1989, o Brasi cria a Relaçấ Nacional de Medicamentos Essenciais (RENAME) prioridade na politica farmadeutica do Pais. Os criterios de seleçấo dos medicamentos contidos na RENAME obedecem anos principios de eficacia, segurança e custo-efetividade, a que favorece aos dilames do Uso Racional de Medicamenios. 7 O URM se

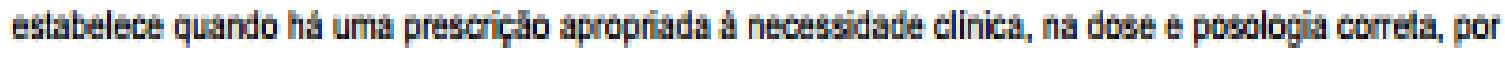
um periodo de tempo adequado a eficacia e ao menor custo para si e para a comuridade. No entanio, a

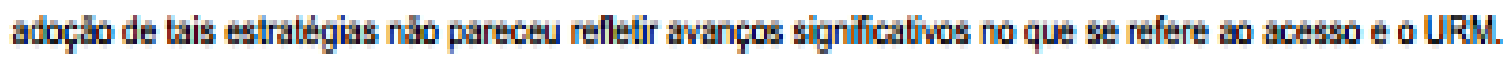
Naś areas mais pobres do Brasil, a exemplo de oulros paises da America Latina, Africa a Asia, os medicamenlos se encontraram inacessiveis para mäis de $50 \%$ da populaçlo, demonsirando que boa partela de pessoas nabo possula acesso regular aos medicamenios essencias. Pesquisas regionaís realizadas no Brasil tem relatado um indice elevado de desabasteomenito de medicamentos essenciais no ambilo do SUS. Na decada de 90 a usuario brasileiro, no locante ao perfil de consumo de medicamenibe, fó dividido em trếs grupos: os que possuiam renda acima de 10 sallarios minimos (15\% da populaçabo) consumiam $48 \%$ da produça lotal de medicamentos; o grupo com renda entre quabo en 10 salarios minimos

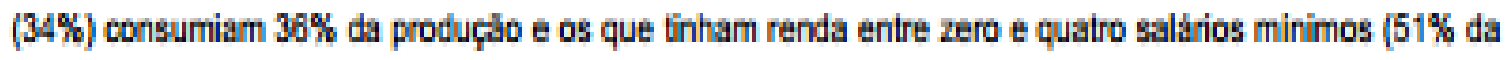
populaçâ) consumiam $16 \%$ da produça. B Este falo evidenciou claramente que, por rasbes mediante o acesso aos medicamentos pelos pacientes, nass quantidades adequadas e no momento necessario. Em vista disso, o Estado gestor orientarse para a provisao de medicamentos considerados essenciais ou que combatam as doenças de grande impacio part a saude publica. No Brasil, a 


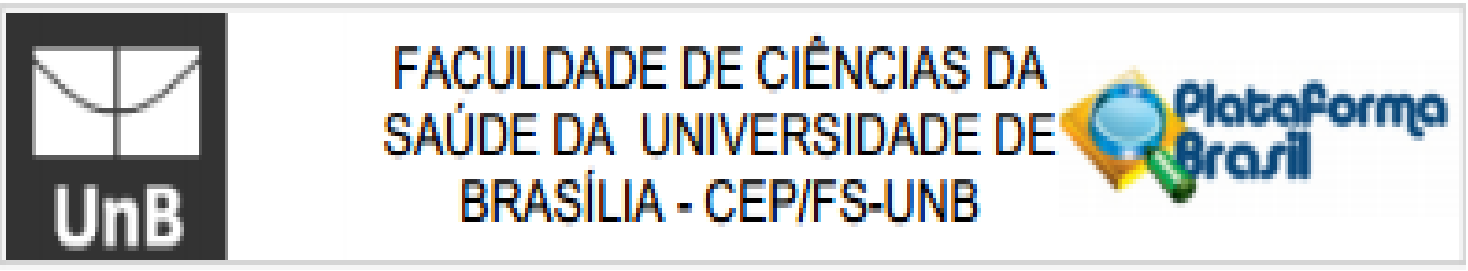

Corthueple os Panor: 714.445

acesso a medicamentos essenciais considerando o Uso Raconal do Medicamento (URM), se inscreve no marco doutrinario do Sistema Único de Saude. 4 Sendo assim, a assistencia farmactubica, en, portanto a garantia de acesso abs medieamentos, devem atender aos principios da Lriversalidadé, integralidade e equidade.

Esta garantia e um findicador da qualidade e resolutividade do sistema de sadde e um determinante importante no cumprimento do tratamento preserito. A literatura indica

que a ausendu de acesso é una cassa frequente de retorno de pacientes abs senç̧os de saude. Añta em 1970, uma lista de medietamentos que atendesse a resoluçá das doenças mais prevalentes en umia determinada populaça foi recomendada pela Organizaça Mundial da Saúde (OMS). Em 1969, o Brasi cria a Relaçato Nacional de Medicamentos Essenciais (RENAME) prioridade na politica farmackulica do Pais. Os eriterios de selectán dos medicamentos contidos na RENAME obedecem aos prifcipios de eficacia,

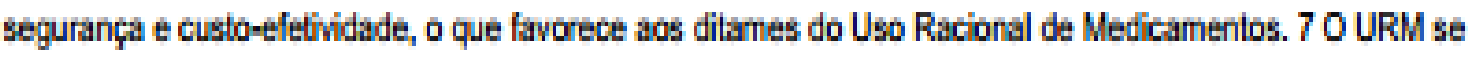
esiabelece quando hả uma prescriça apropriada a necassidade clinica, na dose te posologia correla, poi um periodo de lempo adequado a efiedcia et ao menor custo para si e para a comunidade. No entanio, a adoçbo de tais esirategias náo pareceu refletir avanços signficativos no que se refere ao acesso e o URM. Nas areas mais pobres do Brasil, a exemplo de outros paises da America Latina, Africa e Asia, os medicamenibs se entoniraram inacassives para mais de $50 \%$ da populaçato, demonsirando que bou partela de pessoas nấo possula acesso regular aos medicamentos essenciais. Pesquísas regionais realizadas no Brasil têm relatado um indice elevado de desabastecinento de medicamentos essenciais no ambilo do SUS. Na decada de 90 o usuario brasileiro, no locante á perfil de consumo de medicamenibe, foi dividido em tress grupos: os que possuiam renda acima de 10 sallarios minimos (15\% da populaçăo) consumiam $48 \%$ da produçabo loblal de medicamentos; o grupo con renda entre quato e 10 salarios mirimos (34) consumiam $36 \%$ da produçlo e os que tinham renda enitre zero e quatro salatios minimos (61\% da

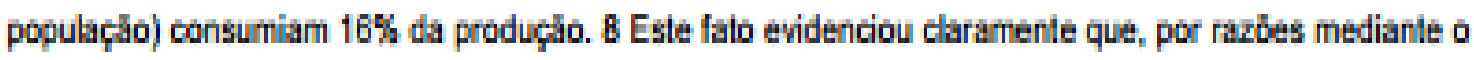
acesso aos medicamentos pelos pacientes, nas quandidades adequadas e no momento necassatio. Em vista disso, o Estado gestor orienta-se para a provisao de medicamentos considerados essenciais ou que combatam as doenças de grande impacto para a saude püblica. No Brasil, o acesso a medicamentos essenciais considerando o Uso Racional do Medicamento (URM), se insereve no marto doutrinarió do Sstema Ünico de Saúde. 4 Sendo assim, a assistencia fanmaceutica, e, portarib a garantia de acesso abs medicamenilos, devem alender às principios dá universalidade, inilegralidade e equidade.

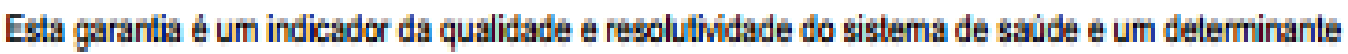




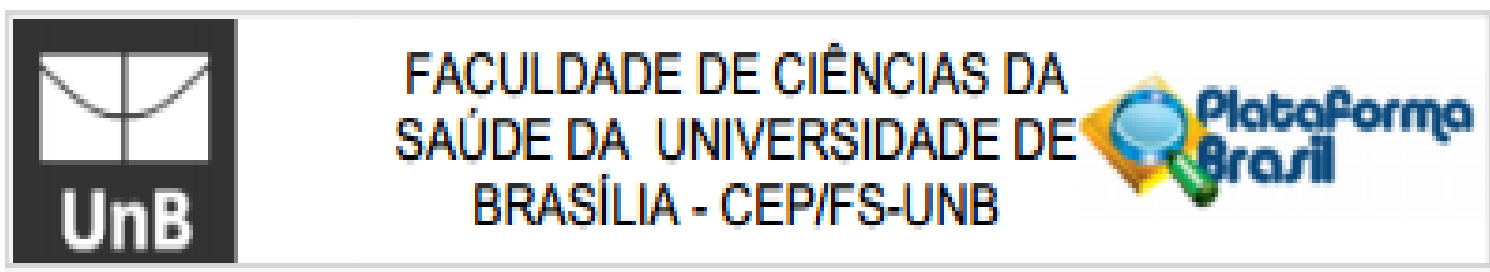

Corthuple de Panor: 714.44s

importante no cumprimento do tratamento prescrito. A literatura indica que a ausencia de acesso te umia causa frequente de relomo de pacientes acs serviços de saủde. Ainda em 1970, uma lista de medicamenibs

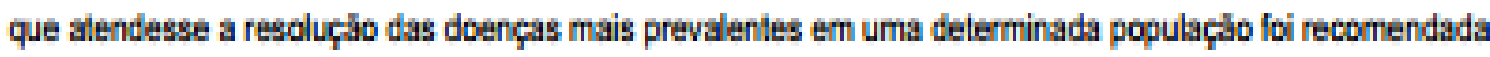
pela Organizaça Mundial da Saủde (OMS). Em 1969, o Brasil crita a Relaçâo Nacional de Medicamenios Essenciais (RENAME), prioridade na politica farmaceutica do Pais. Os criterios de seleçto dos medicamenibs conlidos na RENMME obedecem aos prineipios de efictoia, segurança e custo-efebidade, o que favorece aos dilames do Uso Racional de Medicamentos. 70 URM se estabelece quando had umb prescriçấo apropriada tu necessidade clinica, na dose e posologia correta, por um periodo de tempo adequado a efiescia te ao menor cusib para si e para a cominidade. No entanio, a adoça de tais estrategias ntobo pareceu reflelir avanços significabivos no que se relere ab abesso e o URM. Nas areas más pobres do Brasil, a exemplo de oulros paises da América Latina, Africa e Asia, os medicamentos se enconiraram inacessiveis para ma's de $50 \%$ da populaça, demonstrando que boa parcela de pessoas najo possulia acesso regular aos medicamenibs essencais. Pesquisas regionas realizadas no Brasil tem rekabado um indice elevado de desabastecinenilo de medicamentos essenciais no Ambilo do SUS. Na decada de 90 o usuario brasileiro, no tocante ao perfil de consumo de medicamentos, foi dividido em tres grupos: os que

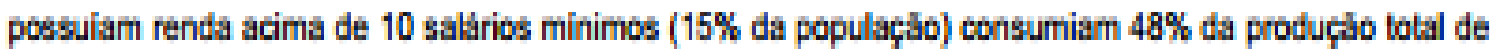
medicamenibs; o grupo com renda entre quatro e 10 salarios minimos (34\%) consumiam $36 \%$ da produça e os que tinham renda entre zero e quatro salabrios minimos ( $51 \%$ da populaçib) consumiam $16 \%$ da produç̧ấo. a Ește fato evidenciou claramente que, por razóes socioeconómicas, o actesso a terapia medicamentosa nșa ocorreu de forma igual na populaçấ, ficando comprometido para os milhóes de

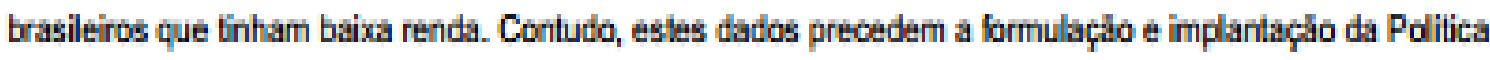
Nacional de Medicanenios e da Politica Nacional de Assistencia Fambetutica, bem como dos programas de governo que priorizaram o acesso a medicamentos, contemplando seu uso racional ao promover a coninuidade do tratamerito. Um dos programas lançados pelo Governo Federal em 2004 foi o Programa Farmb́cia Popular do Brasil, que surgiu como esiralegia de ampliaçao do acesso aos medicamentos essenciass, de modo a enlocar aqueles utilizados para o tratamento da Hpertensấo Arterial Sistemica (qAS) e Diabeles mellitus (DM). No Ambito do Programa, os medicamenios para o tratamento destas doenças eram disponibilizados a baixo eusto para a populaçato que fasia uso de serviços privados, mas possila dificuldade de acesso a medictamentos. No ano de 2011 o govemo lançou o Programa Saude Náo Tem Preço, o qual visa garanif o acesso gratulo aos medcamentos para o iratamenio da HAS e DM. A oferta de 


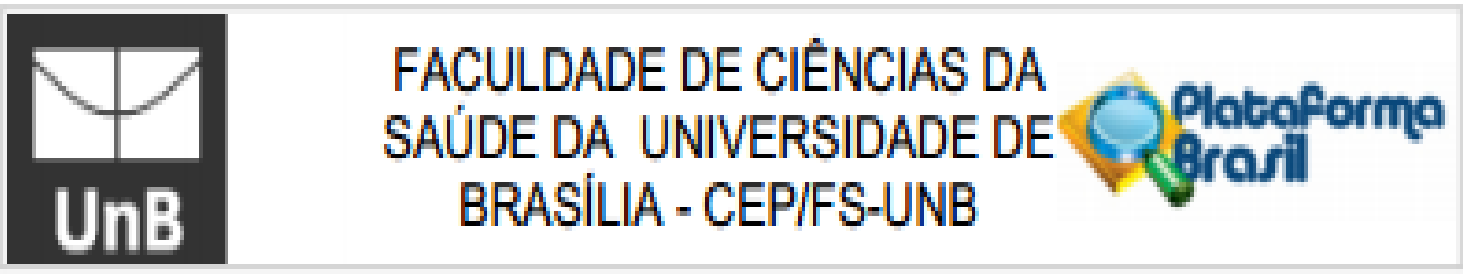

Corthurils de Pawar 714.44

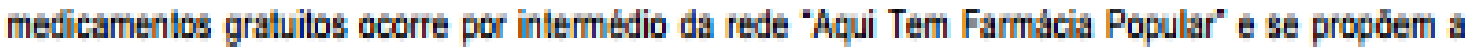
beneficiar 33 milhós de brasieins hipertensos e 7,5 milhós de disbelicos, podendo assim colaborar parta a confinuidade do tratamenib e para o URM. A implementaçato de Programas desta ordem conitribuem para a disporibilidade dos medicamentos, porem nóo garantem necessaniamente o acesso aos mesmos, umi vez que existem oubas dinengóes determinantes para a questab, conforme deseribo anteriomente. 0 acesso asos medicamentos perrivanece sendo um importante desafio para a saude pública, sobrebudo no casb de Doenç̧as Crofricas Nao Transmissiveis (DCNT), que netessitam de lerapia medicameniosa de uso continuo. A Ceilandia, Regonal Administrativa do DF onde se prebende investigar o acesso da populaçá aos medicamentos, apresenta uma história singular de movimentos sociais e culburais de visiblidade naconal e com grande polencial de mobilizaçto, identificadas diretamente com as necasgidades de suja populaçlo e que se reflete inclusive na area de saude. Da populaça de Cellandia $88,85 \%$ utiliza o serviço

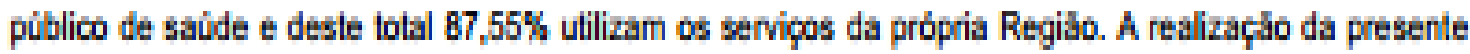

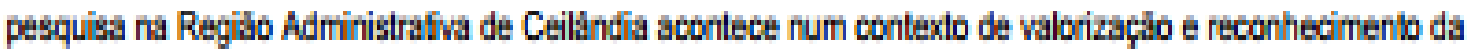
importancia de produçbo lecrica de pesquisas e informaços como subsifo ab planejamento estrategion do

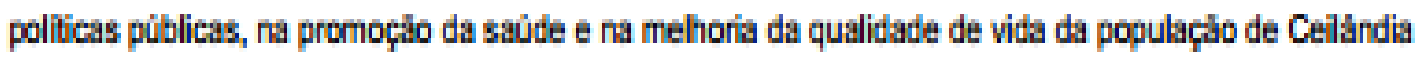

\section{Objetivo da Pesquisa:}

Objetino Primatio:

Avaliar fabres facilitadores e dificultadores do acesso e do uso racional de medicamentos pela populaçá de Cetilindia

Objetino Secundario:

- Caracterizar a utilizacto de medicamenibs para as doenças mais prevalentes,

a ldentificar as formas e bocis de obiençio de medicamenios

- Avaliar os indicadores de racoonalidade do uso de medicamentos e do grai de seguimento das prescriçoes

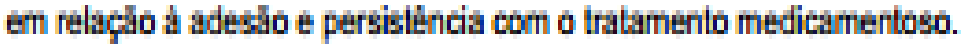

- Avaliar o atesso a medicamentos segundo variaveis demograficas, sociais e econdmicas - Avaliar a

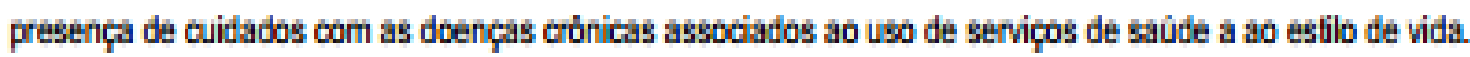
- Avaliar possiveis efeilos das politicas publicas de acasso a medicamenios na reductio dos gastos individuais com medicamentos a no combate a iniquidade 


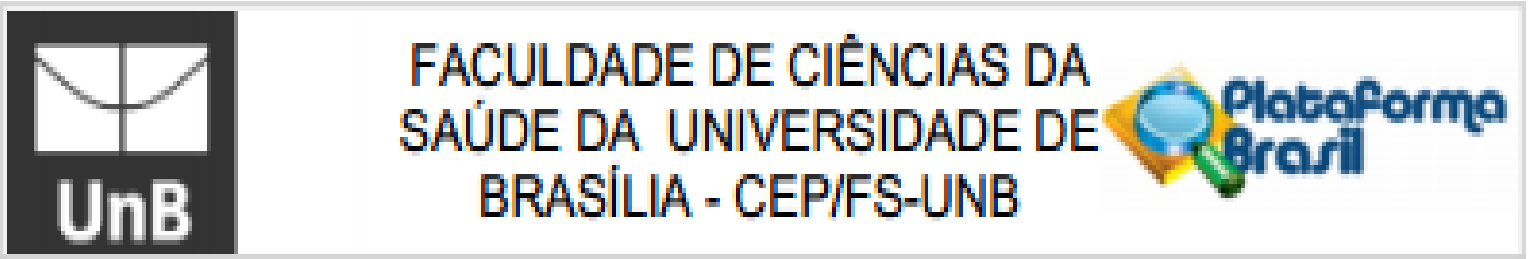

Corthucplo do Pawar: 714.44

\section{Avaliaçio dos Riscos e Beneficios:}

Embora a pesquisadora mentione que a pesquisa apresente fisto minimo, A partieipaçáno neste eštudo apresenta risco minimo, acresceniando: "O risco que você corre te semelhanie aquele sentido quando conversa com um profissional da saúde sobre sua condiçăo de saúde. Entrebanib, considerando o ilem $V$ caput da Resoluçato 466/2012CNSMS, solicita-se que a pesquisadora explicite os risoos possiveis aos sujeitos da pesquisa, bem como, quais medidas seráo adoladas para seu conirole. Destaca-se neste

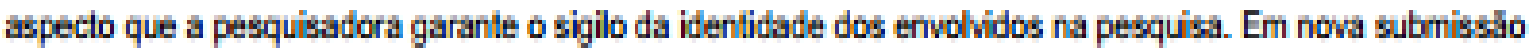
a pesquisadora deixa charos os riscos es as medidas que serdo adobadas em caso de algumia interconrencia. Como beneficios indica Conibibuir para politicas püblicas de assistencia farmacética e da qualidade dos serviços de saủde, identificada a partir do acasso da populaç.to aos medicamentos

\section{Comentários e Consideraçós sobre a Pesquisa:}

Trablasese de epidemiolbgico a ser realizado por Inquetrito domioliar com delineamento transversal, Seráo entrevistados individuos residentes na Regiảo Adminisirativa da Ceilandia. O tamanho da amositra foi estimado em 400 indivduos. 0 instrumento de inquérilo domicifar a ser utilizado na pesquisa serd o mesmo úlilizado pella Pesquişa Nacional sobre Acesso, Utilizaça e Promoçblo do Uso Racional de medicamentos no Brasil (PNALM) com modficaobes. A pesquisadora da Universidade de Brasifa, Dr" Margo Gomes de OFieira Kamikowski responsutvel pela PNAUM è a mesma responstuvel pela presente pesquisa. A PNAUM foi aprovada pelo CONEP sob ó número do CAAE: 18947013.6.0000.0008. Os questionários serấo aplicatos por enitevistadores previamente treinados e preparados para aplicaçián do inquérilo. A projelo se refere ao elrso de doutorado da aluna Fabiana Xavier Cartaxo Salgado do Programa de Pos Graduaçăo Curso Cencia e Tecnologia em Saude - UnB/ Ceilandia, sob orientaçăo da Profa Dra Margó Gomes de Olveira Kamikowski. A pesquisadora submeteu a este CEP a seguinte docLmentaças 1) Folha de rosto; 2) Termo de concordaneia insilitucional assinado pela Profa Dra Diana Lucia Moura Pinho, Direlora da Faculdade de Ceilandia/UnB; 3)Curriculo lattes das pesquisadoras Fabiana Xovier Cartao Salgado e Profa Dra Margo Gomes de Oliveira Karnikowski; 5) Projelo de pesquisa acompanhado; 6) Cronograma de desenwolvimento do projelo; 7) Plarilha de orçamenio; 8) Carta de apresentaçlo do projelo acs sujeilos da pesquisa; 9) Temo de Consentimento Live e Esclarecido. A documentaça apresentada acompanha parcialmente as determinaçoes da resoluçto $466 / 2012$ CNSMS. Os curriculos das pesquisadoras responsaveis sto compativeis com a complewdade do projeto. A planilia de euslos encontra-se eompativel com o desenvolvimento do projeto que sera realizado com recursos probrios. 0 cronograma de 


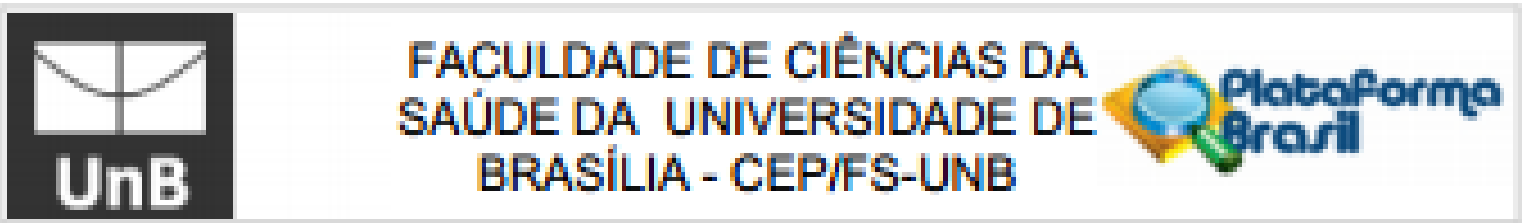

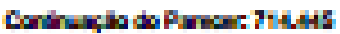

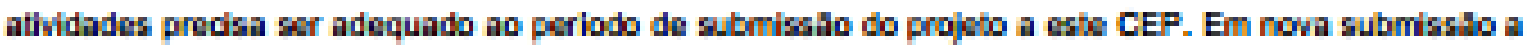

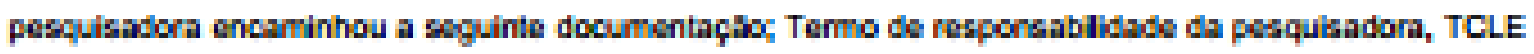

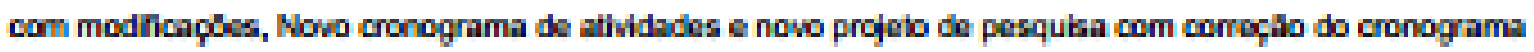
de

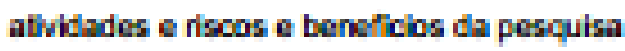

Conelderactes sobre os Termos de apresentacto obripaldria:

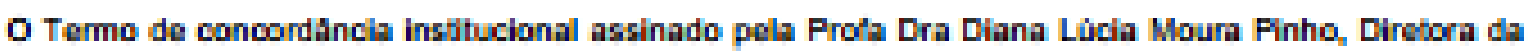

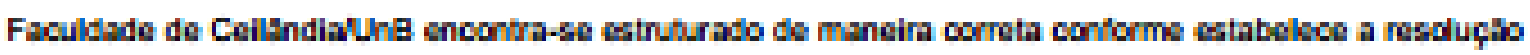

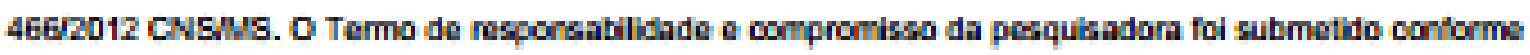

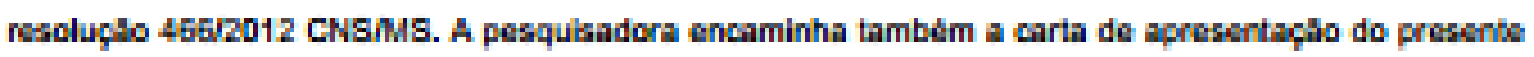
projeto a tamo de Conanthanb Lhre e esclarechb. Form retirados da amosira os menores de 18 anos.

Recomandachas:

Conclusbas ou Pundencias a Lhta de lhaduquaçuas:

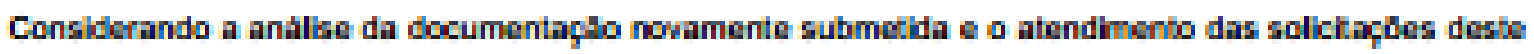

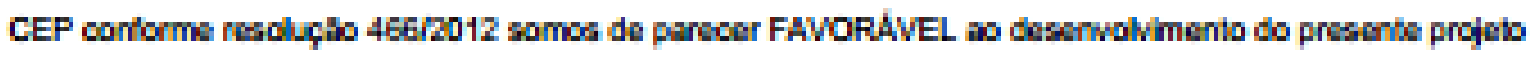

Bituacto do Parcar:

Aprovisio

Hecasha Apreciacho da CONEP:

NHo

Conederacos Finals a critrio do CEP:

ERasIla, 10 de Julha de 2014

Assinade por:

Marie Topasi

[Coordanudor]

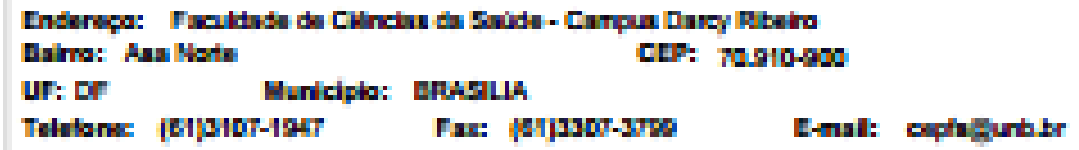




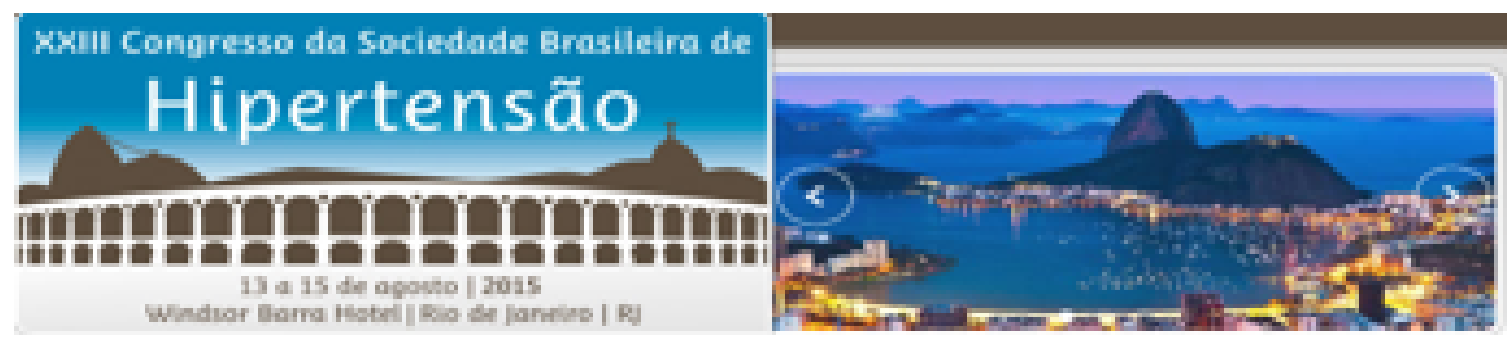

\section{CARACTERIZACÄO DO HIPERTENSO FUMANTE E EX-FUMANTE EM UMA POPULAC̈AO DA CIDADE DE CEILANDIA - DISTRITO FEDERAL}

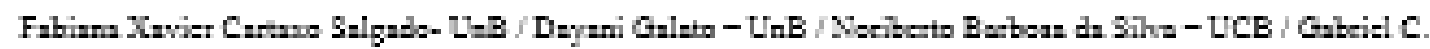

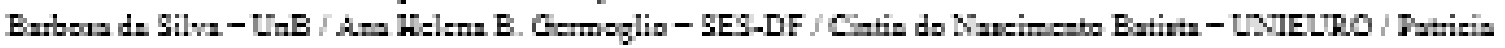

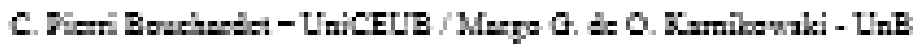

Introduçäo - A Hipertensẫo Arterial Severa (HAS) e o tabagismo gấo dois importantes fatores de risco para as doenças cardiovasculares $O$ tabagiemo tem-se mostrado un forte preditor para o desenvolvimento da HAS, além de dificultar o controle da pressabo arterial em pacientes hipertensos. A nicotina é um potente vasoconstrictor, aumentando a Preasấo Arterial acima do nivel basal. Objetivo: caracterizar o hipertenso fumante e ex-fumante na populaçăo da cidade de Ceilandia-DF. Método - Estudo epidemiológico e transversal, realizado através de inquérito domiciliar, parte de un projeto de doutorado. A popularä́o foi constituida por 400 individuos, com idade $\geq 18$ anos residentes em Ceilandia-DF, no periodo de maio a julho de 2014. O instrmento utilizado foi o "fonmulario para inquérito damiciliar da Pesquisa Nacional de Acesso e Uso Racional de Medicamentos", com modificaŗốes. As variaveis investigadas entre os fumantes foram: idade que iniciou o fumo, frequencia do fumo, cigarros fumados/dia. Eutre os ex-fumanted investigou-ge a idade que iniciou e cesous of fumo. Em ambos os grupos foi investigado o sexo, idade, se algum médico aconselhou a parar de fumar e idade que foi diagnosticada a HAS. Resultados: $\alpha$ hipertenos conesponderam a $35 \%(n=140)$ da amostra, sendo $77,1 \%$ do gexo feminino e $22,9 \%$ masculino, com idade de $57,45 \pm 13,7$ anos. Os hipertensos. fumantes e ex-fumantes correspondem a $40,7 \%$ ( $n=57$ ). 0 hipertensos ex-fimantes $\left(71,9 \%\right.$ ) apregentaram idade de $61,1 \pm 11_{z} 8$ anos, gendo $68,3 \%$ do sexo feminino. Este grupo iniciou of fumo as $18,4 \pm 5,6$ anos e ceasaram as $38,6 \pm 10,2$ anos, o que conreppondeu a um tempo de fumo de $22,2 \pm 13,8$ anos. Foram diagnosticados com HAS apos $29,4 \pm 14,6$ anos de funo e $34,1 \%$ receberam, na ocasiốo, orientaça mo medica de cessar o fumo. No grupo de hipertensos fumantes $(28,1 \%)$ a idade foi de $56,9 \pm 10,8$ anos, gendo $87,5 \%$ mulheres. Neste gnupo $93,75 \%$ relataram fumar todos os dias una media de $14,5 \pm 9,4$ cigarros, e todos afirmaram que receberam orientaçăo médica de cessar o fumo. Estes fumantes apresentam tempo de fumo de $36,9 \pm 12,1$ anos, que foi iniciado aos $18,3 \pm 5$ anos O diagnóstico de HAS foi declarado após $22,4 \pm 14,2$ anos de tabagismo. Conclusẩo: A maioria da populaçón hipertensa fumante e ex-fumante de Ceilandia é feminina, bem como a populaçấo geral. O fumo foi iniciado na juventude em ambos os grupos e a HAS manifestou-se mais precoce no grupo dos atuais fumantes, embora apresentasem menor tempo de fumo e orientaçâo médica de cessar of fumo. 


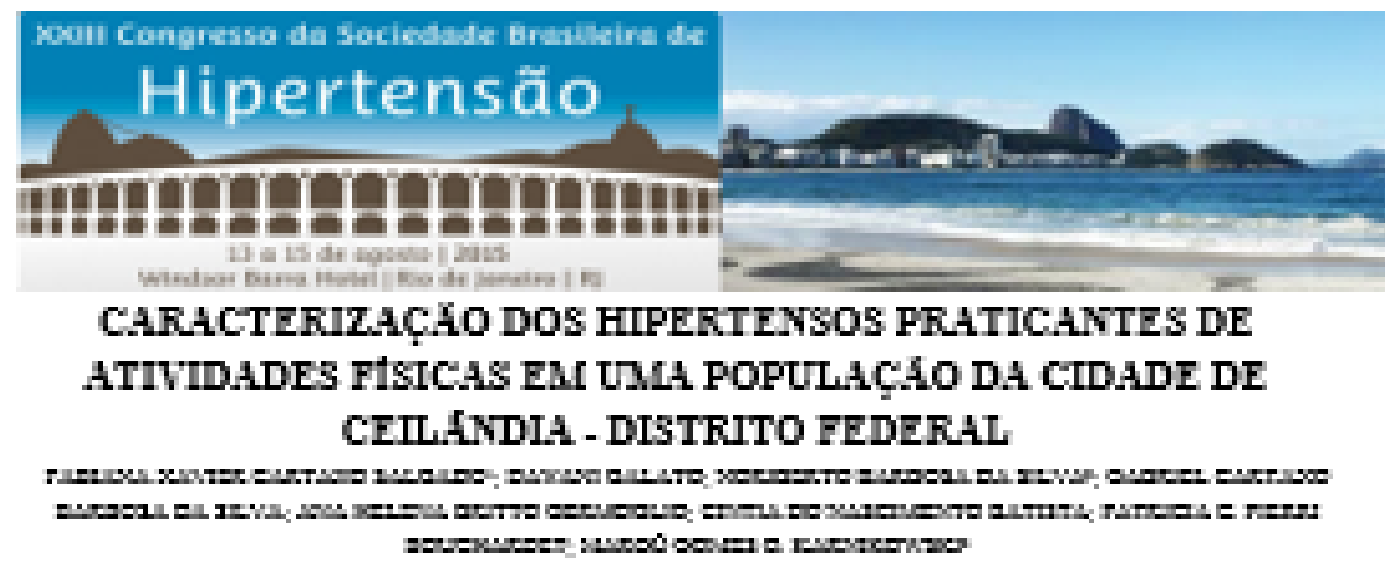

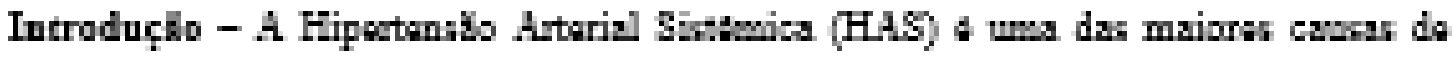

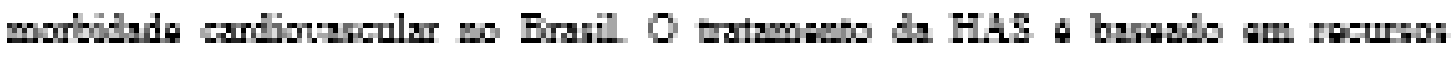

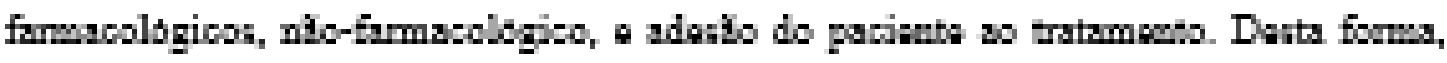

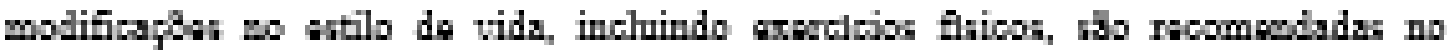

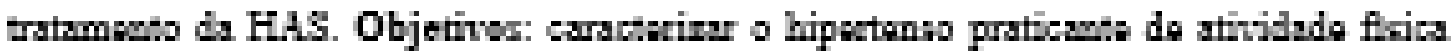

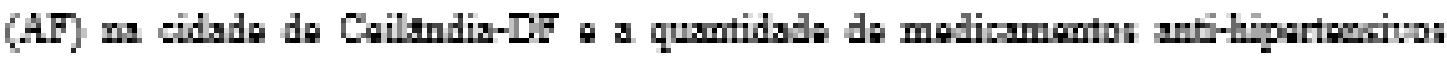

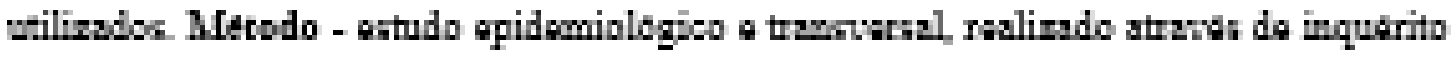

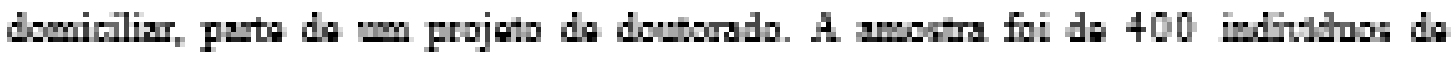
Coilmdia, com idade z-18 anos, wo parlodo do maio a julbo da 2014 o intrumanto utilizodo foi o "fomulario para inquato domiciline da Pequia Nociosal do Acoso o Uno Racional do Modicamentor", com modifesploc. Form imotigador: idado man,

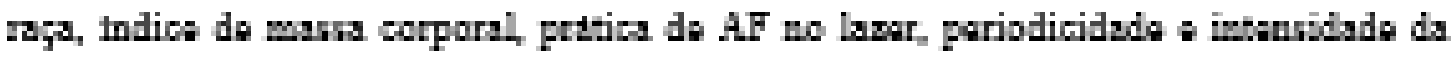

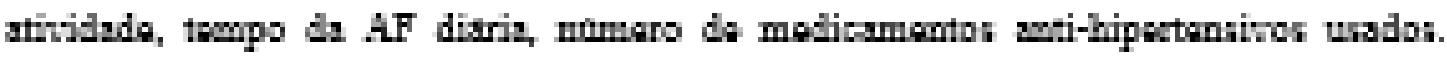

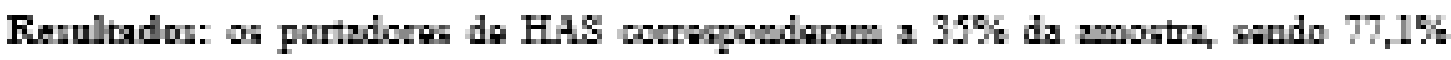
fominio o $22,9 \%$ manculion. A idsdo motia foi do $57,45=13,7$ anor, a raga pards

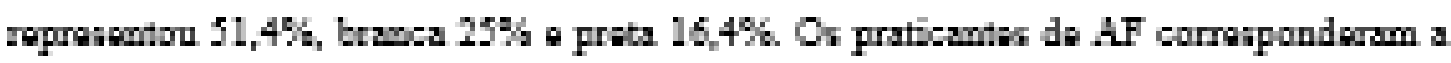
$21,4 \%$ do kipatonos, sado $7,8 \%$ AF intanas o $13,5 \%$ do moliz intanidada Da

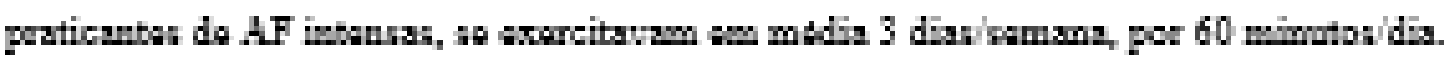

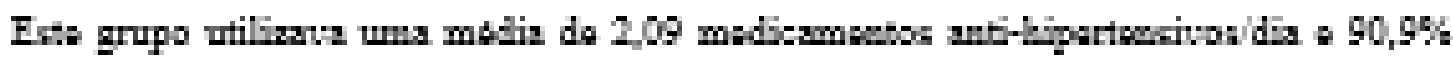

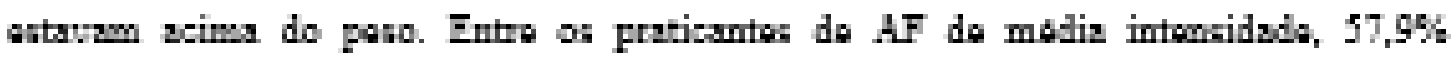
atsonm acims do poso eonrumiam am madia 1,04 modicamantor anti-

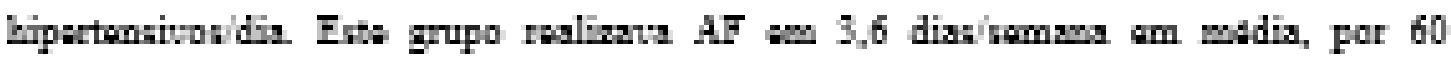

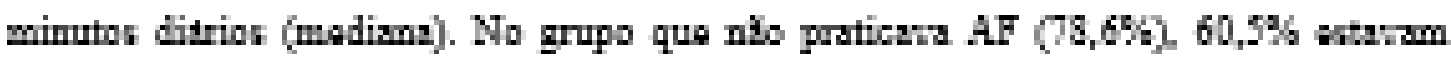
acims do poso sormal o consumiam 1,6 modicamantor anthipartosivosids.

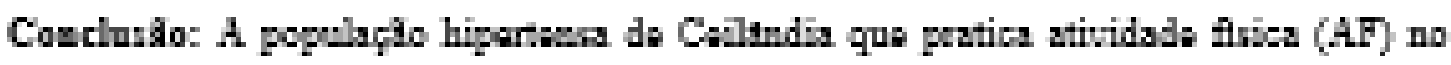




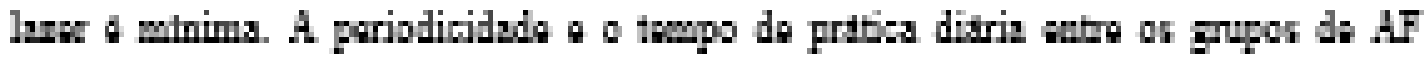

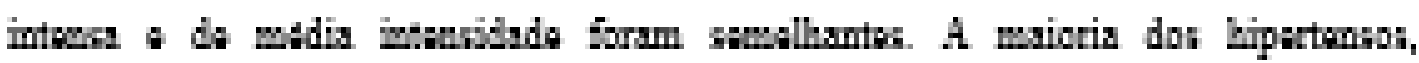

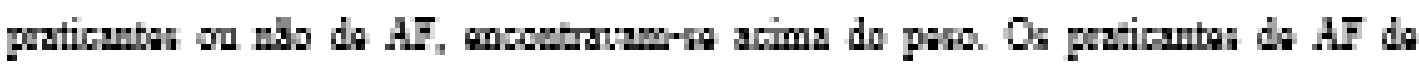

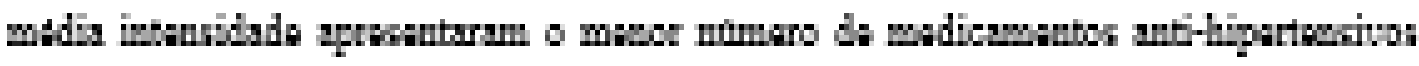

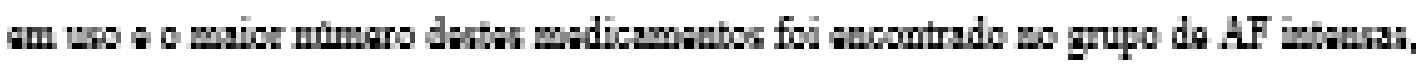

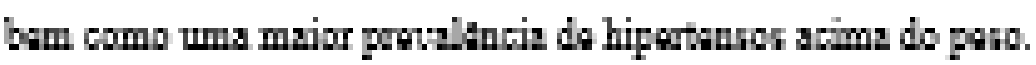




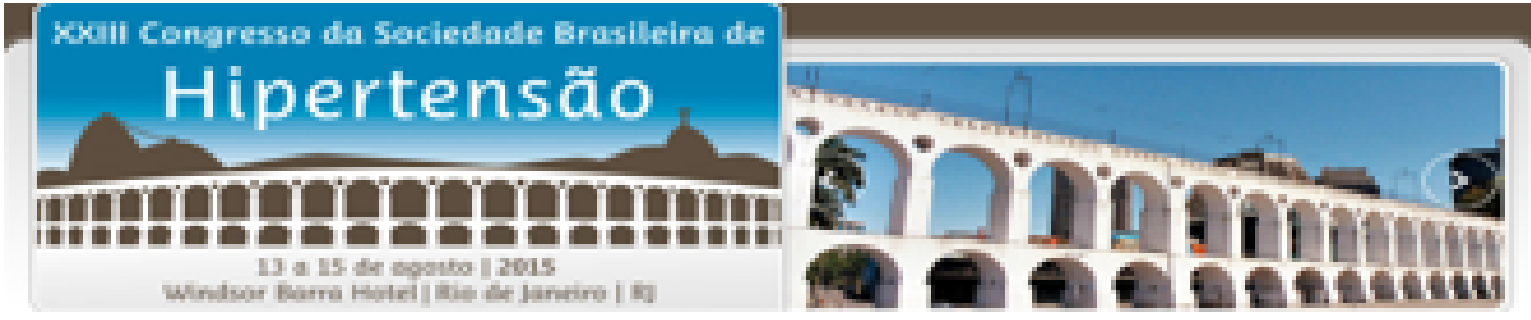

\section{PERFIL EPIDEMIOLOGICO E DE MEDICAMENTOS ANTI- HIPERTENSIVOS EM UMA POPULACAO DA CIDADE DE CEILANDLA - DISTRITO FEDERAL}

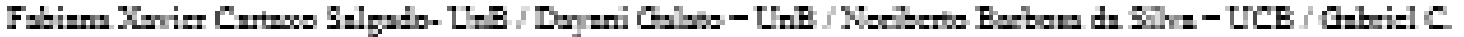

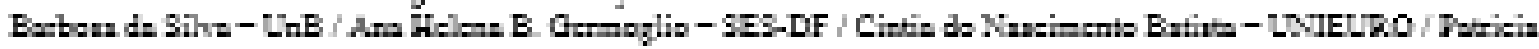

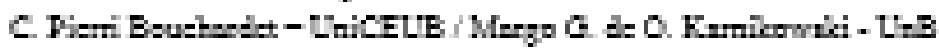

Introduçăo - A Hipertensăo Arterial Sistemica (HAS) ể um importante problema de gaude publica. Caracterizada por niveis elevados e sustentados de pressẫo arterial, associado ao aumento do risco de eventos cardiovaculares fatais e váo-fatais. 0 tratamento medicamentoso visa à proteçäo dos argấos-zlwos; reduçăo do impacto causado pela elevaçóo da Pregăo Arterial e pela presenge de fatores de risco associados. Objetivos: conhecer o perfil epidemiologico da populapio com HAS na cidade de Ceilândia - DF e os medicamentos anti-hipertensivos mais utilizados. Método - Estudo epidemiologico com delineamento transversal, realizado através de inquérito domiciliar, parte de un projeto de doutorado. A amostra foi de 400 individuos, com idade $\geq 18$ anos residentes na Ceilandia-DF, no periodo de maio a jutho de 2014 . 0 instrumento utilizado foi o "formulário para inquerito domiciliar da Pequisa Nacional de Acesso e Uso Racional de Medicamentos", com modificoróces. As variaveis imvestigedas form: idade, gero, estado civil, raça, escolaridade, idade do diagnostico de hipertensâo, complicaçóces asociadas a HAS e medicamentos usados no tratemento. Resultados: os portadores de HAS corresponderam a $35 \%(\mathrm{n}=140)$ da amostra, sendo $77,1 \%$ do seno feminino e $2,9 \%$ masculino. A idade média do grupo foi de $57,45 \pm 13,7$ anos, onde $57,1 \%$ vivem com compankeiro, $35 \%$ ji viveu com companheiro antes e $7,9 \%$ nunca vivel com companbeiro. A raça parda representou $51,4 \%$, branca com $25 \%$ e pretz $16,4 \%$. 0 diagnostico de HAS ocomeu aos $43 \pm 12,3$ anos em media. As complicą̧óes advindas da HAS relatadas em $40 \%$ dos portadores, foram problema circulatorio/AVC $(u=37)$, problema de viata fundo de olho $(n=15)$. problema nos rins ( $n=13)$, entre outros problemas ( $\mathrm{n}=10$ ). A pesquisa revelou que $50,3 \%$ estudaram até o $\mathrm{l}^{*}$ grau escolar, $36,8 \%$ atê o $2^{2}$ grau, e $9,8 \%$ até o curso superior. Os medicamentos arti-hipertensiwos mais utilizados foram: Losartana $16,8 \%$, hidroclorotiazida $14,6 \%$, atenolol $12,8 \%$ anlodipino $11,9 \%$, enalapril $10,6 \%$, indapamida $9,2 \%$ e captopril $4,4 \%$, que representaram $80,53 \%$ dos medicamentos citados. Conclusäo: A maioria da populzçáo hipertensa de Ceilândia a feminima, vive com companheiros, é da raça parda e a metade possui eacolaridade até o $l^{*}$ grau O diagnóstico de HAS ocorreu por volia dos 40 anos a as complicaçóes circulatorias form as mais relatadas associadas a HAS. Os medicamentos mais utilizados foram: Losartana, hidroclorotiazida, atenolol, anlodipino, enalapril, indapamida e aptopril. 
PNAUM - Pesquisa Nacional sobre Acesso, Utilização e Promoção do Uso Racional de Medicamentos no Brasil

\section{Questionário do Inquérito Domiciliar.}

Horário do Início da entrevista I $|:|$

\section{I01- INFORMAÇÕES DO ENTREVISTADO}

Vou começar fazendo algumas perguntas sobre a(o) $\operatorname{Sr}(a)$.

\begin{tabular}{|c|c|c|c|}
\hline 1.1 & № na lista de identificação dos moradores & \multicolumn{2}{|c|}{$I_{-} I_{-} \mid$} \\
\hline 1.2 & Em qual estado o(a) Sr(a) nasceu? & \multicolumn{2}{|c|}{ I_l__ l } \\
\hline 1.3 & Em qual cidade deste estado o(a) $\mathrm{Sr}(\mathrm{a})$ nasceu? & \\
\hline 1.4 & É casado(a) ou vive com companheiro(a)? & \multicolumn{2}{|c|}{$\begin{array}{l}\text { [] Sim } \\
2 \text { [] Não, mas já viveu antes } \\
3 \text { [] Nunca viveu }\end{array}$} \\
\hline 1.5 & $\begin{array}{l}\text { A sua cor ou raça é: } \\
\text { *Ler as alternativas* }\end{array}$ & \multicolumn{2}{|c|}{$\begin{array}{l}1 \text { [] Branca } \\
2 \text { [] Preta } \\
3 \text { [] Amarela } \\
4 \text { [] Parda } \\
5 \text { [] Indígena } \\
9 \text { [] NS/NR }\end{array}$} \\
\hline 1.6 & Qual é o seu peso atual? & \multicolumn{2}{|c|}{$I_{999} I_{-N S / N R} I_{-} \mid K g$} \\
\hline 1.7 & Qual é a sua altura? & \multicolumn{2}{|c|}{ 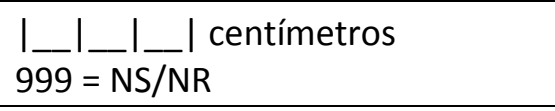 } \\
\hline 1.8 & Sabe ler e escrever? & \multicolumn{2}{|c|}{$\begin{array}{l}1 \text { [] Sim } \\
2 \text { [] Não => Passe para } 2.1 .0\end{array}$} \\
\hline \multirow[t]{8}{*}{1.9} & $\begin{array}{l}\text { Até que série e grau o(a) Sr(a) estudou? } \\
\text { *Considere as séries completas de estudo* }\end{array}$ & & \\
\hline & Curso primário & [] & $1[$ [] [] 3 [] 4 [] 5 [] \\
\hline & Admissão & [] & 4[] \\
\hline & Curso ginasial ou ginásio & [] & 1 [] 2 [] 3 [] 4 [] \\
\hline & $\begin{array}{l}\text { 1o grau ou fundamental ou supletivo de } \\
\text { primeiro grau ou EJA }\end{array}$ & [] & $\begin{array}{l}1 \text { [] } 2 \text { [] } 3 \text { [] } 4 \text { [] } 5 \text { [] } 6 \text { [] } \\
7 \text { [] } 8 \text { [] } 9 \text { [] }\end{array}$ \\
\hline & $\begin{array}{l}\text { 20 grau ou colégio técnico ou normal ou } \\
\text { científico ou ensino médio ou supletivo de } \\
\text { segundo grau ou EJA }\end{array}$ & [] & 1 [] 2 [] 3 [] \\
\hline & 30 grau ou curso superior & [] & $\begin{array}{l}\text { [] Completo } \\
\text { [] Incompleto }\end{array}$ \\
\hline & $\begin{array}{l}\text { Pós-graduação (especialização, mestrado, } \\
\text { doutorado) }\end{array}$ & [] & \\
\hline
\end{tabular}




\begin{tabular}{|l|l|l|l|}
\hline & Nunca estudou & {[]} & \\
\hline & NS/NR & {[]} & \\
\hline
\end{tabular}

102 - DOENÇAS CRÔNICAS

Agora, vou fazer algumas perguntas sobre a sua saúde.

\begin{tabular}{|c|c|c|}
\hline \multicolumn{3}{|c|}{ HIPERTENSÃO } \\
\hline 2.1 .0 & $\begin{array}{l}\text { Algum médico já lhe disse que o(a) Sr(a) } \\
\text { tem hipertensão ou pressão alta? }\end{array}$ & $\begin{array}{l}1 \text { [] Sim } \\
2 \text { [] Não => Passe para 2.2.0 }\end{array}$ \\
\hline 2.1 .1 & $\begin{array}{l}\text { Que idade o(a) Sr(a) tinha na primeira } \\
\text { vez em que o médico lhe disse que tinha } \\
\text { pressão alta? } \\
\text { *Caso o entrevistado relate uma idade } \\
\text { aproximada, anote a idade aproximada } \\
\text { declarada por ele* }\end{array}$ & $\begin{array}{l}I_{-} I_{\text {Le }} \mid \text { anos } \\
00=\text { menos de } 1 \text { ano } \\
99=\mathrm{NS} / \mathrm{NR}\end{array}$ \\
\hline 2.1 .2 & $\begin{array}{l}\text { O(a) Sr(a) tem indicação médica para } \\
\text { usar algum remédio para a pressão alta? }\end{array}$ & $\begin{array}{l}1 \text { [] Sim } \\
2 \text { [] Não => Passe para 2.1.8 }\end{array}$ \\
\hline 2.1 .3 & $\begin{array}{l}\mathrm{O}(\mathrm{a}) \mathrm{Sr}(\mathrm{a}) \text { está tomando algum desses } \\
\text { remédios? }\end{array}$ & $\begin{array}{l}1 \text { [] Sim } \\
2 \text { [] Não => Passe para 2.1.7 }\end{array}$ \\
\hline 2.1 .4 & Qual(is)? & *Listar abaixo os remédios* \\
\hline $2.1 .4 a$ & Remédio 1 & \\
\hline $2.1 .4 \mathrm{~b}$ & Remédio 2 & \\
\hline $2.1 .4 \mathrm{c}$ & Remédio 3 & \\
\hline 2.1 .5 & $\begin{array}{l}\text { Nos últimos } 30 \text { dias, o(a) } \mathrm{Sr}(\mathrm{a}) \text { ficou sem } \\
\text { algum desses remédios por algum } \\
\text { tempo? }\end{array}$ & $\begin{array}{l}1 \text { [] Sim } \\
2 \text { [] Não => Passe para 2.1.6 } \\
9 \text { [] NS/NR => Passe para 2.1.6 }\end{array}$ \\
\hline $2.1 .5 a$ & $\begin{array}{l}\text { Qual(is)? } \\
\text { *Preencha os campos correspondentes } \\
\text { aos remédios que o entrevistado relatou } \\
\text { que deixou de tomar* }\end{array}$ & $\begin{array}{l}\text { [] Remédio } 1 \\
\text { [] Remédio } 2 \\
\text { [] Remédio } 3\end{array}$ \\
\hline & Remédio 1: & \\
\hline $2.1 .5 b$ & Por quanto tempo? & I___l dias \\
\hline \multirow[t]{2}{*}{$2.1 .5 c$} & Por que ficou sem este remédio? & \\
\hline & Remédio 2: & \\
\hline $2.1 .5 \mathrm{~d}$ & Por quanto tempo? & I___l dias \\
\hline \multirow[t]{2}{*}{$2.1 .5 \mathrm{e}$} & Por que ficou sem este remédio? & \\
\hline & Remédio 3: & \\
\hline $2.1 .5 f$ & Por quanto tempo? & I_I_I dias \\
\hline $2.1 .5 \mathrm{~g}$ & Por que ficou sem este remédio? & \\
\hline 2.1 .6 & $\begin{array}{l}\text { Tem algum remédio, que o(a) Sr(a) } \\
\text { deveria estar usando, nos últimos } 30 \\
\text { dias, para a pressão alta, e não está? }\end{array}$ & $\begin{array}{l}1 \text { [] Sim } \\
2 \text { [] Não => Passe para 2.1.8 } \\
9 \text { [] NS/NR => Passe para 2.1.8 }\end{array}$ \\
\hline
\end{tabular}




\begin{tabular}{|c|c|c|}
\hline 2.1 .7 & $\begin{array}{l}\text { Qual(is) o(s) remédios que o(a) } \operatorname{Sr}(a) \\
\text { deveria estar usando e não está? }\end{array}$ & *Listar abaixo os remédios* \\
\hline 2.1.7a & Remédio 4 & \\
\hline $2.1 .7 \mathrm{~b}$ & Por que ficou sem usar este remédio? & \\
\hline $2.1 .7 \mathrm{c}$ & Remédio 5 & \\
\hline $2.1 .7 d$ & Por que ficou sem usar este remédio? & \\
\hline $2.1 .7 e$ & Remédio 6 & \\
\hline 2.1.7f & Por que ficou sem usar este remédio? & \\
\hline 2.1 .8 & $\begin{array}{l}\text { Quando foi a última vez que o(a) Sr(a) } \\
\text { mediu a pressão? }\end{array}$ & $\begin{array}{l}1 \text { [] no último mês } \\
2 \text { [] entre } 1 \text { mês e } 6 \text { meses } \\
3 \text { [] mais de } 6 \text { meses a } 1 \text { ano } \\
4 \text { [] mais de } 1 \text { ano a } 5 \text { anos } \\
5 \text { [] mais de } 5 \text { anos } \\
9 \text { [] NS/NR }\end{array}$ \\
\hline 2.1 .9 & $\begin{array}{l}\text { Algum médico já lhe disse que a pressão } \\
\text { alta causou algum outro problema de } \\
\text { saúde no(a) } \operatorname{Sr}(a) \text { ? }\end{array}$ & $\begin{array}{l}1 \text { [] Sim } \\
2 \text { [] Não => Passe para 2.1.11 } \\
9 \text { [] NS/NR => Passe para 2.1.11 }\end{array}$ \\
\hline 2.1 .10 & $\begin{array}{l}\text { Qual(is) } \\
\text { problema(s)? } \\
\text { *Ler as } \\
\text { alternativas* }\end{array}$ & $\begin{array}{l}\text { - [] Problema de vista, fundo de } \\
\text { olho? => Passe para 2.1.11 } \\
\text { - } \quad \text { [] Problema nos rins? => Passe } \\
\text { para 2.1.11 } \\
\text { - [] Problema circulatório, AVC, } \\
\text { derrame? => Passe para 2.1.11 - [] } \\
\text { Outro? } \\
-\quad \text { [] NS/NR => Passe para 2.1.11 }\end{array}$ \\
\hline 2.1.10a & Qual? & \\
\hline 2.1 .11 & $\begin{array}{l}\text { No dia a dia, quanto a pressão alta } \\
\text { limita as suas atividades habituais? } \\
\text { *Ler as alternativas* }\end{array}$ & $\begin{array}{l}1 \text { [] } \\
\text { Não } \\
\text { limita } \\
2 \text { [] } \\
\text { Um } \\
\text { pouco } \\
3 \text { [] Moderadamente } \\
4 \text { [] Intensamente } \\
5 \text { [] Muito intensamente }\end{array}$ \\
\hline
\end{tabular}

\begin{tabular}{|c|c|c|}
\hline \multicolumn{3}{|c|}{ DIABETES } \\
\hline 2.2 .0 & $\begin{array}{l}\text { Algum médico já Ihe disse que o(a) } \operatorname{Sr}(a) \text { tem } \\
\text { diabetes ou açúcar alto no sangue? }\end{array}$ & $\begin{array}{l}1 \text { [] Sim } \\
2 \text { [] Não => Passe para 2.3.0 }\end{array}$ \\
\hline 2.2 .1 & $\begin{array}{l}\text { Que idade o(a) Sr(a) tinha na primeira vez que o } \\
\text { médico lhe disse que tinha diabetes? } \\
\text { *Caso o entrevistado relate uma idade aproximada, } \\
\text { anote a idade aproximada declarada por ele* }\end{array}$ & $\begin{array}{l}I_{-} I_{\text {LE }} \mid I_{\text {anos }} \\
99=\mathrm{NS} / \mathrm{NR}\end{array}$ \\
\hline \multirow[t]{2}{*}{2.2 .2} & $\begin{array}{l}\text { O(a) Sr(a) tem indicação médica para usar algum } \\
\text { remédio para diabetes que não seja a insulina? }\end{array}$ & $\begin{array}{l}1 \text { [] Sim } \\
2 \text { [] Não => Passe para 2.2.6 }\end{array}$ \\
\hline & Para controlar o diabetes: & \\
\hline 2.2 .3 & O(a) Sr(a) está usando algum destes remédios? & $\begin{array}{l}1 \text { [] Sim } \\
2 \text { [] Não => Passe para 2.2.6 }\end{array}$ \\
\hline
\end{tabular}




\begin{tabular}{|c|c|c|}
\hline 2.2 .4 & Qual(is)? & *Listar abaixo os remédios* \\
\hline $2.2 .4 a$ & Remédio 1 & \\
\hline $2.2 .4 \mathrm{~b}$ & Remédio 2 & \\
\hline $2.2 .4 \mathrm{c}$ & Remédio 3 & \\
\hline 2.2 .5 & $\begin{array}{l}\text { Nos últimos } 30 \text { dias, o(a) Sr(a) ficou sem algum } \\
\text { destes remédios por algum tempo? }\end{array}$ & $\begin{array}{l}1 \text { [] Sim } \\
2 \text { [] Não => Passe para 2.2.6 } \\
9 \text { [] NS/NR => Passe para 2.2.6 }\end{array}$ \\
\hline \multirow[t]{2}{*}{$2.2 .5 a$} & $\begin{array}{l}\text { Qual(is)? } \\
\text { *Preencha os campos correspondentes aos remédios } \\
\text { que o entrevistado relatou que deixou de tomar* }\end{array}$ & $\begin{array}{l}\text { [] Remédio } 1 \\
\text { [] Remédio } 2 \\
\text { [] Remédio } 3\end{array}$ \\
\hline & Remédio 1: & \\
\hline $2.2 .5 b$ & Por quanto tempo? & I_I_l dias \\
\hline \multirow[t]{2}{*}{$2.2 .5 c$} & Por que ficou sem este remédio? & \\
\hline & Remédio 2: & \\
\hline $2.2 .5 d$ & Por quanto tempo? & I_l_l dias \\
\hline
\end{tabular}

\begin{tabular}{|c|c|c|}
\hline 2.2.5e & Por que ficou sem este remédio? & \\
\hline & Remédio 3: & \\
\hline $2.2 .5 f$ & Por quanto tempo? & $I \ldots I \ldots \mid$ dias $\quad 99=N S / N R$ \\
\hline $2.2 .5 \mathrm{~g}$ & Por que ficou sem este remédio? & \\
\hline 2.2 .6 & $\mathrm{O}(\mathrm{a}) \mathrm{Sr}(\mathrm{a})$ tem indicação médica para usar insulina? & $\begin{array}{l}1 \text { [] Sim } \\
2 \text { [] Não => Passe para 2.2.18 } \\
9 \text { [] NS/NR => Passe para 2.2.18 }\end{array}$ \\
\hline 2.2.6a & $\mathrm{O}(\mathrm{a}) \mathrm{Sr}(\mathrm{a})$ usa insulina? & $\begin{array}{l}1 \text { [] Sim } \\
2 \text { [] Não => Passe para 2.2.18 } \\
9 \text { [] NS/NR => Passe para 2.2.18 }\end{array}$ \\
\hline 2.2 .7 & Quantas vezes ao dia? & $\begin{array}{l}1 \text { [] Apenas uma vez } \\
2 \text { [] Duas ou mais vezes => Passe } \\
\text { para } 2.2 .9 \\
3 \text { [] Tantas quanto necessário => } \\
\text { Passe para } 2.2 .9\end{array}$ \\
\hline 2.2 .8 & Qual horário? & $\begin{array}{l}1 \text { [] Manhã => Passe para 2.2.9 } \\
2 \text { [] Noite => Passe para } 2.2 .9 \\
3 \text { [] Outro }\end{array}$ \\
\hline $2.2 .8 a$ & Qual? & \\
\hline 2.2 .9 & $\begin{array}{l}\text { Como o(a) Sr(a) adquire as seringas e agulhas que } \\
\text { utiliza para aplicar a insulina? }\end{array}$ & $\begin{array}{l}\text { - [] Compra => Passe para } 2.2 .9 b \\
\text { - [] Ganha do SUS => Passe para } \\
\text { 2.2.9b } \\
\text { - [] Outro } \\
\text { - [] NS/NR => Passe para 2.2.9b }\end{array}$ \\
\hline 2.2.9a & Como? & \\
\hline
\end{tabular}




\begin{tabular}{|c|c|c|}
\hline 2.2.9b & $\begin{array}{l}\text { O(a) Sr(a) utiliza as mesmas seringas e agulhas mais } \\
\text { de uma vez? }\end{array}$ & $\begin{array}{l}1 \text { [] Sim } \\
2 \text { [] Não } \\
3 \text { [] Às vezes } \\
9 \text { [] NS/NR }\end{array}$ \\
\hline $2.2 .10 a$ & $\begin{array}{l}\text { Antes de usar insulina, faz teste de glicose, ou açúcar } \\
\text { no sangue? }\end{array}$ & $\begin{array}{l}1 \text { [] Sim } \\
2 \text { [] Não => Passe para } 2.2 .14 \\
3 \text { [] Às vezes }\end{array}$ \\
\hline $2.2 .10 \mathrm{~b}$ & $\begin{array}{l}\text { Quantas vezes costuma fazer o teste de glicose por } \\
\text { dia? }\end{array}$ & $\begin{array}{l}I \ldots I \ldots \text { _ } l \text { vezes } \\
66=\text { Não faz todos os dias } \\
77=\text { Sempre que tem tiras } \\
88=\text { Tantas quanto necessário } \\
99=\text { NS/NR }\end{array}$ \\
\hline $2.2 .11 \mathrm{a}$ & $\mathrm{O}(\mathrm{a}) \mathrm{Sr}(\mathrm{a})$ possui o aparelho para medir a glicose? & $\begin{array}{l}1 \text { [] Sim } \\
2 \text { [] Não => Passe para 2.2.14 } \\
9 \text { [] NS/NR => Passe para 2.2.14 }\end{array}$ \\
\hline $2.2 .11 b$ & Como o(a) Sr(a) obteve este aparelho? & $\begin{array}{l}\text { - [] Comprou => Passe para 2.2.12 } \\
\text { - [] Ganhou do SUS => Passe para } \\
\text { 2.2.12 } \\
\text { - [] Outro } \\
\text { - [] NS/NR => Passe para 2.2.12 }\end{array}$ \\
\hline 2.2.11c & Como? & \\
\hline
\end{tabular}

\begin{tabular}{|c|c|c|}
\hline 2.2.12 & $\begin{array}{l}\text { Como o(a) } \mathrm{Sr}(\mathrm{a}) \text { adquire as tiras para o } \\
\text { aparelho? }\end{array}$ & $\begin{array}{l}\text { - [] Compra => Passe para 2.2.13 } \\
\text { - [] Ganha do SUS => Passe para 2.2.13 } \\
\text { - [] Outro } \\
\text { - [] NS/NR => Passe para 2.2.13 }\end{array}$ \\
\hline $2.2 .12 \mathrm{a}$ & Como? & \\
\hline 2.2 .13 & $\begin{array}{l}\mathrm{O}(\mathrm{a}) \mathrm{Sr}(\mathrm{a}) \text { utiliza as mesmas tiras para o } \\
\text { aparelho mais de uma vez? }\end{array}$ & $\begin{array}{l}1 \text { [] Sim } \\
2 \text { [] Não } \\
3 \text { [] Às vezes } \\
9 \text { [] NS/NR }\end{array}$ \\
\hline 2.2 .14 & $\begin{array}{l}\text { Algum médico, farmacêutico ou lhe explicou } \\
\text { como utilizar a insulina? }\end{array}$ & $\begin{array}{l}1 \text { [] Sim } \\
2 \text { [] Não } \\
9 \text { [] NS/NR }\end{array}$ \\
\hline 2.2 .15 & $\begin{array}{l}\text { Alguém já lhe explicou sobre a possibilidade } \\
\text { da glicose, ou açúcar no sangue, baixar muito? }\end{array}$ & $\begin{array}{l}1 \text { [] Sim } \\
2 \text { [] Não } \\
9 \text { [] NS/NR }\end{array}$ \\
\hline 2.2 .16 & $\begin{array}{l}\text { O(a) } \operatorname{Sr}(a) \text {, ou os seus familiares, sabem o que } \\
\text { fazer quando a glicose baixa muito? }\end{array}$ & $\begin{array}{l}1 \text { [] Sim } \\
2 \text { [] Não } \\
9 \text { [] NS/NR }\end{array}$ \\
\hline 2.2 .17 & $\begin{array}{l}\text { Nos últimos } 30 \text { dias, o(a) Sr(a) ficou sem usar } \\
\text { insulina por algum tempo? }\end{array}$ & $\begin{array}{l}1 \text { [] Sim } \\
2 \text { [] Não => Passe para 2.2.18 } \\
9 \text { [] NS/NR => Passe para 2.2.18 }\end{array}$ \\
\hline
\end{tabular}




\begin{tabular}{|c|c|c|}
\hline 2.2.17a & Por quanto tempo? & $\begin{array}{l}I-I_{-} \mid \text {dias } \\
99=N S / N R\end{array}$ \\
\hline 2.2.17b & Qual foi o motivo? & \\
\hline 2.2.18 & $\begin{array}{l}\text { Tem algum remédio, que o(a) Sr(a) deveria } \\
\text { estar usando, nos últimos } 30 \text { dias, para a } \\
\text { diabetes, e não está? }\end{array}$ & $\begin{array}{l}1 \text { [] Sim } \\
2 \text { [] Não => Passe para } \mathbf{2 . 2 . 2 0} \\
9 \text { [] NS/NR => Passe para 2.2.20 }\end{array}$ \\
\hline 2.2.19 & $\begin{array}{l}\text { Qual(is) os remédios que o(a) Sr(a) deveria } \\
\text { estar usando e não está? }\end{array}$ & *Listar abaixo os remédios* \\
\hline 2.2.19a & Remédio 4 & \\
\hline $2.2 .19 b$ & Por que ficou sem usar este remédio? & \\
\hline 2.2.19c & Remédio 5 & \\
\hline 2.2.19d & Por que ficou sem usar este remédio? & \\
\hline 2.2.19e & Remédio 6 & \\
\hline 2.2.19f & Por que ficou sem usar este remédio? & \\
\hline 2.2.20 & $\mathrm{O}(\mathrm{a}) \mathrm{Sr}(\mathrm{a})$ faz dieta para diabetes? & $\begin{array}{l}1 \text { [] Sim } \\
2 \text { [] Não } \\
3 \text { [] Às vezes } \\
9 \text { [] NS/NR }\end{array}$ \\
\hline 2.2.21 & $\begin{array}{l}\text { Algum médico já lhe disse que o diabetes } \\
\text { causou algum problema de saúde no(a) Sr(a)? }\end{array}$ & $\begin{array}{l}1 \text { [] Sim } \\
2 \text { [] Não => Passe para 2.2.23 } \\
9 \text { [] NS/NR => Passe para 2.2.23 }\end{array}$ \\
\hline 2.2 .22 & $\begin{array}{l}\text { Qual(is) } \\
\text { problema(s)? }{ }^{*} \text { Ler } \\
\text { as alternativas* }\end{array}$ & 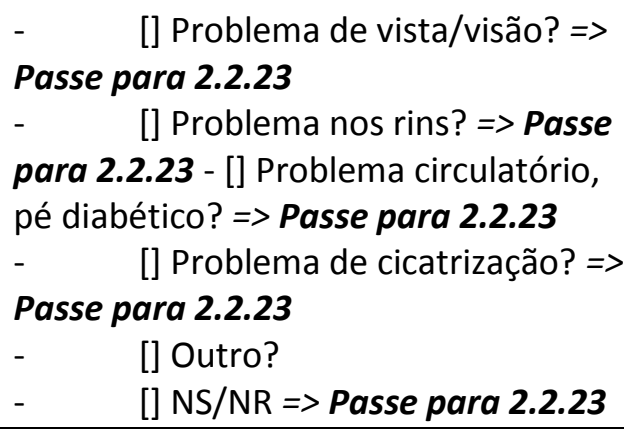 \\
\hline 2.2.22a & Qual? & \\
\hline 2.2 .23 & $\begin{array}{l}\text { No dia a dia, quanto o diabetes limita } \\
\text { as suas atividades habituais? }{ }^{*} \text { Ler as } \\
\text { alternativas* }\end{array}$ & $\begin{array}{l}1 \text { [] } \\
\text { Não } \\
\text { limita } \\
2 \text { [] } \\
\text { Um } \\
\text { pouco } \\
3 \text { [] Moderadamente } \\
4 \text { [] Intensamente } \\
5 \text { [] Muito intensamente }\end{array}$ \\
\hline
\end{tabular}




\begin{tabular}{|c|c|c|}
\hline 2.3.0 & $\begin{array}{l}\text { Algum médico já Ihe disse que o(a) Sr(a) } \\
\text { tem, ou teve, doença do coração, como } \\
\text { infarto, angina, insuficiência cardíaca, } \\
\text { arritmia ou outra? }\end{array}$ & $\begin{array}{l}1 \text { [] Sim } \\
2 \text { [] Não => Passe para 2.4.0 }\end{array}$ \\
\hline 2.3.1 & $\begin{array}{l}\text { Quais doenças do coração o médico disse que } \\
\text { o(a) Sr(a) tem ou teve: }\end{array}$ & $\begin{array}{l}\text { - [] Infarto => Passe para 2.3.2 } \\
\text { - [] Angina => Passe para 2.3.2 } \\
\text { - [] Insuficiência cardíaca => Passe para } \\
\text { 2.3.2 } \\
\text { - [] Arritmia => Passe para 2.3.2 } \\
\text { - [] Outra } \\
\text { - [] NS/NR => Passe para 2.3.2 }\end{array}$ \\
\hline 2.3.1a & Qual? & \\
\hline 2.3 .2 & $\begin{array}{l}\text { Que idade o(a) Sr(a) tinha na primeira vez que } \\
\text { o médico lhe disse que tinha esta(s) } \\
\text { doença(s)? }{ }^{*} \text { Caso o entrevistado relate uma } \\
\text { idade aproximada, anote a idade aproximada } \\
\text { declarada por ele* }\end{array}$ & $\begin{array}{l}I \_I_{-} \mid \text {anos } \\
00=\text { Se menos de } 1 \text { ano } \\
99=\text { NS/NR }\end{array}$ \\
\hline 2.3.3 & $\begin{array}{l}\mathrm{O}(\mathrm{a}) \mathrm{Sr}(\mathrm{a}) \text { tem indicação médica para usar } \\
\text { algum remédio para esta(s) doença(s)? }\end{array}$ & $\begin{array}{l}1 \text { [] Sim } \\
2 \text { [] Não => Passe para 2.3.9 }\end{array}$ \\
\hline 2.3 .4 & O(a) Sr(a) está usando algum desses remédios? & $\begin{array}{l}1 \text { [] Sim } \\
2 \text { [] Não => Passe para 2.3.8 }\end{array}$ \\
\hline 2.3 .5 & Qual(is)? & *Listar abaixo os remédios* \\
\hline 2.3.5a & Remédio 1 & \\
\hline $2.3 .5 b$ & Remédio 2 & \\
\hline $2.3 .5 c$ & Remédio 3 & \\
\hline 2.3.6 & $\begin{array}{l}\text { Nos últimos } 30 \text { dias, o(a) } \mathrm{Sr}(\mathrm{a}) \text { ficou sem algum } \\
\text { desses remédios por algum tempo? }\end{array}$ & $\begin{array}{l}1 \text { [] Sim } \\
2 \text { [] Não => Passe para 2.3.7 } \\
9 \text { [] NS/NR => Passe para 2.3.7 }\end{array}$ \\
\hline \multirow[t]{2}{*}{ 2.3.6a } & $\begin{array}{l}\text { Qual(is)? } \\
\text { *Preencha os campos correspondentes aos } \\
\text { remédios que o entrevistado relatou que deixou } \\
\text { de tomar* }\end{array}$ & $\begin{array}{l}\text { [] Remédio } 1 \\
\text { [] Remédio } 2 \\
\text { [] Remédio } 3\end{array}$ \\
\hline & Remédio 1: & \\
\hline $2.3 .6 b$ & Por quanto tempo? & I_I_l dias \\
\hline \multirow[t]{2}{*}{ 2.3.6c } & Por que ficou sem este remédio? & \\
\hline & Remédio 2: & \\
\hline 2.3.6d & Por quanto tempo? & I___l dias \\
\hline \multirow[t]{2}{*}{ 2.3.6e } & Por que ficou sem este remédio? & \\
\hline & Remédio 3: & \\
\hline 2.3.6f & Por quanto tempo? & I_I_l dias \\
\hline 2.3.7 & $\begin{array}{l}\text { Tem algum remédio, que o(a) Sr(a) deveria } \\
\text { estar usando, nos últimos } 30 \text { dias, para o } \\
\text { coração, e não está? }\end{array}$ & $\begin{array}{l}1 \text { [] Sim } \\
2 \text { [] Não => Passe para 2.3.9 } \\
9 \text { [] NS/NR => Passe para 2.3.9 }\end{array}$ \\
\hline
\end{tabular}




\begin{tabular}{|c|c|c|}
\hline 2.3 .8 & $\begin{array}{l}\text { Qual(is) o(s) remédios que o(a) Sr(a) deveria } \\
\text { estar usando e não está? }\end{array}$ & *Listar abaixo os remédios* \\
\hline 2.3.8a & Remédio 4 & \\
\hline $2.3 .8 \mathrm{~b}$ & Por que ficou sem usar este remédio? & \\
\hline $2.3 .8 \mathrm{c}$ & Remédio 5 & \\
\hline 2.3.8d & Por que ficou sem usar este remédio? & \\
\hline $2.3 .8 \mathrm{e}$ & Remédio 6 & \\
\hline $2.3 .8 f$ & Por que ficou sem usar este remédio? & \\
\hline 2.3.9 & $\begin{array}{l}\text { No dia a dia, quanto esta doença limita as } \\
\text { suas atividades habituais? * Ler as } \\
\text { alternativas* }\end{array}$ & $\begin{array}{l}1 \text { [] } \\
\text { Não } \\
\text { limita } \\
2 \text { [] Um } \\
\text { pouco } \\
3 \text { [] Moderadamente } \\
4 \text { [] Intensamente } \\
5 \text { [] Muito intensamente }\end{array}$ \\
\hline
\end{tabular}

\begin{tabular}{|c|c|c|}
\hline \multicolumn{3}{|c|}{ COLESTEROL ALTO } \\
\hline 2.4.0 & $\begin{array}{l}\text { Algum médico já lhe disse que o(a) Sr(a) tem } \\
\text { colesterol alto? }\end{array}$ & $\begin{array}{l}1 \text { [] Sim } \\
2 \text { [] Não => Passe para 2.5.0 }\end{array}$ \\
\hline 2.4 .1 & $\begin{array}{l}\text { Que idade o(a) Sr(a) tinha na primeira vez que o } \\
\text { médico lhe disse que tinha colesterol alto? } \\
\text { *Caso o entrevistado relate uma idade } \\
\text { aproximada, anote a idade aproximada } \\
\text { declarada por ele* }\end{array}$ & $\begin{array}{l}I \_I_{-} \mid \mathrm{I} \text { anos } \\
00=\text { Se menos de } 1 \text { ano } \\
99=\mathrm{NS} / \mathrm{NR}\end{array}$ \\
\hline 2.4 .2 & $\begin{array}{l}\text { O(a) Sr(a) tem indicação médica para usar } \\
\text { algum remédio para o colesterol? }\end{array}$ & $\begin{array}{l}1 \text { [] Sim } \\
2 \text { [] Não => Passe para } 2.4 .8\end{array}$ \\
\hline 2.4 .3 & O(a) Sr(a) está usando algum desses remédios? & $\begin{array}{l}1 \text { [] Sim } \\
2 \text { [] Não => Passe para 2.4.7 }\end{array}$ \\
\hline 2.4 .4 & Qual(is)? & *Listar abaixo os remédios* \\
\hline $2.4 .4 a$ & Remédio 1 & \\
\hline $2.4 .4 b$ & Remédio 2 & \\
\hline $2.4 .4 \mathrm{c}$ & Remédio 3 & \\
\hline 2.4 .5 & $\begin{array}{l}\text { Nos últimos } 30 \text { dias, o(a) Sr(a) ficou sem algum } \\
\text { desses remédios por algum tempo? }\end{array}$ & $\begin{array}{l}1 \text { [] Sim } \\
2 \text { [] Não => Passe para } 2.4 .6 \\
9 \text { [] NS/NR => Passe para 2.4.6 }\end{array}$ \\
\hline \multirow[t]{2}{*}{$2.4 .5 a$} & $\begin{array}{l}\text { Qual(is)? } \\
\text { *Preencha os campos correspondentes aos } \\
\text { remédios que o entrevistado relatou que deixou } \\
\text { de tomar* }\end{array}$ & $\begin{array}{l}\text { [] Remédio } 1 \\
\text { [] Remédio } 2 \\
\text { [] Remédio } 3\end{array}$ \\
\hline & Remédio 1: & \\
\hline $2.4 .5 b$ & Por quanto tempo? & I_I_ dias $\quad 99=$ NS/NR \\
\hline
\end{tabular}




\begin{tabular}{|c|c|c|}
\hline $2.4 .5 \mathrm{c}$ & Por que ficou sem este remédio? & \\
\hline & Remédio 2: & \\
\hline $2.4 .5 \mathrm{~d}$ & Por quanto tempo? & I_I_l dias \\
\hline \multirow[t]{2}{*}{$2.4 .5 \mathrm{e}$} & Por que ficou sem este remédio? & \\
\hline & Remédio 3: & \\
\hline $2.4 .5 f$ & Por quanto tempo? & I_I_I dias \\
\hline $2.4 .5 \mathrm{~g}$ & Por que ficou sem este remédio? & \\
\hline 2.4 .6 & $\begin{array}{l}\text { Tem algum remédio, que o(a) Sr(a) deveria } \\
\text { estar usando, nos últimos } 30 \text { dias, para o } \\
\text { colesterol, e não está? }\end{array}$ & $\begin{array}{l}1 \text { [] Sim } \\
2 \text { [] Não => Passe para 2.4.8 } \\
9 \text { [] NS/NR => Passe para 2.4.8 }\end{array}$ \\
\hline 2.4.7 & $\begin{array}{l}\text { Qual(is) o(s) remédios que o(a) Sr(a) deveria } \\
\text { estar usando e não está? }\end{array}$ & *Listar abaixo os remédios* \\
\hline $2.4 .7 a$ & Remédio 4 & \\
\hline $2.4 .7 b$ & Por que ficou sem usar este remédio? & \\
\hline 2.4.7c & Remédio 5 & \\
\hline $2.4 .7 d$ & Por que ficou sem usar este remédio? & \\
\hline 2.4.7e & Remédio 6 & \\
\hline 2.4.7f & Por que ficou sem usar este remédio? & \\
\hline 2.4 .8 & $\begin{array}{l}\text { Quando foi a última vez que o(a) } \mathrm{Sr}(\mathrm{a}) \mathrm{fez} \\
\text { exame de sangue para medir o colesterol? }\end{array}$ & $\begin{array}{l}1 \text { [] Há menos de } 6 \text { meses } \\
2 \text { [] Entre } 6 \text { meses e menos de } 1 \text { ano } \\
3 \text { [] Entre } 1 \text { ano e menos de } 2 \text { anos } \\
4 \text { [] Entre } 2 \text { anos e menos de } 3 \text { anos } \\
5 \text { [] } 3 \text { anos ou mais atrás } \\
9 \text { [] NS/NR }\end{array}$ \\
\hline 2.4 .9 & $\begin{array}{l}\text { No dia a dia, quanto o colesterol alto limita } \\
\text { as suas atividades habituais? *Ler as } \\
\text { alternativas* }\end{array}$ & $\begin{array}{l}1 \text { [] } \\
\text { Não } \\
\text { limita } \\
2 \text { [] } \\
\text { Um } \\
\text { pouco } \\
3 \text { [] Moderadamente } \\
4 \text { [] Intensamente } \\
5 \text { [] Muito intensamente }\end{array}$ \\
\hline
\end{tabular}

\begin{tabular}{|l|l|l|}
\hline \multicolumn{2}{|l|}{ AVC (ACIDENTE VASCULAR CEREBRAL) } \\
\hline 2.5 .0 & $\begin{array}{l}\text { Algum médico já lhe disse que o(a) Sr(a) teve } \\
\text { AVC (Acidente Vascular Cerebral) ou } \\
\text { derrame? }\end{array}$ & $\begin{array}{l}1 \text { [] Sim } \\
2 \text { [] Não => Passe para 2.6.0 }\end{array}$ \\
\hline 2.5 .1 & $\begin{array}{l}\text { Que idade o(a) Sr(a) tinha na primeira vez que } \\
\text { o médico lhe disse que teve AVC? } \\
\text { *Caso o entrevistado relate uma idade } \\
\text { aproximada, anote a idade aproximada } \\
\text { declarada por ele* }\end{array}$ & $\begin{array}{l}\text { I_l anos } \\
00=\text { menos de } 1 \text { ano } \\
99=\text { NS/NR }\end{array}$ \\
\hline
\end{tabular}




\begin{tabular}{|c|c|c|}
\hline 2.5 .2 & $\begin{array}{l}\text { O(a) Sr(a) tem indicação médica para usar } \\
\text { algum remédio por causa do AVC? }\end{array}$ & $\begin{array}{l}1 \text { [] Sim } \\
2 \text { [] Não => Passe para 2.5.8 }\end{array}$ \\
\hline 2.5 .3 & $\begin{array}{l}\mathrm{O}(\mathrm{a}) \mathrm{Sr}(\mathrm{a}) \text { está usando algum desses } \\
\text { remédios? }\end{array}$ & $\begin{array}{l}1 \text { [] Sim } \\
2 \text { [] Não => Passe para } 2.5 .7\end{array}$ \\
\hline 2.5 .4 & Qual(is)? & *Listar abaixo os remédios* \\
\hline 2.5.4a & Remédio 1 & \\
\hline $2.5 .4 b$ & Remédio 2 & \\
\hline 2.5.4c & Remédio 3 & \\
\hline 2.5 .5 & $\begin{array}{l}\text { Nos últimos } 30 \text { dias, o(a) Sr(a) ficou sem } \\
\text { algum desses remédios por algum tempo? }\end{array}$ & $\begin{array}{l}1 \text { [] Sim } \\
2 \text { [] Não => Passe para 2.5.6 } \\
9 \text { [] NS/NR => Passe para 2.5.6 }\end{array}$ \\
\hline \multirow[t]{2}{*}{ 2.5.5a } & $\begin{array}{l}\text { Qual(is)? } \\
\text { *Preencha os campos correspondentes aos } \\
\text { remédios que o entrevistado relatou que } \\
\text { deixou de tomar* }\end{array}$ & $\begin{array}{l}\text { [] Remédio } 1 \\
\text { [] Remédio } 2 \\
\text { [] Remédio } 3\end{array}$ \\
\hline & Remédio 1: & \\
\hline $2.5 .5 b$ & Por quanto tempo? & I_I_I dias \\
\hline \multirow[t]{2}{*}{$2.5 .5 \mathrm{c}$} & Por que ficou sem este remédio? & \\
\hline & Remédio 2: & \\
\hline $2.5 .5 d$ & Por quanto tempo? & I_I_ d dias $\quad 99=$ NS/NR \\
\hline \multirow[t]{2}{*}{$2.5 .5 \mathrm{e}$} & Por que ficou sem este remédio? & \\
\hline & Remédio 3: & \\
\hline $2.5 .5 f$ & Por quanto tempo? & I_I_I dias \\
\hline $2.5 .5 \mathrm{~g}$ & Por que ficou sem este remédio? & \\
\hline 2.5 .6 & $\begin{array}{l}\text { Tem algum remédio, que o(a) Sr(a) deveria } \\
\text { estar usando, nos últimos } 30 \text { dias, para o AVC, } \\
\text { e não está? }\end{array}$ & $\begin{array}{l}1 \text { [] Sim } \\
2 \text { [] Não => Passe para } 2.5 .8 \\
9 \text { [] NS/NR => Passe para 2.5.8 }\end{array}$ \\
\hline 2.5 .7 & $\begin{array}{l}\text { Qual(is) o(s) remédios que o(a) Sr(a) deveria } \\
\text { estar usando e não está? }\end{array}$ & *Listar abaixo os remédios* \\
\hline 2.5.7a & Remédio 4 & \\
\hline $2.5 .7 b$ & Por que ficou sem usar este remédio? & \\
\hline 2.5.7c & Remédio 5 & \\
\hline $2.5 .7 d$ & Por que ficou sem usar este remédio? & \\
\hline 2.5.7e & Remédio 6 & \\
\hline 2.5.7f & Por que ficou sem usar este remédio? & \\
\hline 2.5 .8 & $\begin{array}{l}\text { Atualmente por causa do AVC o(a) Sr(a) faz: } \\
\text { Fisioterapia ou outras terapias de } \\
\text { reabilitação? }\end{array}$ & $\begin{array}{l}1 \text { [] Sim } \\
2 \text { [] Não } \\
9 \text { [] NS/NR }\end{array}$ \\
\hline
\end{tabular}




\begin{tabular}{|c|c|c|}
\hline 2.5 .9 & $\begin{array}{l}\text { No dia a dia, quanto o AVC limita as suas } \\
\text { atividades habituais? } \\
\text { *Ler as alternativas* }\end{array}$ & $\begin{array}{l}1 \text { [] Não } \\
\text { limita } 2 \\
\text { [] Um } \\
\text { pouco } \\
3 \text { [] Moderadamente } \\
4 \text { [] Intensamente } \\
5 \text { [] Muito intensamente }\end{array}$ \\
\hline
\end{tabular}

\begin{tabular}{|c|c|c|}
\hline \multicolumn{3}{|c|}{ DOENÇA PULMONAR CRÔNICA (ASMA, BRONQUITE CRÔNICA, ENFISEMA OU OUTRA) } \\
\hline 2.6.0 & $\begin{array}{l}\text { Algum médico já lhe disse que o(a) } \mathrm{Sr}(\mathrm{a}) \text { tem asma, } \\
\text { bronquite crônica, enfisema ou outra doença } \\
\text { pulmonar? }\end{array}$ & $\begin{array}{l}1 \text { [] Sim } \\
2 \text { [] Não => Passe para 2.7.0 }\end{array}$ \\
\hline 2.6.1 & $\begin{array}{l}\text { Quais doenças do pulmão o médico disse que o(a) } \\
\text { Sr(a) tem? }\end{array}$ & $\begin{array}{l}\text { - [] Asma => Passe para } \mathbf{2 . 6 . 2} \\
\text { - [] Bronquite crônica => Passe } \\
\text { para 2.6.2 } \\
\text { - [] Enfisema pulmonar => Passe } \\
\text { para 2.6.2 } \\
\text { - [] Outra doença pulmonar } \\
\text { - [] NS/NR => Passe para 2.6.2 }\end{array}$ \\
\hline 2.6.1a & Qual? & \\
\hline 2.6 .2 & $\begin{array}{l}\text { Que idade o(a) Sr(a) tinha quando o médico lhe disse } \\
\text { que tinha esta doença? } \\
\text { *Caso o entrevistado relate uma idade aproximada, } \\
\text { anote a idade aproximada declarada por ele* }\end{array}$ & 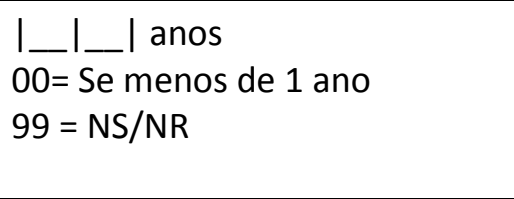 \\
\hline 2.6.3 & $\begin{array}{l}\mathrm{O}(\mathrm{a}) \mathrm{Sr}(\mathrm{a}) \text { tem indicação médica para usar algum } \\
\text { remédio para esta doença? }\end{array}$ & $\begin{array}{l}1 \text { [] Sim } \\
2 \text { [] Não => Passe para 2.6.10 }\end{array}$ \\
\hline 2.6 .4 & O(a) Sr(a) está usando algum desses remédios? & $\begin{array}{l}1 \text { [] Sim } \\
2 \text { [] Não => Passe para } 2.6 .9\end{array}$ \\
\hline 2.6 .5 & Qual(is)? & *Listar abaixo os remédios* \\
\hline 2.6.5a & Remédio 1 & \\
\hline
\end{tabular}




\begin{tabular}{|c|c|c|}
\hline $2.6 .5 b$ & Remédio 2 & \\
\hline $2.6 .5 c$ & Remédio 3 & \\
\hline 2.6 .6 & $\begin{array}{l}\text { Nos últimos } 30 \text { dias, o(a) Sr(a) ficou sem algum } \\
\text { desses remédios por algum tempo? }\end{array}$ & $\begin{array}{l}1 \text { [] Sim } \\
2 \text { [] Não => Passe para } 2.6 .8 \\
9 \text { [] NS/NR => Passe para } 2.6 .8\end{array}$ \\
\hline \multirow[t]{2}{*}{ 2.6.7a } & $\begin{array}{l}\text { Qual(is)? } \\
\text { *Preencha os campos correspondentes aos } \\
\text { remédios que o entrevistado relatou que deixou } \\
\text { de tomar* }\end{array}$ & $\begin{array}{l}\text { [] Remédio } 1 \\
\text { [] Remédio } 2 \\
\text { [] Remédio } 3\end{array}$ \\
\hline & Remédio 1: & \\
\hline $2.6 .7 b$ & Por quanto tempo? & I_I_I dias \\
\hline \multirow[t]{2}{*}{ 2.6.7c } & Por que ficou sem este remédio? & \\
\hline & Remédio 2: & \\
\hline 2.6.7d & Por quanto tempo? & I___ dias $99=$ NS/NR \\
\hline \multirow[t]{2}{*}{ 2.6.7e } & Por que ficou sem este remédio? & \\
\hline & Remédio 3: & \\
\hline 2.6.7f & Por quanto tempo? & I___ l dias $\quad 99=\mathrm{NS} / \mathrm{NR}$ \\
\hline $2.6 .7 \mathrm{~g}$ & Por que ficou sem este remédio? & \\
\hline 2.6 .8 & $\begin{array}{l}\text { Tem algum remédio, que o(a) Sr(a) deveria } \\
\text { estar usando, nos últimos } 30 \text { dias, para a(s) } \\
\text { doenças do pulmão, e não está? }\end{array}$ & $\begin{array}{l}1 \text { [] Sim } \\
2 \text { [] Não => Passe para 2.6.10 } \\
9 \text { [] NS/NR => Passe para } 2.6 .10\end{array}$ \\
\hline 2.6 .9 & $\begin{array}{l}\text { Qual(is) o(s) remédios que o(a) Sr(a) deveria } \\
\text { estar usando e não está? }\end{array}$ & *Listar abaixo os remédios* \\
\hline 2.6.9a & Remédio 4 & \\
\hline $2.6 .9 \mathrm{~b}$ & Por que ficou sem usar este remédio? & \\
\hline $2.6 .9 c$ & Remédio 5 & \\
\hline $2.6 .9 d$ & Por que ficou sem usar este remédio? & \\
\hline 2.6.9e & Remédio 6 & \\
\hline 2.6.9f & Por que ficou sem usar este remédio? & \\
\hline 2.6.10 & $\begin{array}{l}\text { Atualmente por causa desta(s) doença(s), o(a) } \\
\text { Sr(a) faz: }\end{array}$ & \\
\hline 2.6.10a & $\begin{array}{l}\text { Controle do ambiente doméstico do tipo: evita } \\
\text { ter tapetes, cortinas, animais domésticos? }\end{array}$ & $\begin{array}{l}1 \text { [] Sim } \\
2 \text { [] Não }\end{array}$ \\
\hline 2.6 .11 & Atividade física? & $\begin{array}{l}1 \text { [] Sim } \\
2 \text { [] Não }\end{array}$ \\
\hline 2.6 .11 & Fisioterapia respiratória? & $\begin{array}{l}1 \text { [] Sim } \\
2 \text { [] Não }\end{array}$ \\
\hline
\end{tabular}




\begin{tabular}{|c|c|c|}
\hline 2.6 .12 & Nebulização? & $\begin{array}{l}1 \text { [] Sim } \\
2 \text { [] Não }\end{array}$ \\
\hline 2.6 .13 & Vacina para gripe? & $\begin{array}{l}1 \text { [] Sim } \\
2 \text { [] Não }\end{array}$ \\
\hline 2.6 .14 & Outras vacinas? & $\begin{array}{l}1 \text { [] Sim } \\
2 \text { [] Não => Passe para 2.6.15 }\end{array}$ \\
\hline 2.6.14a & Quais? & \\
\hline 2.6.15 & $\begin{array}{l}\text { No dia a dia, quanto esta doença limita } \\
\text { as suas atividades habituais? }{ }^{*} \text { Ler as } \\
\text { alternativas* }\end{array}$ & $\begin{array}{l}1 \text { [] } \\
\text { Não } \\
\text { limita } \\
2 \text { [] } \\
\text { Um } \\
\text { pouco } \\
3 \text { [] Moderadamente } \\
4 \text { [] Intensamente } \\
5 \text { [] Muito intensamente }\end{array}$ \\
\hline
\end{tabular}

\begin{tabular}{|c|c|c|}
\hline \multicolumn{3}{|c|}{ ARTRITE OU REUMATISMO } \\
\hline 2.7 .0 & $\begin{array}{l}\text { Algum médico já Ihe disse que o(a) Sr(a) tem } \\
\text { artrite, artrose, ou reumatismo? }\end{array}$ & $\begin{array}{l}1 \text { [] Sim } \\
2 \text { [] Não => Passe para } \mathbf{2 . 8 . 0}\end{array}$ \\
\hline 2.7.1 & $\begin{array}{l}\text { Que idade o(a) Sr(a) tinha na primeira vez que } \\
\text { o médico lhe disse que tinha artrite, artrose } \\
\text { ou reumatismo? } \\
\text { *Caso o entrevistado relate uma idade } \\
\text { aproximada, anote a idade aproximada } \\
\text { declarada por ele* }\end{array}$ & $\begin{array}{l}I \ldots I_{-} \mid I_{\text {anos }} \\
00=\text { Se menos de } 1 \text { ano } \\
99=\text { NS/NR }\end{array}$ \\
\hline 2.7 .2 & $\begin{array}{l}\mathrm{O}(\mathrm{a}) \mathrm{Sr}(\mathrm{a}) \text { tem indicação médica para usar } \\
\text { algum remédio para a artrite ou reumatismo? }\end{array}$ & $\begin{array}{l}1 \text { [] Sim } \\
2 \text { [] Não => Passe para } 2.7 .9\end{array}$ \\
\hline 2.7 .3 & $\begin{array}{l}\mathrm{O}(\mathrm{a}) \mathrm{Sr}(\mathrm{a}) \text { está usando algum desses } \\
\text { remédios? }\end{array}$ & $\begin{array}{l}1 \text { [] Sim } \\
2 \text { [] Não => Passe para } 2.7 .8\end{array}$ \\
\hline 2.7 .4 & Qual(is)? & *Listar abaixo os remédios* \\
\hline 2.7.4a & Remédio 1 & \\
\hline $2.7 .4 b$ & Remédio 2 & \\
\hline $2.7 .4 \mathrm{c}$ & Remédio 3 & \\
\hline 2.7 .6 & $\begin{array}{l}\text { Nos últimos } 30 \text { dias, o(a) Sr(a) ficou sem } \\
\text { algum desses remédios por algum tempo? }\end{array}$ & $\begin{array}{l}1 \text { [] Sim } \\
2 \text { [] Não => Passe para 2.7.7 } \\
9 \text { [] NS/NR => Passe para 2.7.7 }\end{array}$ \\
\hline \multirow[t]{2}{*}{ 2.7.6a } & $\begin{array}{l}\text { Qual(is)? } \\
\text { *Preencha os campos correspondentes aos } \\
\text { remédios que o entrevistado relatou que } \\
\text { deixou de tomar* }\end{array}$ & $\begin{array}{l}\text { [] Remédio } 1 \\
\text { [] Remédio } 2 \\
\text { [] Remédio } 3\end{array}$ \\
\hline & Remédio 1: & \\
\hline
\end{tabular}




\begin{tabular}{|c|c|c|}
\hline $2.7 .6 \mathrm{~b}$ & Por quanto tempo? & I___l dias \\
\hline \multirow[t]{2}{*}{ 2.7.6c } & Por que ficou sem este remédio? & \\
\hline & Remédio 2: & \\
\hline $2.7 .6 \mathrm{~d}$ & Por quanto tempo? & I_I_l dias \\
\hline \multirow[t]{2}{*}{ 2.7.6e } & Por que ficou sem este remédio? & \\
\hline & Remédio 3: & \\
\hline $2.7 .6 f$ & Por quanto tempo? & I_I_ l dias $99=$ NS/NR \\
\hline 2.7.6g & Por que ficou sem este remédio? & \\
\hline 2.7 .7 & $\begin{array}{l}\text { Tem algum remédio, que o(a) } \mathrm{Sr}(\mathrm{a}) \text { deveria } \\
\text { estar usando, nos últimos } 30 \text { dias, para a } \\
\text { artrite ou reumatismo, e não está? }\end{array}$ & $\begin{array}{l}1 \text { [] Sim } \\
2 \text { [] Não => Passe para 2.7.9 } \\
9 \text { [] NS/NR => Passe para 2.7.9 }\end{array}$ \\
\hline 2.7 .8 & $\begin{array}{l}\text { Qual(is) o(s) remédios que o(a) } \mathrm{Sr}(\mathrm{a}) \text { deveria } \\
\text { estar usando e não está? }\end{array}$ & *Listar abaixo os remédios* \\
\hline $2.7 .8 \mathrm{a}$ & Remédio 4 & \\
\hline $2.7 .8 \mathrm{~b}$ & Por que ficou sem usar este remédio? & \\
\hline $2.7 .8 \mathrm{c}$ & Remédio 5 & \\
\hline $2.7 .8 \mathrm{~d}$ & Por que ficou sem usar este remédio? & \\
\hline $2.7 .8 \mathrm{e}$ & Remédio 6 & \\
\hline $2.7 .8 f$ & Por que ficou sem usar este remédio? & \\
\hline 2.7 .9 & $\begin{array}{l}\text { Atualmente por causa da artrite ou } \\
\text { reumatismo o(a) Sr(a) faz algum outro } \\
\text { tratamento como: }\end{array}$ & \\
\hline 2.7.9a & Exercício físico? & $\begin{array}{l}1 \text { [] Sim } \\
2 \text { [] Não }\end{array}$ \\
\hline $2.7 .9 \mathrm{~b}$ & Fisioterapia? & $\begin{array}{l}1 \text { [] Sim } \\
2 \text { [] Não }\end{array}$ \\
\hline $2.7 .9 c$ & Acupuntura? & $\begin{array}{l}1 \text { [] Sim } \\
2 \text { [] Não }\end{array}$ \\
\hline 2.7.10 & $\begin{array}{l}\text { No dia a dia, quanto a artrite, ou reumatismo, } \\
\text { limita as suas atividades habituais? } \\
\text { *Ler as alternativas* }\end{array}$ & $\begin{array}{l}1 \text { [] } \\
\text { Não } \\
\text { limita } \\
2 \text { [] } \\
\text { Um } \\
\text { pouco } \\
3 \text { [] Moderadamente } \\
4 \text { [] Intensamente } \\
5 \text { [] Muito intensamente }\end{array}$ \\
\hline
\end{tabular}




\begin{tabular}{|c|c|c|}
\hline 2.8 .0 & $\begin{array}{l}\text { Algum médico já lhe disse que o(a) Sr(a) tem } \\
\text { depressão? }\end{array}$ & $\begin{array}{l}1 \text { [] Sim } \\
2 \text { [] Não => Passe para } 2.9 .0\end{array}$ \\
\hline 2.8 .1 & $\begin{array}{l}\text { Que idade o(a) } \mathrm{Sr}(\mathrm{a}) \text { tinha na primeira vez } \\
\text { que o médico lhe disse que tinha depressão? } \\
{ }^{*} \text { Caso o entrevistado relate uma idade } \\
\text { aproximada, anote a idade aproximada } \\
\text { declarada por ele* }\end{array}$ & $\begin{array}{l}I_{-} I_{\text {_L }} \mid \text { anos } \\
00=\text { Se menos de } 1 \text { ano } \\
99=\text { NS/NR }\end{array}$ \\
\hline 2.8 .2 & $\begin{array}{l}\text { O(a) Sr(a) tem indicação médica para usar } \\
\text { algum remédio para a depressão? }\end{array}$ & $\begin{array}{l}1 \text { [] Sim } \\
2 \text { [] Não => Passe para } \mathbf{2 . 8 . 8}\end{array}$ \\
\hline 2.8 .3 & $\begin{array}{l}\mathrm{O}(\mathrm{a}) \mathrm{Sr}(\mathrm{a}) \text { está usando algum desses } \\
\text { remédios? }\end{array}$ & $\begin{array}{l}1 \text { [] Sim } \\
2 \text { [] Não => Passe para } 2.8 .7\end{array}$ \\
\hline 2.8 .4 & Qual(is)? & *Listar abaixo os remédios* \\
\hline $2.8 .4 a$ & Remédio 1 & \\
\hline $2.8 .4 \mathrm{~b}$ & Remédio 2 & \\
\hline $2.8 .4 \mathrm{c}$ & Remédio 3 & \\
\hline 2.8 .5 & $\begin{array}{l}\text { Nos últimos } 30 \text { dias, o(a) Sr(a) ficou sem } \\
\text { algum desses remédios por algum tempo? }\end{array}$ & $\begin{array}{l}1 \text { [] Sim } \\
2 \text { [] Não => Passe para 2.8.6 } \\
9 \text { [] NS/NR => Passe para 2.8.6 }\end{array}$ \\
\hline \multirow[t]{2}{*}{$2.8 .5 a$} & $\begin{array}{l}\text { Qual(is)? } \\
\text { *Preencha os campos correspondentes aos } \\
\text { remédios que o entrevistado relatou que } \\
\text { deixou de tomar* }\end{array}$ & $\begin{array}{l}\text { [] Remédio } 1 \\
\text { [] Remédio } 2 \\
\text { [] Remédio } 3\end{array}$ \\
\hline & Remédio 1: & \\
\hline $2.8 .5 b$ & Por quanto tempo? & I____ I dias \\
\hline \multirow[t]{2}{*}{$2.8 .5 \mathrm{c}$} & Por que ficou sem este remédio? & \\
\hline & Remédio 2: & \\
\hline $2.8 .5 \mathrm{~d}$ & Por quanto tempo? & 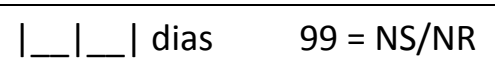 \\
\hline \multirow[t]{2}{*}{$2.8 .5 \mathrm{e}$} & Por que ficou sem este remédio? & \\
\hline & Remédio 3: & \\
\hline $2.8 .5 f$ & Por quanto tempo? & I__ $I_{\text {_l }}$ dias $\quad 99=\mathrm{NS} / \mathrm{NR}$ \\
\hline $2.8 .5 \mathrm{~g}$ & Por que ficou sem este remédio? & \\
\hline 2.8 .6 & $\begin{array}{l}\text { Tem algum remédio, que o(a) Sr(a) deveria } \\
\text { estar usando, nos últimos } 30 \text { dias, para a } \\
\text { depressão, e não está? }\end{array}$ & $\begin{array}{l}1 \text { [] Sim } \\
2 \text { [] Não => Passe para } 2.8 .8 \\
9 \text { [] NS/NR => Passe para } 2.8 .8\end{array}$ \\
\hline 2.8 .7 & $\begin{array}{l}\text { Qual(is) o(s) remédios que o(a) Sr(a) deveria } \\
\text { estar usando e não está? }\end{array}$ & *Listar abaixo os remédios* \\
\hline $2.8 .7 a$ & Remédio 4 & \\
\hline $2.8 .7 \mathrm{~b}$ & Por que ficou sem usar este remédio? & \\
\hline
\end{tabular}




\begin{tabular}{|c|c|c|}
\hline 2.8.7c & Remédio 5 & \\
\hline $2.8 .7 d$ & Por que ficou sem usar este remédio? & \\
\hline 2.8.7e & Remédio 6 & \\
\hline $2.8 .7 f$ & Por que ficou sem usar este remédio? & \\
\hline 2.8 .8 & $\begin{array}{l}\text { Atualmente o(a) } \mathrm{Sr}(\mathrm{a}) \text { faz algum tipo de } \\
\text { terapia não medicamentosa para tratar a } \\
\text { depressão? }\end{array}$ & $\begin{array}{l}1 \text { [] Sim } \\
2 \text { [] Não => Passe para 2.8.9 }\end{array}$ \\
\hline $2.8 .8 \mathrm{a}$ & Qual? & \\
\hline 2.8 .9 & $\begin{array}{l}\text { No dia a dia, quanto a depressão limita } \\
\text { as suas atividades habituais? *Ler as } \\
\text { alternativas* }\end{array}$ & $\begin{array}{l}1 \text { [] } \\
\text { Não } \\
\text { limita } \\
2 \text { [] } \\
\text { Um } \\
\text { pouco } \\
3 \text { [] Moderadamente } \\
4 \text { [] Intensamente } \\
5 \text { [] Muito intensamente }\end{array}$ \\
\hline
\end{tabular}

\begin{tabular}{|c|c|c|}
\hline \multicolumn{3}{|c|}{ OUTRA DOENÇA COM MAIS DE 6 MESES DE DURAÇÃO } \\
\hline 2.9 .0 & $\begin{array}{l}\text { Algum médico já lhe disse que o(a) Sr(a) tem } \\
\text { alguma outra doença com mais de seis meses } \\
\text { de duração? }\end{array}$ & $\begin{array}{l}1 \text { [] Sim } \\
2 \text { [] Não => Passe para 2.9.28 }\end{array}$ \\
\hline 2.9 .1 & Quais? & *Listar abaixo as doenças* \\
\hline $2.9 .1 \mathrm{a}$ & Doença 1 & \\
\hline $2.9 .1 b$ & Doença 2 & \\
\hline \multirow[t]{2}{*}{$2.9 .1 \mathrm{c}$} & Doença 3 & \\
\hline & Doença 1: & \\
\hline 2.9 .2 & $\begin{array}{l}\text { Que idade o(a) Sr(a) tinha na primeira vez que } \\
\text { o médico lhe disse que tinha } \\
\text { ? }\end{array}$ & $\begin{array}{l}I_{-} I_{-} \mid{ }_{\text {anos }} \\
00=\text { Se menos de } 1 \text { ano } \\
99=\mathrm{NS} / \mathrm{NR}\end{array}$ \\
\hline 2.9 .3 & $\begin{array}{l}\text { O(a) Sr(a) tem indicação médica para usar } \\
\text { algum remédio para__ }\end{array}$ & $\begin{array}{l}1 \text { [] Sim } \\
2 \text { [] Não => Passe para 2.9.10 }\end{array}$ \\
\hline 2.9 .4 & $\begin{array}{l}\mathrm{O}(\mathrm{a}) \mathrm{Sr}(\mathrm{a}) \text { está usando algum desses } \\
\text { remédios? }\end{array}$ & $\begin{array}{l}1 \text { [] Sim } \\
2 \text { [] Não => Passe para 2.9.9 }\end{array}$ \\
\hline 2.9 .5 & Qual(is)? & *Listar abaixo os remédios* \\
\hline 2.9.5a & Remédio 1 & \\
\hline $2.9 .5 b$ & Remédio 2 & \\
\hline $2.9 .5 \mathrm{c}$ & Remédio 3 & \\
\hline
\end{tabular}




\begin{tabular}{|l|l|l|}
\hline 2.9.6 & $\begin{array}{l}\text { Nos últimos 30 dias, o(a) Sr(a) ficou sem } \\
\text { algum desses remédios por algum tempo? }\end{array}$ & $\begin{array}{l}1 \text { [] Sim } \\
2 \text { [] Não => Passe para 2.9.8 } \\
9 \text { [] NS/NR => Passe para 2.9.8 }\end{array}$ \\
\hline 2.9.7a & $\begin{array}{l}\text { Qual(is)? } \\
\text { *Preencha os campos correspondentes aos } \\
\text { remédios que o entrevistado relatou que } \\
\text { deixou de tomar* }\end{array}$ & $\begin{array}{l}\text { [] Remédio 1 } \\
\text { [] Remédio 2 } \\
\text { [] Remédio 3 }\end{array}$ \\
\hline & Remédio 1: & \\
\hline
\end{tabular}

\begin{tabular}{|c|c|c|}
\hline $2.9 .7 b$ & Por quanto tempo? & I__l_ l dias \\
\hline \multirow[t]{2}{*}{ 2.9.7c } & Por que ficou sem este remédio? & \\
\hline & Remédio 2: & \\
\hline 2.9.7d & Por quanto tempo? & I____l dias \\
\hline \multirow[t]{2}{*}{ 2.9.7e } & Por que ficou sem este remédio? & \\
\hline & Remédio 3: & \\
\hline 2.9.7f & Por quanto tempo? & 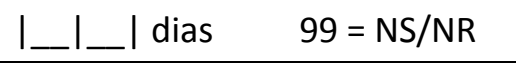 \\
\hline 2.9.7g & Por que ficou sem este remédio? & \\
\hline 2.9 .8 & $\begin{array}{l}\text { Tem algum remédio, que o(a) Sr(a) deveria } \\
\text { estar usando, nos últimos } 30 \text { dias, para } \\
\text {, e não está? }\end{array}$ & $\begin{array}{l}1 \text { [] Sim } \\
2 \text { [] Não => Passe para 2.9.10 } \\
9 \text { [] NS/NR => Passe para 2.9.10 }\end{array}$ \\
\hline 2.9 .9 & $\begin{array}{l}\text { Qual(is) o(s) remédios que o(a) Sr(a) deveria } \\
\text { estar usando e não está? }\end{array}$ & *Listar abaixo os remédios* \\
\hline 2.9.9a & Remédio 4 & \\
\hline $2.9 .9 b$ & Por que ficou sem usar este remédio? & \\
\hline $2.9 .9 c$ & Remédio 5 & \\
\hline 2.9.9d & Por que ficou sem usar este remédio? & \\
\hline $2.9 .9 \mathrm{e}$ & Remédio 6 & \\
\hline 2.9.9f & Por que ficou sem usar este remédio? & \\
\hline \multirow[t]{2}{*}{2.9 .10} & $\begin{array}{l}\text { No dia a dia, quanto o(a) } \\
\text { limita as suas atividades habituais? }{ }^{*} \text { Ler as } \\
\text { alternativas* }\end{array}$ & $\begin{array}{l}1 \text { [] } \\
\text { Não } \\
\text { limita } \\
2 \text { [] } \\
\text { Um } \\
\text { pouco } \\
3 \text { [] Moderadamente } \\
4 \text { [] Intensamente } \\
5 \text { [] Muito intensamente }\end{array}$ \\
\hline & Doença 2: & \\
\hline
\end{tabular}




\begin{tabular}{|c|c|c|}
\hline 2.9.11 & $\begin{array}{l}\text { Que idade o(a) } \mathrm{Sr}(\mathrm{a}) \text { tinha na primeira vez que } \\
\text { o médico lhe disse que tinha } \\
\text { ? }\end{array}$ & $\begin{array}{l}I_{-} I_{L} \mid I_{\text {anos }} \\
00=\text { Se menos de } 1 \text { ano } \\
99=\text { NS/NR }\end{array}$ \\
\hline 2.9.12 & $\begin{array}{l}\text { O(a) } \mathrm{Sr}(\mathrm{a}) \text { tem indicação médica para usar } \\
\text { algum remédio para }\end{array}$ & $\begin{array}{l}1 \text { [] Sim } \\
2 \text { [] Não => Passe para 2.9.18 }\end{array}$ \\
\hline 2.9 .13 & $\begin{array}{l}\text { O(a) Sr(a) está usando algum desses } \\
\text { remédios? }\end{array}$ & $\begin{array}{l}1 \text { [] Sim } \\
2 \text { [] Não => Passe para 2.9.17 }\end{array}$ \\
\hline 2.9.14 & Qual(is)? & *Listar abaixo os remédios* \\
\hline 2.9.14a & Remédio 1 & \\
\hline $2.9 .14 b$ & Remédio 2 & \\
\hline $2.9 .14 \mathrm{c}$ & Remédio 3 & \\
\hline 2.9.15 & $\begin{array}{l}\text { Nos últimos } 30 \text { dias, o(a) } \mathrm{Sr}(\mathrm{a}) \text { ficou sem } \\
\text { algum desses remédios por algum tempo? }\end{array}$ & $\begin{array}{l}1 \text { [] Sim } \\
2 \text { [] Não => Passe para 2.9.16 } \\
9 \text { [] NS/NR => Passe para 2.9.16 }\end{array}$ \\
\hline \multirow[t]{2}{*}{$2.9 .15 a$} & $\begin{array}{l}\text { Qual(is)? } \\
\text { *Preencha os campos correspondentes aos } \\
\text { remédios que o entrevistado relatou que } \\
\text { deixou de tomar* }\end{array}$ & $\begin{array}{l}\text { [] Remédio } 1 \\
\text { [] Remédio } 2 \\
\text { [] Remédio } 3\end{array}$ \\
\hline & Remédio 1: & \\
\hline $2.9 .15 b$ & Por quanto tempo? & I__l_l dias \\
\hline \multirow[t]{2}{*}{$2.9 .15 c$} & Por que ficou sem este remédio? & \\
\hline & Remédio 2: & \\
\hline 2.9.15d & Por quanto tempo? & I__l_l dias \\
\hline \multirow[t]{2}{*}{$2.9 .15 \mathrm{e}$} & Por que ficou sem este remédio? & \\
\hline & Remédio 3: & \\
\hline 2.9.15f & Por quanto tempo? & I__l_ l dias $\quad 99=$ NS/NR \\
\hline $2.9 .15 \mathrm{~g}$ & Por que ficou sem este remédio? & \\
\hline 2.9.16 & $\begin{array}{l}\text { Tem algum remédio, que o(a) } \operatorname{Sr}(a) \text { deveria } \\
\text { estar usando, nos últimos } 30 \text { dias, para } \\
\text {, e não está? }\end{array}$ & $\begin{array}{l}1 \text { [] Sim } \\
2 \text { [] Não => Passe para 2.9.18 } \\
9 \text { [] NS/NR => Passe para 2.9.18 }\end{array}$ \\
\hline 2.9.17 & $\begin{array}{l}\text { Qual(is) o(s) remédios que o(a) Sr(a) deveria } \\
\text { estar usando e não está? }\end{array}$ & *Listar abaixo os remédios* \\
\hline $2.9 .17 a$ & Remédio 4 & \\
\hline $2.9 .17 b$ & Por que ficou sem usar este remédio? & \\
\hline $2.9 .17 c$ & Remédio 5 & \\
\hline 2.9.17d & Por que ficou sem usar este remédio? & \\
\hline 2.9.17e & Remédio 6 & \\
\hline
\end{tabular}




\begin{tabular}{|c|c|c|}
\hline $2.9 .17 f$ & Por que ficou sem usar este remédio? & \\
\hline \multirow[t]{2}{*}{ 2.9.18 } & $\begin{array}{l}\text { No dia a dia, quanto o(a) } \\
\text { limita as suas atividades habituais? }{ }^{*} \text { Ler as } \\
\text { alternativas* }\end{array}$ & $\begin{array}{l}1 \text { [] } \\
\text { Não } \\
\text { limita } \\
2 \text { [] } \\
\text { Um } \\
\text { pouco } \\
3 \text { [] Moderadamente } \\
4 \text { [] Intensamente } \\
5 \text { [] Muito intensamente }\end{array}$ \\
\hline & Doença 3: & \\
\hline 2.9.19 & $\begin{array}{l}\text { Que idade o(a) Sr(a) tinha na primeira vez que } \\
\text { o médico lhe disse que tinha } \\
\text { ? }\end{array}$ & $\begin{array}{l}I_{-} I_{\text {_L }} \mid \text { anos } \\
00=\text { Se menos de } 1 \text { ano } \\
99=\text { NS/NR }\end{array}$ \\
\hline 2.9 .20 & $\begin{array}{l}\mathrm{O}(\mathrm{a}) \mathrm{Sr}(\mathrm{a}) \text { tem indicação médica para usar } \\
\text { algum remédio para }\end{array}$ & $\begin{array}{l}1 \text { [] Sim } \\
2 \text { [] Não => Passe para 2.9.27 }\end{array}$ \\
\hline 2.9 .21 & $\begin{array}{l}\mathrm{O}(\mathrm{a}) \mathrm{Sr}(\mathrm{a}) \text { está usando algum desses } \\
\text { remédios? }\end{array}$ & $\begin{array}{l}1 \text { [] Sim } \\
2 \text { [] Não => Passe para 2.9.26 }\end{array}$ \\
\hline 2.9 .22 & Qual(is)? & *Listar abaixo os remédios* \\
\hline 2.9.22a & Remédio 1 & \\
\hline $2.9 .22 b$ & Remédio 2 & \\
\hline $2.9 .22 \mathrm{c}$ & Remédio 3 & \\
\hline 2.9 .23 & $\begin{array}{l}\text { Nos últimos } 30 \text { dias, o(a) Sr(a) ficou sem usar } \\
\text { algum desses remédios por algum tempo? }\end{array}$ & $\begin{array}{l}1 \text { [] Sim } \\
2 \text { [] Não => Passe para 2.9.25 } \\
9 \text { [] NS/NR => Passe para 2.9.25 }\end{array}$ \\
\hline \multirow[t]{2}{*}{$2.9 .24 a$} & $\begin{array}{l}\text { Qual(is)? } \\
\text { *Preencha os campos correspondentes aos } \\
\text { remédios que o entrevistado relatou que } \\
\text { deixou de tomar* }\end{array}$ & $\begin{array}{l}\text { [] Remédio } 1 \\
\text { [] Remédio } 2 \\
\text { [] Remédio } 3\end{array}$ \\
\hline & Remédio 1: & \\
\hline $2.9 .24 b$ & Por quanto tempo? & I__l_l dias \\
\hline \multirow[t]{2}{*}{$2.9 .24 \mathrm{c}$} & Por que ficou sem este remédio? & \\
\hline & Remédio 2: & \\
\hline 2.9.24d & Por quanto tempo? & $I_{-} I_{\text {__ }} \mid$ dias \\
\hline \multirow[t]{2}{*}{$2.9 .24 \mathrm{e}$} & Por que ficou sem este remédio? & \\
\hline & Remédio 3: & \\
\hline $2.9 .24 f$ & Por quanto tempo? & 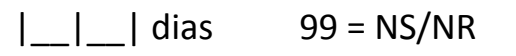 \\
\hline $2.9 .24 \mathrm{~g}$ & Por que ficou sem este remédio? & \\
\hline
\end{tabular}




\begin{tabular}{|c|c|c|}
\hline 2.9 .25 & $\begin{array}{l}\text { Tem algum remédio, que o(a) } \operatorname{Sr}(a) \text { deveria } \\
\text { estar usando, nos últimos } 30 \text { dias, para } \\
\text {, e não está? }\end{array}$ & $\begin{array}{l}1 \text { [] Sim } \\
2 \text { [] Não => Passe para 2.9.27 } \\
9 \text { [] NS/NR => Passe para 2.9.27 }\end{array}$ \\
\hline 2.9 .26 & $\begin{array}{l}\text { Qual(is) o(s) remédios que o(a) Sr(a) deveria } \\
\text { estar usando e não está? }\end{array}$ & *Listar abaixo os remédios* \\
\hline 2.9.26a & Remédio 4 & \\
\hline $2.9 .26 \mathrm{~b}$ & Por que ficou sem usar este remédio? & \\
\hline 2.9.26c & Remédio 5 & \\
\hline 2.9.26d & Por que ficou sem usar este remédio? & \\
\hline 2.9.26e & Remédio 6 & \\
\hline 2.9.26f & Por que ficou sem usar este remédio? & \\
\hline 2.9.27 & $\begin{array}{l}\text { No dia a dia, quanto o(a) } \\
\text { limita as suas atividades habituais? *Ler as } \\
\text { alternativas* }\end{array}$ & $\begin{array}{l}1 \text { [] } \\
\text { Não } \\
\text { limita } \\
2 \text { [] } \\
\text { Um } \\
\text { pouco } \\
3 \text { [] Moderadamente } \\
4 \text { [] Intensamente } \\
5 \text { [] Muito intensamente }\end{array}$ \\
\hline
\end{tabular}

\begin{tabular}{|l|l|l|}
\hline 2.9 .28 & $\begin{array}{l}\text { Total de remédios citados para o tratamento das } \\
\text { doenças crônicas: } \\
\text { *Preencher sem perguntar* }\end{array}$ & I___l \\
\hline
\end{tabular}

Agora vou fazer algumas perguntas sobre atendimento em serviços de emergência e internações em hospital.

\begin{tabular}{|c|c|c|}
\hline \multicolumn{3}{|c|}{ ATENDIMENTOS EM EMERGÊNCIA E INTERNAÇÕES } \\
\hline 2.9.29 & $\begin{array}{l}\text { Nos últimos } 12 \text { meses, o(a) Sr(a) precisou ser } \\
\text { atendido(a) em alguma emergência? }\end{array}$ & $\begin{array}{l}1 \text { [] Sim } \\
2 \text { [] Não => Passe para questão } \\
\text { 2.9.32 } \\
9 \text { [] NS/NR => Passe para questão } \\
\text { 2.9.32 }\end{array}$ \\
\hline 2.9.30 & Quantas vezes? & $\begin{array}{l}1 \text { [] Uma única vez } \\
2 \text { [] Duas vezes } \\
3 \text { [] Três vezes } \\
4 \text { [] Quatro ou mais vezes } \\
9 \text { [] NS/NR }\end{array}$ \\
\hline
\end{tabular}




\begin{tabular}{|l|l|l|}
\hline 2.9.31 & $\begin{array}{l}\text { Qual(is) foi(foram) o(s) motivo(s) deste(s) } \\
\text { atendimento(s)? } \\
\text { *Anotar todos os motivos relatados pelo entrevistado* }\end{array}$ & $\begin{array}{l}\text { 1 [] Sim } \\
2 \text { [] Não => Encerre o bloco. } \\
9 \text { [] NS/NR => Encerre o bloco. }\end{array}$ \\
\hline 2.9 .32 & $\begin{array}{l}\text { Nos últimos 12 meses, o(a) Sr(a) precisou ser } \\
\text { internado(a) em hospital? }\end{array}$ & $\begin{array}{l}1 \text { [] Uma única vez } \\
2 \text { [] Duas vezes } \\
3 \text { [] Três vezes } \\
4 \text { [] Quatro ou mais vezes } \\
9 \text { [] NS/NR }\end{array}$ \\
\hline 2.9.33 & Quantas vezes? & \\
\hline 2.9.34 & $\begin{array}{l}\text { Qual(is) foi(foram) o(s) motivo(s) desta(s) } \\
\text { internação(ões)? } \\
\text { *Anotar todos os motivos relatados pelo entrevistado* }\end{array}$ \\
\hline
\end{tabular}

*Se entrevistado citou o uso de remédios, preencher a tabela de remédios de uso crônico.

Se entrevistado não tiver doença crônica passe para 4.1*

Agora vamos falar sobre os remédios que o(a) $\operatorname{Sr}(a)$ usa para o tratamento das doenças que o(a) $\operatorname{Sr}($ a) citou.

\begin{tabular}{|c|c|c|}
\hline \multicolumn{3}{|c|}{ FICHA DE REMÉDIOS DE USO CRÔNICO } \\
\hline MC.1 & $\begin{array}{l}\text { Para o tratamento de qual doença o(a) } \\
\text { entrevistado(a) utiliza este remédio: }\end{array}$ & $\begin{array}{ll}1 & \text { [] Hipertensão } \\
2 & \text { [] Diabetes } \\
3 & \text { [] Doenças do coração } \\
4 & \text { [] Colesterol alto } \\
5 & \text { [] AVC } \\
6 & \text { [] Asma, bronquite, (DPBOC) } \\
7 & \text { [] Artrite ou reumatismo } \\
8 & \text { [] Depressão } \\
\text { Outras doenças crônicas } \\
9 \text { [] Doença } 1 \\
10 \text { [] Doença } 2 \\
11 \text { [] Doença } 3\end{array}$ \\
\hline MC.2 & $\begin{array}{l}\text { Tem alguma embalagem? } \\
\text { *Observar e preencher* } \\
\text { *Considere como embalagem a caixa, } \\
\text { cartela, bisnaga ou outro recipiente que } \\
\text { contenha o remédios e suas informações }{ }^{*}\end{array}$ & $\begin{array}{l}1 \text { [] Sim } \\
2 \text { [] Não }\end{array}$ \\
\hline MC.3 & $\begin{array}{l}\text { O remédio é genérico? } \\
\text { * Observar e preencher* } \quad G \text { Medicamento } \\
\text { (Tarja amarela com G, Lei } \\
9787 \text { ) }\end{array}$ & $\begin{array}{l}1 \text { [] Sim } \\
2 \text { [] Não } \\
9 \text { [] NS/NR }\end{array}$ \\
\hline
\end{tabular}




\begin{tabular}{|c|c|c|}
\hline MC.4 & $\begin{array}{l}\text { Data de validade } \\
\qquad \text { *Observar e preencher* }\end{array}$ & $I_{99-N S / N R}$ \\
\hline MC.5 & $\begin{array}{l}\text { Forma Farmacêutica } \\
\text { *Observar e preencher* } \\
\text { Se respondido “4 [] Pomada, creme, gel, } \\
\text { bisnaga ou spray de pele => } \\
\text { Passe para MC.6 “, não deverá aparecer a } \\
\text { questão MC.8 }\end{array}$ & 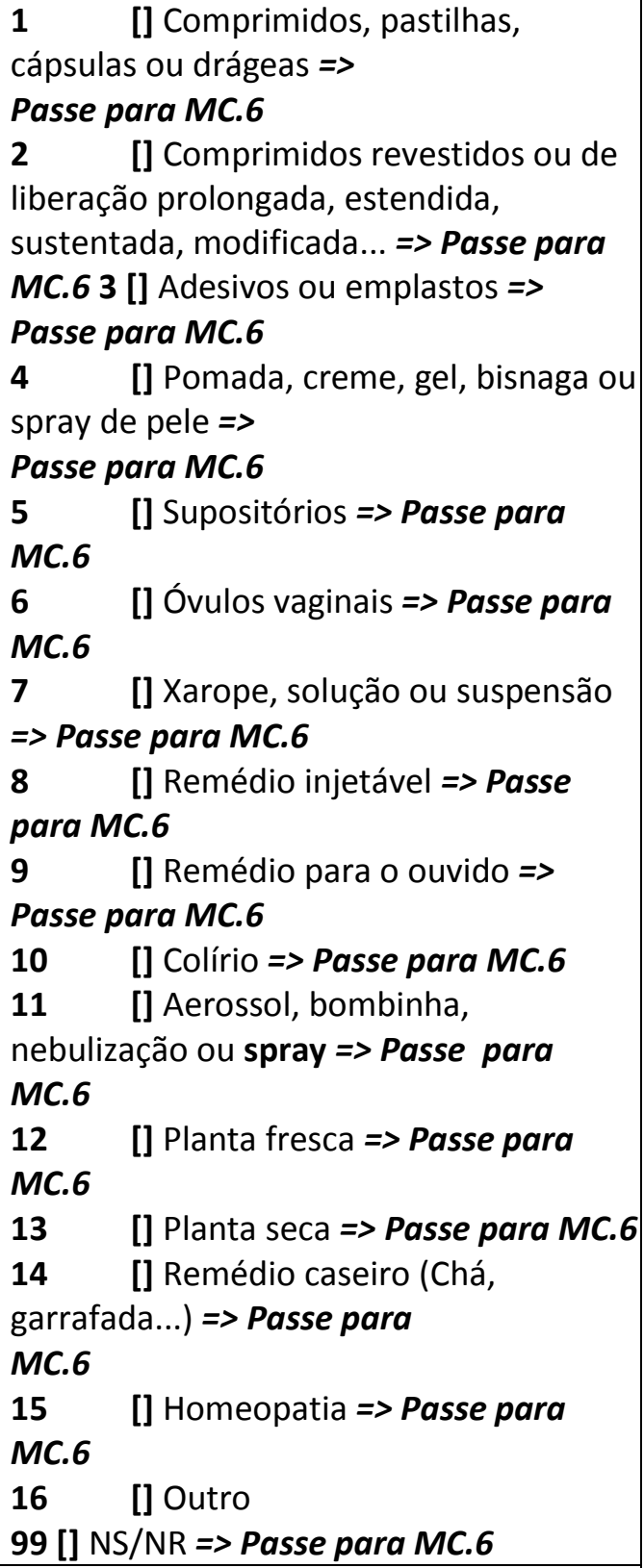 \\
\hline MC.5a & Se outro, qual: & \\
\hline
\end{tabular}

\begin{tabular}{|l|l|l|l|}
\hline MC.6 & Qual é a concentração deste remédio? & \multicolumn{2}{|l|}{$\begin{array}{l}\text { I_____________l } \\
\text { *Desconsiderar as unidades de } \\
\text { concentração, anotar apenas os } \\
\text { números* 99-NS/NR }\end{array}$} \\
\hline MC.7 & Há quanto tempo está usando? & I____l & $\begin{array}{l}\mathbf{1} \text { [] Dias } \\
\mathbf{2} \text { [] Semanas } \\
\mathbf{3}[] \text { Meses } \\
\mathbf{4}[] \text { Anos }\end{array}$ \\
\hline
\end{tabular}




\begin{tabular}{|c|c|c|c|}
\hline & & 99[] $\mathrm{NS} / \mathrm{NR}$ & \\
\hline MC.8 & Quantas unidades o(a) Sr(a) usa por vez? & \multicolumn{2}{|c|}{$\begin{array}{l}I_{\text {unidade }} I_{\text {_l }} \text { comprimidos/jatos/gotas ou outra } \\
\text { a }\end{array}$} \\
\hline \multirow[t]{2}{*}{ MC.9 } & \multirow[t]{2}{*}{ Quantas vezes? } & $\begin{array}{l}\text { I____l Vez(es) } \\
\text { Anotar o número de vezes }\end{array}$ & $\begin{array}{l}1 \text { [] Dia } \\
2 \text { [] Mês => } \\
\text { Passe para } \\
\text { MC.10b } \\
3 \text { [] Ano => } \\
\text { Passe para } \\
\text { MC.10b }\end{array}$ \\
\hline & & \multicolumn{2}{|c|}{$\begin{array}{l}\mathbf{7 7} \text { [] Sempre que sente os sintomas da doença } \\
\mathbf{8 8} \text { [] Tantas quanto necessário } \\
\mathbf{9 9}[] \text { NS/NR }\end{array}$} \\
\hline MC.10a & $\begin{array}{l}\text { Na última semana, quantas vezes esqueceu } \\
\text { de tomar algum } \\
\text { comprimido/cápsula/dose/jato? }\end{array}$ & \multicolumn{2}{|l|}{$\begin{array}{l}\text { I_l_l vez(es) } \\
88-\text { nenhuma vez } \\
\text { => Passe para MC.11 }\end{array}$} \\
\hline MC.10b & $\begin{array}{l}\text { No último mês, quantas vezes esqueceu de } \\
\text { tomar algum } \\
\text { comprimido/cápsula/dose/jato? }\end{array}$ & \multicolumn{2}{|l|}{$\begin{array}{l}I_{-} \\
-I \\
- \\
\text { vez } \\
\text { (es } \\
\text { ) } \\
88 \\
- \\
\text { ne } \\
\text { nh } \\
\text { um } \\
\text { a } \\
\text { vez }\end{array}$} \\
\hline MC.11 & Como este remédio funciona para o(a) Sr(a)? & \multicolumn{2}{|l|}{$\begin{array}{l}1 \text { [] Bem } \\
2 \text { [] Mais ou menos } \\
\mathbf{3} \text { [] Não muito bem }\end{array}$} \\
\hline MC.12 & Este remédio incomoda(ou) o(a) Sr(a)? & \multicolumn{2}{|c|}{$\begin{array}{l}1 \text { [] Sim } \\
2 \text { [] Não => Passe para ME.13 } \\
9 \text { [] NS/NR => Passe para ME.13 }\end{array}$} \\
\hline MC.12a & De que forma este remédio lhe incomoda(ou)? & & \\
\hline MC.13 & $\begin{array}{l}\text { Este remédio causa(ou) problema(s) de saúde } \\
\text { para o(a) } \mathrm{Sr}(\mathrm{a}) \text { ? }\end{array}$ & \multicolumn{2}{|c|}{$\begin{array}{l}1 \text { [] Sim } \\
2 \text { [] Não => Passe para ME.14 } \\
9 \text { [] NS/NR => Passe para ME.14 }\end{array}$} \\
\hline MC.13a & Quais? & & \\
\hline MC.14 & $\begin{array}{l}\text { Conseguir este remédio é: }{ }^{*} \text { Ler } \\
\text { as alternativas* }\end{array}$ & \multicolumn{2}{|l|}{$\begin{array}{l}1 \text { [] Muito difícil } \\
2 \text { [] Um pouco difícil } \\
3 \text { [] Não é difícil } \\
9 \text { [] NS/NR }\end{array}$} \\
\hline
\end{tabular}




\begin{tabular}{|c|c|c|}
\hline MC.15 & Este remédio foi pago? & $\begin{array}{l}1 \text { [] Não => Passe para MC.18 } \\
2 \text { [] Sim } \\
9 \text { [] NS/NR }\end{array}$ \\
\hline MC.16 & $\begin{array}{l}\text { Onde comprou? } \\
\text { *Caso respondido "2 [] Farmácia } \\
\text { Comercial", o entrevistado deverá } \\
\text { responder às questões referentes a } \\
\text { "IB06_B Farmácia Privada" no bloco } \\
\text { "IB06_Servicos_Farmacia"”* }\end{array}$ & $\begin{array}{l}1 \text { [] Programa Farmácia Popular } \\
2 \text { [] Farmácia Comercial } \\
3 \text { [] Outro } \\
9 \text { [] NS/NR }\end{array}$ \\
\hline MC.17 & $\begin{array}{l}\text { Quanto custou este remédio? }{ }^{*} \text { Encerre } \\
\text { a ficha* }\end{array}$ & $\begin{array}{l}\text { R\$I_I.I_l_l_l,I_l_l } \\
\text { 99-NS/NR }\end{array}$ \\
\hline MC.18 & $\begin{array}{l}\text { Onde obteve? } \\
\text { *Caso respondido "1 [] SUS", o entrevistado } \\
\text { deverá responder às questões referentes a } \\
\text { "IB06_A Farmácia do SUS" no bloco } \\
\text { "IB06_Servicos_Farmacia"* }\end{array}$ & $\begin{array}{l}1 \text { [] SUS } \\
2 \text { [] Programa Farmácia Popular } \\
\mathbf{3} \text { [] Amostra grátis } \\
4 \text { [] Instituição de caridade/Igreja } \\
5 \text { [] Amigos, parentes ou vizinhos } \\
6 \text { [] Outro } \\
\mathbf{9} \text { [] NS/NR }\end{array}$ \\
\hline
\end{tabular}

\section{3 - SERVIÇOS DE SAÚDE}

Agora, vou fazer algumas perguntas sobre o lugar onde o(a) $\mathrm{Sr}(a)$ busca o tratamento desta(s) doença(s).

\begin{tabular}{|c|c|c|}
\hline \multicolumn{3}{|c|}{ NOS CASOS EM QUE A PESSOA TEM UMA DOENÇA (SE MAIS DE UMA => Passe para 3.9) } \\
\hline 3.1 & $\begin{array}{l}\mathrm{O}(\mathrm{a}) \mathrm{Sr}(\mathrm{a}) \text { visita o médico ou serviço } \\
\text { de saúde regularmente por causa } \\
\text { dessa doença? }\end{array}$ & $\begin{array}{l}1 \text { [] Sim => Passe para a } 3.3 \\
2 \text { [] Não }\end{array}$ \\
\hline 3.2 & $\begin{array}{l}\text { Por que o(a) Sr(a) não visita o } \\
\text { médico ou serviço de saúde } \\
\text { regularmente por causa dessa } \\
\text { doença? }\end{array}$ & 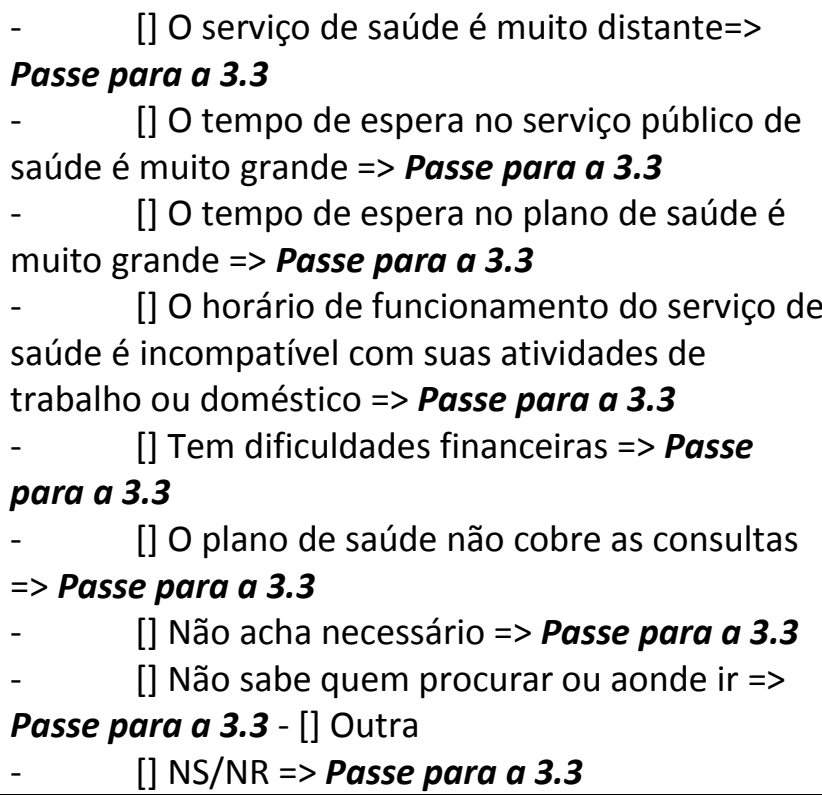 \\
\hline $3.2 \mathrm{a}$ & Qual? & \\
\hline
\end{tabular}




\begin{tabular}{|c|c|c|}
\hline 3.3 & $\begin{array}{l}\text { O médico que cuida desta doença é } \\
\text { sempre o mesmo? }\end{array}$ & $\begin{array}{l}1 \text { [] Sim => Passe para } 3.5 \\
2 \text { [] Não }\end{array}$ \\
\hline 3.4 & $\begin{array}{l}\text { Algum dos médicos que cuidam } \\
\text { desta doença é do SUS? }\end{array}$ & $\begin{array}{l}1 \text { [] Sim => Passe para } 3.7 \\
2 \text { [] Não => Passe para } 3.8 \\
9 \text { [] NS/NR => Passe para } 3.8\end{array}$ \\
\hline 3.5 & Qual a especialidade deste médico? & $\begin{array}{l}1 \text { [] Geriatra => Passe para } 3.6 \\
2 \text { [] Clínico Geral => Passe para } 3.6 \\
3 \text { [] Médico da Família => Passe para } 3.6 \\
4 \text { [] Cardiologista => Passe para } 3.6 \\
5 \text { [] Endocrinologista => Passe para } 3.6 \\
6 \text { [] Psiquiatra => Passe para } 3.6 \\
7 \text { [] Reumatologista => Passe para } 3.6 \\
8 \text { [] Pneumologista => Passe para } 3.6 \\
9 \text { [] Outro } \\
99 \text { [] NS/NR => Passe para } 3.6\end{array}$ \\
\hline 3.5a & Qual? & \\
\hline 3.6 & $\begin{array}{l}\text { Este médico é: } \\
* \text { Ler as alternativas* }\end{array}$ & $\begin{array}{l}1 \text { [] Do SUS } \\
2 \text { [] Do convênio => Passe para } 3.8 \\
3 \text { [] Particular => Passe para } 3.8 \\
9 \text { [] NS/NR }\end{array}$ \\
\hline 3.7 & $\begin{array}{l}\text { Em que lugar este médico lhe } \\
\text { atende? }\end{array}$ & $99=N S / N R$ \\
\hline 3.8 & $\begin{array}{l}\text { Quando foi a última vez que o(a) } \\
\text { Sr(a) consultou este(s) médico(s)? } \\
\text { => Passe para } 4.0 \text {. }\end{array}$ & $\begin{array}{l}1 \text { [] no último mês } \\
2 \text { [] de } 1 \text { mês a } 6 \text { meses } \\
3 \text { [] mais de } 6 \text { meses a } 1 \text { ano } \\
4 \text { [] mais de } 1 \text { ano a } 5 \text { anos } \\
5 \text { [] mais de } 5 \text { anos } \\
9 \text { [] NS/NR }\end{array}$ \\
\hline
\end{tabular}

NOS CASOS EM QUE A PESSOA TEM MAIS DE UMA DOENÇA

\begin{tabular}{l|ll}
3.9 & O(a) $\operatorname{Sr}($ a) visita o médico ou serviço & 1 [] Sim => Passe para a questão 3.11
\end{tabular} de saúde regularmente por causa 2 [] Não dessas doenças? 


\begin{tabular}{|c|c|c|}
\hline 3.10 & $\begin{array}{l}\text { Por que o(a) Sr(a) não visita o } \\
\text { médico ou serviço de saúde } \\
\text { regularmente por causa dessas } \\
\text { doenças? }\end{array}$ & 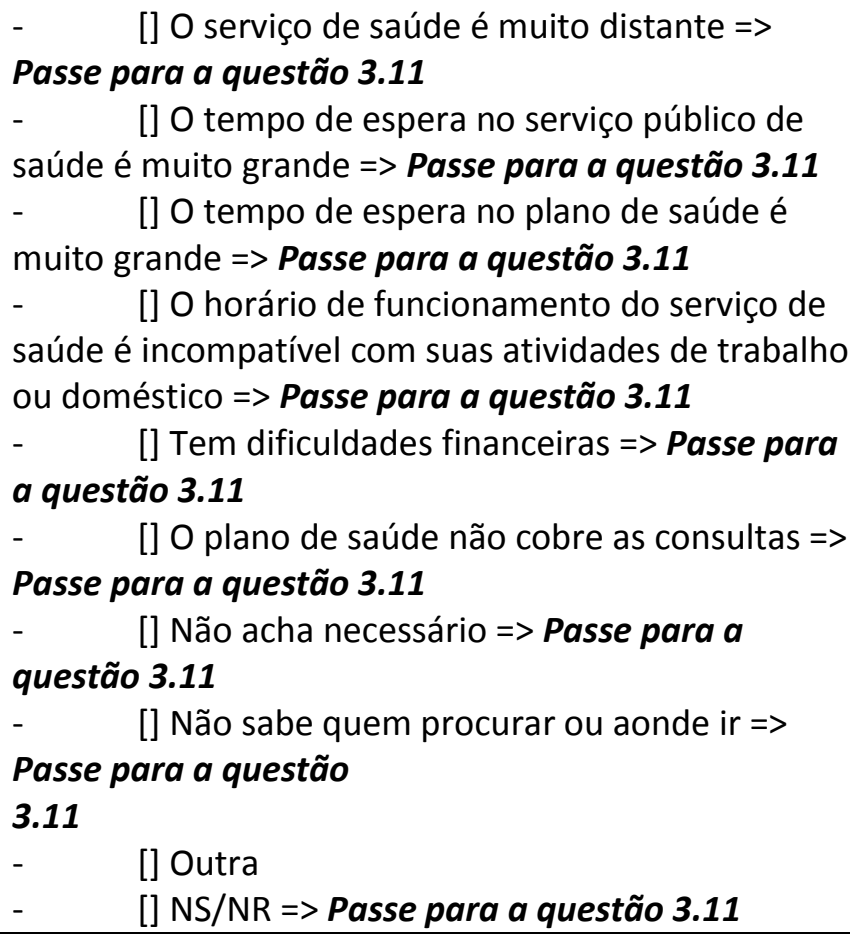 \\
\hline $3.10 \mathrm{a}$ & Qual? & \\
\hline 3.11 & $\begin{array}{l}\text { O(a) } \mathrm{Sr}(\mathrm{a}) \text { tem só um médico que } \\
\text { cuida de todas as suas doenças? }\end{array}$ & $\begin{array}{l}1 \text { [] Sim } \\
2 \text { [] Não => Passe para } 3.15 \\
9 \text { [] NS/NR => Passe para } 3.15\end{array}$ \\
\hline 3.12 & Qual a especialidade deste médico? & $\begin{array}{l}1 \text { [] Geriatra => Passe para } 3.13 \\
2 \text { [] Clínico Geral => Passe para } 3.13 \\
3 \text { [] Médico da Família => Passe para } 3.13 \\
4 \text { [] Cardiologista => Passe para } 3.13 \\
5 \text { [] Endocrinologista => Passe para } 3.13 \\
6 \text { [] Psiquiatra => => Passe para } 3.13 \\
7 \text { [] Reumatologista => Passe para } 3.13 \\
8 \text { [] Pneumologista => Passe para } 3.13 \\
9 \text { [] Outro } \\
99 \text { [] NS/NR => Passe para } 3.13\end{array}$ \\
\hline $3.12 \mathrm{a}$ & Qual? & \\
\hline 3.13 & $\begin{array}{l}\text { Este médico é: } \\
\text { *Ler as alternativas* }\end{array}$ & $\begin{array}{l}1 \text { [] Do SUS } \\
2 \text { [] Do convênio => Passe para } 3.19 \\
3 \text { [] Particular => Passe para } 3.19 \\
9 \text { [] NS/NR }\end{array}$ \\
\hline 3.14 & $\begin{array}{l}\text { Em que lugar este médico lhe } \\
\text { atende? }\end{array}$ & $\begin{array}{l}99=\mathrm{NS} / \mathrm{NR} \\
=>\text { Passe para } 3.19\end{array}$ \\
\hline 3.15 & $\begin{array}{l}\text { O(a) } \mathrm{Sr}(\mathrm{a}) \text { tem um médico para cada } \\
\text { uma das doenças? }\end{array}$ & $\begin{array}{l}1 \text { [] Sim } \\
2 \text { [] Não => Passe para } 3.18 \\
9 \text { [] NS/NR => Passe para } 3.18\end{array}$ \\
\hline
\end{tabular}




\begin{tabular}{|c|c|c|}
\hline 3.16 & $\begin{array}{l}\text { Quais as especialidades destes } \\
\text { médicos? }\end{array}$ & $\begin{array}{l}\text { - [] Geriatra => Passe para } 3.17 \\
\text { - [] Clínico Geral => Passe para } 3.17 \\
\text { - [] Médico da Família => Passe para } 3.17 \\
\text { - [] Cardiologista => Passe para } 3.17 \\
\text { - [] Endocrinologista => Passe para } 3.17 \\
\text { - [] Psiquiatra => => Passe para } 3.17 \\
\text { - [] Reumatologista => Passe para } 3.17 \\
\text { - [] Pneumologista => Passe para } 3.17 \\
\text { - [] Outro } \\
\text { - [] NS/NR => Passe para } 3.17\end{array}$ \\
\hline $3.16 a$ & Qual(is)? & \\
\hline 3.17 & $\begin{array}{l}\text { Algum destes médicos é: * Ler } \\
\text { as alternativas* }\end{array}$ & \\
\hline $3.17 a$ & Particular? & $\begin{array}{l}1 \text { [] Sim } \\
2 \text { [] Não } \\
9 \text { [] NS/NR }\end{array}$ \\
\hline $3.17 b$ & Do convênio? & $\begin{array}{l}1 \text { [] } \operatorname{Sim} \\
2 \text { [] Não } \\
9 \text { [] NS/NR }\end{array}$ \\
\hline $3.17 c$ & Do SUS? & $\begin{array}{l}1 \text { [] Sim } \\
2 \text { [] Não => Passe para } 3.19 \\
9 \text { [] NS/NR => Passe para } 3.19\end{array}$ \\
\hline 3.18 & $\begin{array}{l}\text { De todos os lugares onde o(a) } \operatorname{Sr}(a) \\
\text { recebe atendimento para estas } \\
\text { doenças, qual é o que o(a) } \operatorname{Sr}(a) \\
\text { mais utiliza? }\end{array}$ & \\
\hline 3.19 & $\begin{array}{l}\text { Quando foi a última vez que o(a) } \\
\text { Sr(a) consultou este(s) médico(s)? } \\
\text { => Passe para } 4.0 \text {. }\end{array}$ & $\begin{array}{l}1 \text { [] no último mês } \\
2 \text { [] de } 1 \text { mês a } 6 \text { meses } \\
3 \text { [] mais de } 6 \text { meses a } 1 \text { ano } \\
4 \text { [] mais de } 1 \text { ano a } 5 \text { anos } \\
5 \text { [] mais de } 5 \text { anos } \\
9 \text { [] NS/NR }\end{array}$ \\
\hline
\end{tabular}

\section{I04 - REMÉDIOS DE USO EVENTUAL}

Agora, vamos voltar a falar sobre remédios.

\begin{tabular}{|l|l|l|}
\hline & $\begin{array}{l}\text { Entrevistados que apresentaram alguma } \\
\text { doença crônica: }\end{array}$ & \\
\hline 4.0 & $\begin{array}{l}\text { Além dos remédios já citados, o(a) Sr(a) usou } \\
\text { algum outro remédio nos últimos } 15 \text { dias, } \\
\text { para: } \\
\text { *Passe para 4.2* }\end{array}$ & \\
\hline
\end{tabular}




\begin{tabular}{|c|c|c|}
\hline & $\begin{array}{l}\text { Entrevistados que não apresentaram } \\
\text { doenças crônicas: }\end{array}$ & \\
\hline 4.1 & $\begin{array}{l}\text { Nos últimos } 15 \text { dias, usou algum remédio } \\
\text { para: }\end{array}$ & \\
\hline 4.2 & Para infecção? & $\begin{array}{l}1 \text { [] Sim } \\
2 \text { [] Não => Passe para } 4.3 \\
9 \text { [] NS/NR => Passe para } 4.3\end{array}$ \\
\hline $4.2 \mathrm{a}$ & Qual o local da infecção? & $\begin{array}{l}\text { - [] Vias respiratórias => Passe para } 4.2 c \\
\text { - [] Pele => Passe para } 4.2 c \\
\text { - [] Trato urinário => Passe para } 4.2 c \\
\text { - [] Outro } \\
\text { - [] NS/NR => Passe para } 4.2 c\end{array}$ \\
\hline $4.2 b$ & Qual? & \\
\hline $4.2 \mathrm{c}$ & Remédio 01 & \\
\hline $4.2 \mathrm{~d}$ & Remédio 02 & \\
\hline $4.2 \mathrm{e}$ & Remédio 03 & \\
\hline 4.3 & Para dormir ou para os nervos? & $\begin{array}{l}1 \text { [] Sim } \\
2 \text { [] Não => Passe para } 4.4 \\
9 \text { [] NS/NR => Passe para } 4.4\end{array}$ \\
\hline $4.3 a$ & Remédio 01 & \\
\hline $4.3 b$ & Remédio 02 & \\
\hline $4.3 c$ & Remédio 03 & \\
\hline 4.4 & Para problemas no estômago ou intestino? & $\begin{array}{l}1 \text { [] Sim } \\
2 \text { [] Não=> Passe para } 4.5 \\
9 \text { [] NS/NR => Passe para } 4.5\end{array}$ \\
\hline $4.4 a$ & Remédio 01 & \\
\hline $4.4 \mathrm{~b}$ & Remédio 02 & \\
\hline $4.4 \mathrm{c}$ & Remédio 03 & \\
\hline 4.5 & Para febre? & $\begin{array}{l}1 \text { [] Sim } \\
2 \text { [] Não => Passe para } 4.6 \\
9 \text { [] NS/NR => Passe para } 4.6\end{array}$ \\
\hline $4.5 \mathrm{a}$ & Remédio 01 & \\
\hline $4.5 b$ & Remédio 02 & \\
\hline $4.5 c$ & Remédio 03 & \\
\hline 4.6 & Para dor? & $\begin{array}{l}1 \text { [] Sim } \\
2 \text { [] Não => Passe para } 4.7 \\
9 \text { [] NS/NR => Passe para } 4.7\end{array}$ \\
\hline
\end{tabular}




\begin{tabular}{|c|c|c|}
\hline $4.6 a$ & Qual é o local da dor? & $\begin{array}{l}\text { - [] Cabeça => Passe para } 4.6 c \\
\text { - [] Costas => Passe para } 4.6 c \\
\text { - [] Cólica menstrual => Passe para } 4.6 c \\
\text { - [] Muscular => Passe para } 4.6 c \\
\text { - [] Outro } \\
\text { - [] NS/NR => Passe para 4.6c }\end{array}$ \\
\hline $4.6 b$ & Qual? & \\
\hline $4.6 c$ & Remédio 01 & \\
\hline $4.6 \mathrm{~d}$ & Remédio 02 & \\
\hline $4.6 \mathrm{e}$ & Remédio 03 & \\
\hline 4.7 & Para gripe, resfriado ou rinite alérgica & $\begin{array}{l}1 \text { [] } \mathrm{Sim} \\
2 \text { [] Não=> Passe para } 4.8 \\
9 \text { [] NS/NR => Passe para } 4.8\end{array}$ \\
\hline $4.7 a$ & Remédio 01 & \\
\hline $4.7 \mathrm{~b}$ & Remédio 02 & \\
\hline $4.7 \mathrm{c}$ & Remédio 03 & \\
\hline 4.8 & $\begin{array}{l}\text { Nos últimos } 15 \text { dias, o(a) } \mathrm{Sr}(\mathrm{a}) \text { utilizou } \\
\text { alguma vitamina, suplemento de minerais, } \\
\text { estimulante de apetite ou tônico? }\end{array}$ & $\begin{array}{l}1 \text { [] Sim } \\
2 \text { [] Não => Passe para } 4.9 \\
9 \text { [] NS/NR=> Passe para } 4.9\end{array}$ \\
\hline $4.8 \mathrm{a}$ & Remédio 01 & \\
\hline $4.8 \mathrm{~b}$ & Por que usou este remédio? & \\
\hline $4.8 \mathrm{c}$ & Remédio 02 & \\
\hline $4.8 \mathrm{~d}$ & Por que usou este remédio? & \\
\hline $4.8 \mathrm{e}$ & Remédio 03 & \\
\hline $4.8 \mathrm{f}$ & Por que usou este remédio? & \\
\hline 4.9 & $\begin{array}{l}\text { Nos últimos } 15 \text { dias, o(a) Sr(a) utilizou } \\
\text { algum outro remédio que ainda não tenha } \\
\text { sido citado? } \\
\text { (Se mulher entre } 15-49 \text { anos, não considerar } \\
\text { contraceptivos) }\end{array}$ & $\begin{array}{l}1 \text { [] Sim } \\
2 \text { [] Não => Passe para } 4.10 \\
9 \text { [] NS/NR=> Passe para } 4.10\end{array}$ \\
\hline $4.9 a$ & Remédio 01 & \\
\hline $4.9 \mathrm{~b}$ & Por que usou este remédio? & \\
\hline $4.9 c$ & Remédio 02 & \\
\hline $4.9 \mathrm{~d}$ & Por que usou este remédio? & \\
\hline $4.9 \mathrm{e}$ & Remédio 03 & \\
\hline $4.9 f$ & Por que usou este remédio? & \\
\hline 4.10 & $\begin{array}{l}\text { Total de medicamentos utilizados nos } \\
\text { últimos } 15 \text { dias } \\
\text { *Preencher sem perguntar* }\end{array}$ & I_l_l \\
\hline
\end{tabular}




\begin{tabular}{|l|l|l|}
\hline 4.11 & $\begin{array}{l}\text { Tem algum remédio ainda não citado que, } \\
\text { nos últimos 15 dias, o(a) Sr(a) deveria ter } \\
\text { tomado e não tomou? }\end{array}$ & $\begin{array}{l}1 \text { [] Sim } \\
2 \text { [] Não => Encerre o bloco }\end{array}$ \\
\hline 4.12 & $\begin{array}{l}\text { Qual(is) os remédios que o(a) Sr(a) deveria } \\
\text { estar usando e não está? }\end{array}$ & *Listar abaixo os remédios* \\
\hline 4.12a & Remédio 4 & \\
\hline $4.12 b$ & Por que ficou sem usar este remédio? & \\
\hline $4.12 \mathrm{c}$ & Remédio 5 & \\
\hline $4.12 \mathrm{~d}$ & Por que ficou sem usar este remédio? & \\
\hline $4.12 \mathrm{e}$ & Remédio 6 & \\
\hline 4.12f & Por que ficou sem usar este remédio? & \\
\hline
\end{tabular}

`Se citado o uso de algum remédio utilizados nos últimos 15

dias, preencher a ficha de remédios de uso eventual*

*Se não citado o uso de remédios nos últimos 15 dias e a entrevistada for mulher entre 15 e 49 anos, passe para 5.1, se entrevistada fora desta faixa etária ou homem, passe para 6.1* 
Agora vamos falar sobre os remédios que o(a) Sr(a) usou nos últimos 15 dias.

\begin{tabular}{|c|c|c|}
\hline \multicolumn{3}{|c|}{ FICHA DE REMÉDIOS DE USO EVENTUAL } \\
\hline ME.1 & $\begin{array}{l}\text { Qual o motivo que levou o(a) entrevistado(a) a } \\
\text { utilizar este remédio: }\end{array}$ & $\begin{array}{ll}\mathbf{1} & \text { [] Infecção } \\
\mathbf{2} & \text { [] Para dormir ou para os nervos } \\
\mathbf{3} & \text { [] Problemas no estômago ou } \\
\text { intestino } \\
\mathbf{4} & \text { [] Febre } \\
\mathbf{5} & \text { [] Dor } \\
\mathbf{6} & \text { [] Gripe, resfriado ou rinite alérgica } \\
\mathbf{7} & \text { [] Vitaminas, suplementos, } \\
\text { estimulantes de apetite ou tônicos } 8 \text { [] Outros }\end{array}$ \\
\hline ME.2 & $\begin{array}{l}\text { Tem alguma embalagem? } \\
\quad \text { *Observar e preencher* } \\
\quad{ }^{*} \text { Considere como embalagem a caixa, } \\
\text { cartela, bisnaga ou outro recipiente que } \\
\text { contenha o remédios e suas informações* }\end{array}$ & $\begin{array}{l}1 \text { [] Sim } \\
2 \text { [] Não }\end{array}$ \\
\hline ME.3 & $\begin{array}{c}\begin{array}{l}\text { O remédio é genérico? } \\
\text { *Observar e preencher* } \\
\text { (Tarja amarela com G, Lei 9787) }\end{array} \\
\end{array}$ & $\begin{array}{l}1 \text { [] Sim } \\
\mathbf{2} \text { [] Não } \\
\mathbf{9} \text { [] NS/NR }\end{array}$ \\
\hline ME.4 & $\begin{array}{l}\text { Data de validade } \\
\qquad{ }^{*} \text { Observar e preencher* }\end{array}$ & $I_{99-N S / N R} I_{-}\left|/ I_{-}\right|$mês/ano \\
\hline ME.5 & 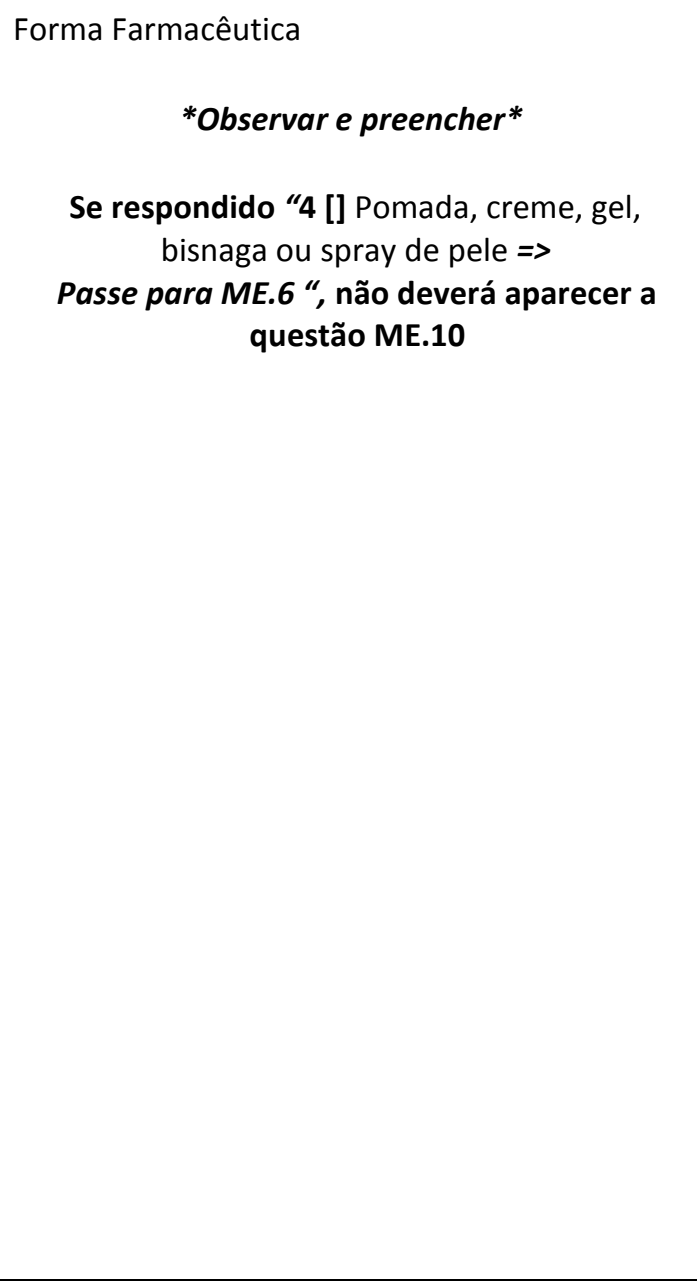 & 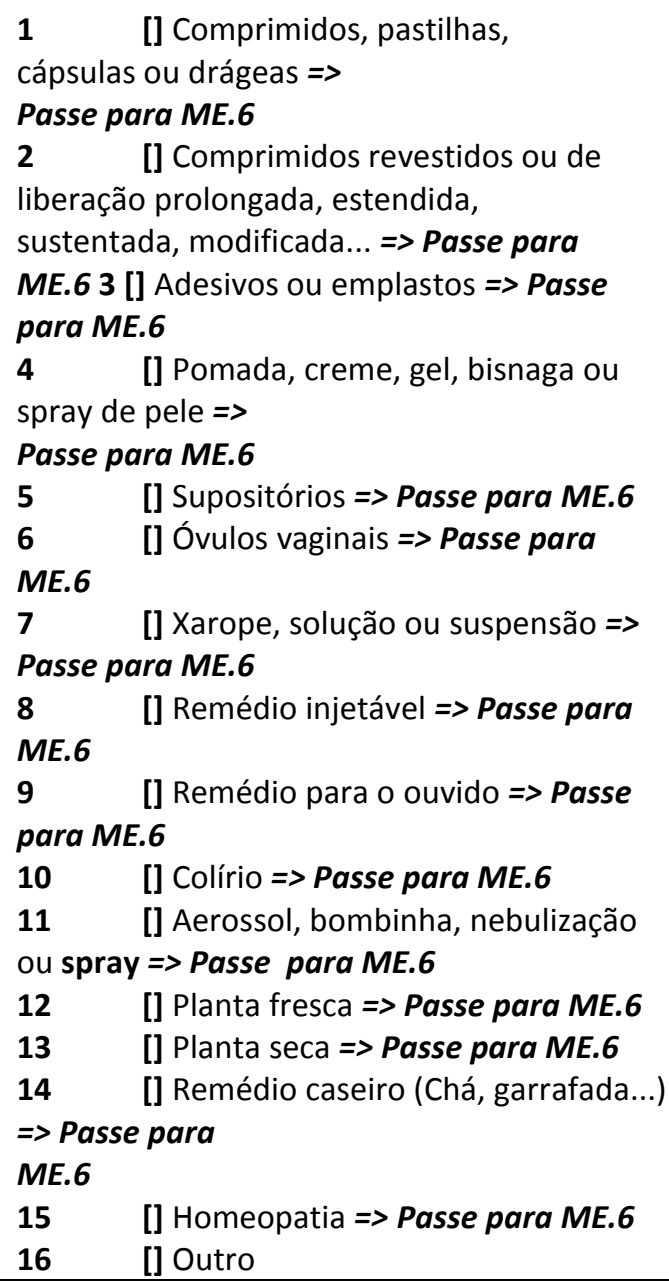 \\
\hline
\end{tabular}




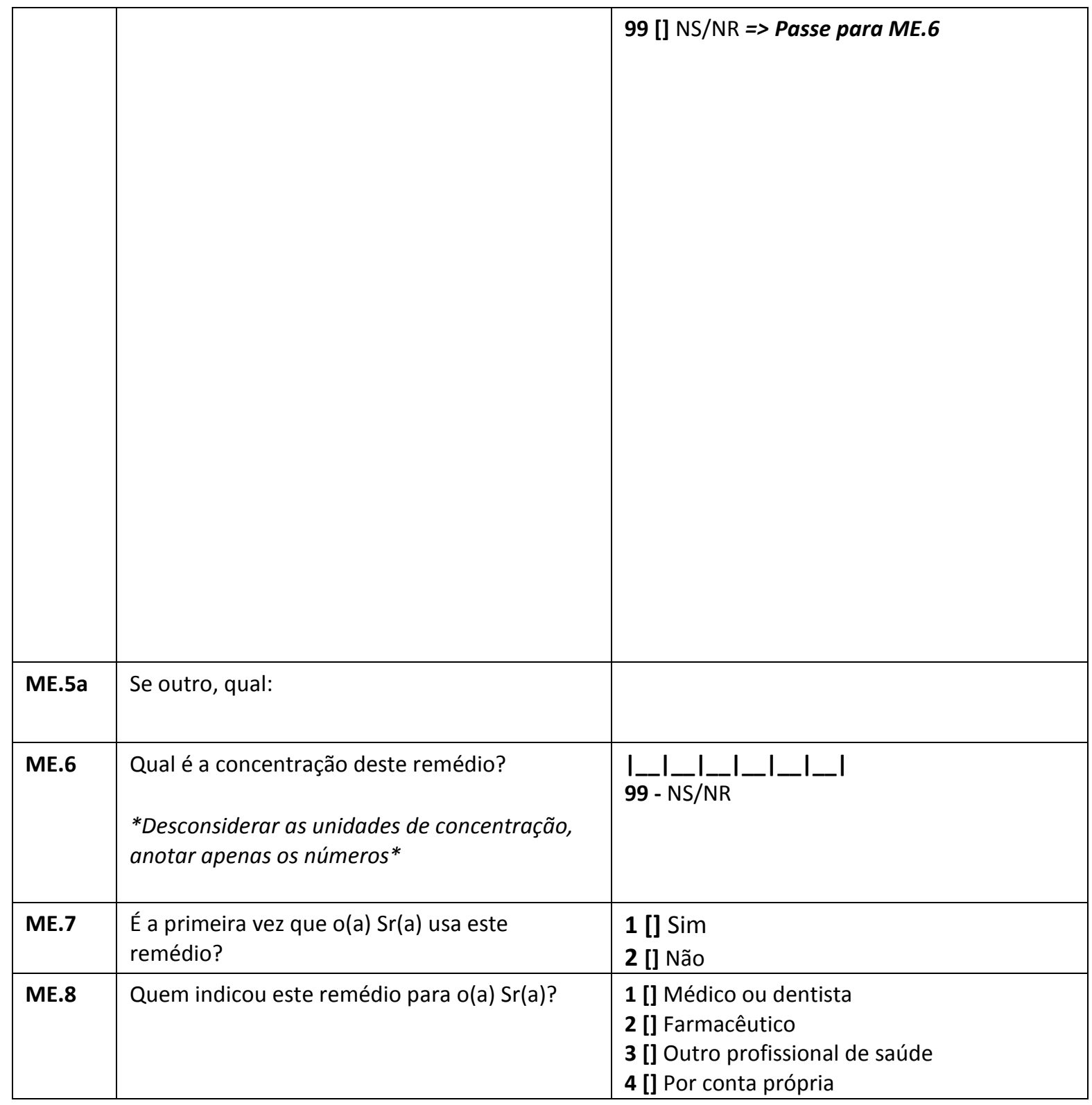

\begin{tabular}{|c|c|c|}
\hline & & $\begin{array}{l}5 \text { [] Parente, amigo ou vizinho } \\
6 \text { [] Esposo(a) ou companheiro(a) } \\
7 \text { [] Balconista da farmácia } \\
\mathbf{8} \text { [] Outro }\end{array}$ \\
\hline & Nos últimos 15 dias: & \\
\hline ME.9 & $\begin{array}{l}\text { Quantas vezes por dia o(a) Sr(a) usou este } \\
\text { remédio? }\end{array}$ & $\begin{array}{l}\text { I____ l vez(es) } \\
\mathbf{8 8}[] \text { Tantas quanto necessário } \\
\mathbf{9 9}[] \mathrm{NS} / \mathrm{NR}\end{array}$ \\
\hline ME.10 & Quantas unidades o(a) Sr(a) usou em cada vez? & $\begin{array}{l}\text { I_l_l comprimidos/jatos/gotas ou outra } \\
\text { unidade } \\
99 \text { - NS/NR }\end{array}$ \\
\hline
\end{tabular}




\begin{tabular}{|c|c|c|}
\hline ME.11 & Quanto tempo vai durar o tratamento? & $\begin{array}{l}\text { I____ dias } \\
44 \text { [] Tomou apenas uma vez } \\
55 \text { [] Até melhorar/curar } \\
66 \text { [] Não vai mais tomar/Tomou até } \\
\text { melhorar } \\
77 \text { [] Sempre que voltarem os sintomas } \\
\mathbf{8 8} \text { [] Para sempre } \\
\mathbf{9 9} \text { [] NS/NR }\end{array}$ \\
\hline ME.12 & $\begin{array}{l}\text { Como este remédio funciona(ou) para o(a) } \\
\operatorname{Sr}(a) \text { ? }\end{array}$ & $\begin{array}{l}1 \text { [] Bem } \\
\mathbf{2} \text { [] Mais ou menos } \\
\mathbf{3} \text { [] Não muito bem }\end{array}$ \\
\hline ME.13 & Este remédio incomoda(ou) o(a) $\operatorname{Sr}(a)$ ? & $\begin{array}{l}1 \text { [] Sim } \\
2 \text { [] Não => Passe para ME.14 } \\
9 \text { [] NS/NR => Passe para ME.14 }\end{array}$ \\
\hline ME.13a & De que forma este remédio the incomoda(ou)? & \\
\hline ME.14 & $\begin{array}{l}\text { Este remédio causa(ou) problema(s) de saúde } \\
\text { para o(a) } \operatorname{Sr}(a) \text { ? }\end{array}$ & $\begin{array}{l}1 \text { [] Sim } \\
2 \text { [] Não => Passe para ME.15 } \\
9 \text { [] NS/NR => Passe para ME.15 }\end{array}$ \\
\hline ME.14a & Quais? & \\
\hline ME.15 & $\begin{array}{l}\text { Para o(a) } \operatorname{Sr}(a) \text {, conseguir este remédio foi: }{ }^{*} \text { Ler } \\
\text { as alternativas* }\end{array}$ & $\begin{array}{l}1 \text { [] Muito difícil } \\
2 \text { [] Um pouco difícil } \\
3 \text { [] Não foi difícil } \\
9 \text { [] NS/NR }\end{array}$ \\
\hline ME.16 & O(a) Sr(a) pagou por este remédio? & $\begin{array}{l}1 \text { [] Sim } \\
2 \text { [] Não => Passe para ME.19 } \\
9 \text { [] NS/NR => Passe para ME.19 }\end{array}$ \\
\hline ME.17 & $\begin{array}{l}\text { Onde comprou? } \\
\text { *Caso respondido "2 [] Farmácia Comercial", o } \\
\text { entrevistado deverá responder às questões } \\
\text { referentes a "IB06_B Farmácia Comercial" no } \\
\text { bloco "IB06_Servicos_Farmacia"* }\end{array}$ & $\begin{array}{l}1 \text { [] Programa Farmácia Popular } \\
2 \text { [] Farmácia Comercial } \\
3 \text { [] Outro } \\
9 \text { [] NS/NR }\end{array}$ \\
\hline ME.18 & Quanto custou este remédio? & 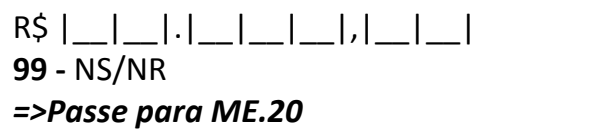 \\
\hline ME.19 & $\begin{array}{l}\text { Onde obteve? } \\
\text { *Caso respondido "1 [] SUS", o } \\
\text { entrevistado deverá responder às } \\
\text { questões referentes a "IB06_A Farmácia } \\
\text { do SUS" no bloco } \\
\text { "IB06_Servicos_Farmacia"* }\end{array}$ & $\begin{array}{l}1 \text { [] SUS } \\
2 \text { [] Programa Farmácia Popular } \\
\mathbf{3} \text { [] Amostra grátis } \\
4 \text { [] Instituição de caridade e/ou ONG } \\
5 \text { [] Amigos, parentes ou vizinhos } \\
6 \text { [] Outro } \\
\mathbf{9} \text { [] NS/NR }\end{array}$ \\
\hline
\end{tabular}




\begin{tabular}{|l|l|l|}
\hline ME.20 & O(a) Sr(a) já indicou este medicamento \\
para outra pessoa com o mesmo problema & $\mathbf{1}$ [] Sim \\
de saúde? & [] Não \\
& & $\mathbf{9}[]$ NS/NR \\
\hline
\end{tabular}

\section{I05-CONTRACEPTIVOS}

Agora vou fazer mais algumas perguntas sobre sua saúde.

\begin{tabular}{|c|c|c|c|}
\hline & $\begin{array}{l}\text { *Apenas para mulheres entre } 15 \text { e } 49 \text { anos de } \\
\text { idade* }\end{array}$ & & \\
\hline 5.1 & A Sra está grávida no momento? & \multicolumn{2}{|c|}{$\begin{array}{l}1 \text { [] Sim } \\
2 \text { [] Não => Passe para } 5.2 \\
9 \text { [] NS/NR => Passe para } 5.2\end{array}$} \\
\hline $5.1 a$ & $\begin{array}{l}\text { A Sra está grávida de quanto tempo? } \\
=>\text { Encerre o bloco }\end{array}$ & $I^{\prime}-I_{-N S / N R}$ & $\begin{array}{l}1 \text { [] } \\
\text { Semana(s) } \\
2 \text { [] Mês(s) }\end{array}$ \\
\hline 5.2 & A Sra está amamentando no momento? & \multicolumn{2}{|l|}{$\begin{array}{l}1 \text { [] } \operatorname{Sim} \\
2 \text { [] Não } \\
9 \text { [] NS/NR } \\
\end{array}$} \\
\hline 5.3 & $\begin{array}{l}\text { A Sra está usando alguma pílula anticoncepcional } \\
\text { para não engravidar? }\end{array}$ & \multicolumn{2}{|c|}{$\begin{array}{l}1 \text { [] Sim => Passe para } 5.4 \\
2 \text { [] Não }\end{array}$} \\
\hline $5.3 a$ & A Sra usa alguma injeção para não engravidar? & \multicolumn{2}{|c|}{$\begin{array}{l}1 \text { [] Sim => Passe para } 5.11 \\
2 \text { [] Não => Passe para } 5.26\end{array}$} \\
\hline & Pílula: & \multirow{2}{*}{\multicolumn{2}{|c|}{$\begin{array}{l}1 \text { [] Médico/Ginecologista } \\
2 \text { [] Enfermeiro } \\
3 \text { [] Farmacêutico } \\
4 \text { [] Outro profissional da saúde } \\
5 \text { [] Balconista da farmácia } \\
6 \text { [] Amigo(a) } \\
7 \text { [] Parceiro ou namorado } \\
8 \text { [] Tomou por conta própria } \\
9 \text { [] NS/NR }\end{array}$}} \\
\hline 5.4 & Quem Ihe indicou esta pílula? & & \\
\hline 5.5 & $\begin{array}{l}\text { A Sra tem alguma embalagem? } \\
\text { *Considere como embalagem a caixa, cartela, } \\
\text { bisnaga ou outro recipiente que contenha o } \\
\text { remédios e suas informações* }\end{array}$ & \multicolumn{2}{|c|}{$\begin{array}{l}1 \text { [] Sim } \\
2 \text { [] Não => Passe para } 5.7\end{array}$} \\
\hline 5.6 & Anote o nome do contraceptivo: & \multicolumn{2}{|c|}{$\Rightarrow$ Passe para 5.8} \\
\hline 5.7 & Qual o nome da pílula que a Sra utiliza? & & \\
\hline
\end{tabular}




\begin{tabular}{|c|c|c|}
\hline 5.8 & $\begin{array}{l}\text { No último mês, a Sra deixou de tomar a pílula por } \\
\text { algum dia? }\end{array}$ & $\begin{array}{l}1 \text { [] Sim } \\
2 \text { []Não => Passe para } 5.9\end{array}$ \\
\hline $5.8 a$ & Por quê? & 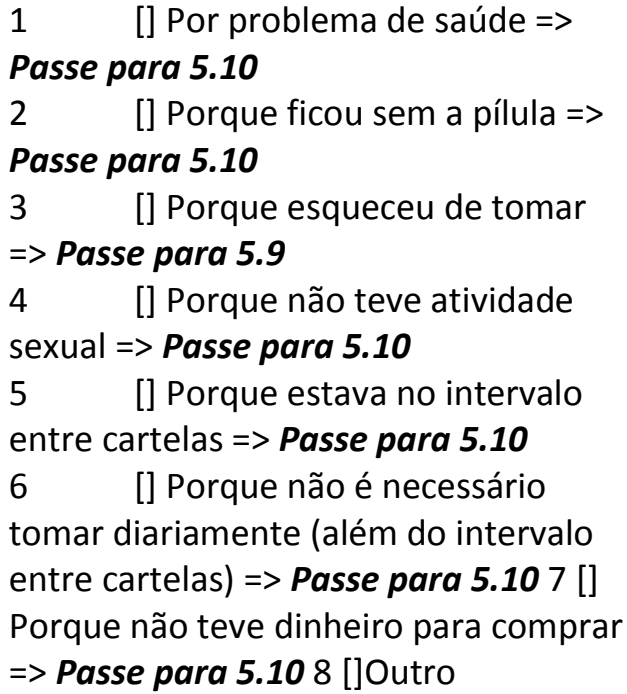 \\
\hline
\end{tabular}

\begin{tabular}{|c|c|c|}
\hline $5.8 b$ & Se outro, anote o motivo: & $=>$ Passe para 5.10 \\
\hline 5.9 & $\begin{array}{l}\text { Na ÚLTIMA VEZ em que esqueceu de tomar a } \\
\text { pílula... }\end{array}$ & \\
\hline $5.9 a$ & $\begin{array}{l}\text { A Sra continuou tomando normalmente (sem } \\
\text { tomar a pílula que esqueceu)? }\end{array}$ & $\begin{array}{l}1 \text { [] Sim => Passe para } 5.9 e \\
2 \text { [] Não }\end{array}$ \\
\hline $5.9 b$ & $\begin{array}{l}\text { A Sra tomou } 2 \text { pílulas no outro dia, no horário de } \\
\text { sempre? }\end{array}$ & $\begin{array}{l}1 \text { [] Sim => Passe para } 5.9 e \\
2 \text { [] Não }\end{array}$ \\
\hline $5.9 c$ & $\begin{array}{l}\text { A Sra tomou a pílula esquecida assim que } \\
\text { lembrou? }\end{array}$ & $\begin{array}{l}1 \text { [] Sim => Passe para } 5.9 e \\
2 \text { [] Não }\end{array}$ \\
\hline $5.9 d$ & A Sra encerrou a cartela? & $\begin{array}{l}1 \text { [] Sim } \\
2 \text { [] Não }\end{array}$ \\
\hline $5.9 e$ & $\begin{array}{l}\text { A Sra tomou algum outro cuidado para não } \\
\text { engravidar? }\end{array}$ & $\begin{array}{ll}1 & \text { [] Sim } \\
2 & \text { [] Não => Passe para } 5.17 \\
3 & \text { [] Não foi necessário pois não } \\
\text { manteve relações sexuais no período } \\
=>\text { Passe para } 5.17 \\
9 \text { [] NS/NR => Passe para } 5.17\end{array}$ \\
\hline $5.9 f$ & $\begin{array}{l}\text { Qual foi o cuidado que a Sra tomou? } \\
{ }^{*} \text { Considere o menor pulo* }\end{array}$ & $\begin{array}{l}\text { - [] Pílula do dia seguinte => Passe } \\
\text { para } 5.17 \\
\text { - [] Preservativo (camisinha) => Passe } \\
\text { para } 5.17 \\
\text { - [] Diafragma => Passe para } 5.17 \\
\text { - [] Evitou relações sexuais até vir a } \\
\text { menstruação => } \\
\text { Passe para } 5.17\end{array}$ \\
\hline
\end{tabular}




\begin{tabular}{|c|c|c|}
\hline & & $\begin{array}{l}\text { - [] Outro } \\
\text { - [] NS/NR => Passe para } 5.17\end{array}$ \\
\hline $5.9 \mathrm{~g}$ & Se outro, anote o cuidado: & $=>$ Passe para 5.17 \\
\hline 5.10 & $\begin{array}{l}\text { Algumas vezes, as mulheres esquecem de tomar } \\
\text { a pílula. Isso já aconteceu com a Sra? }\end{array}$ & $\begin{array}{l}1 \text { [] Sim } \\
2 \text { [] Não => Passe para } 5.17\end{array}$ \\
\hline $5.10 a$ & $\begin{array}{l}\text { Na ÚLTIMA VEZ em que esqueceu de tomar a } \\
\text { pílula... }\end{array}$ & \\
\hline $5.10 \mathrm{~b}$ & $\begin{array}{l}\text { A Sra continuou tomando normalmente (sem } \\
\text { tomar a pílula esquecida)? }\end{array}$ & $\begin{array}{l}1 \text { [] Sim => Passe para } 5.10 f \\
2 \text { [] Não }\end{array}$ \\
\hline $5.10 c$ & $\begin{array}{l}\text { A Sra tomou a pílula esquecida assim que } \\
\text { lembrou? }\end{array}$ & $\begin{array}{l}1 \text { [] Sim => Passe para } 5.10 f \\
2 \text { [] Não }\end{array}$ \\
\hline $5.10 d$ & $\begin{array}{l}\text { A Sra tomou } 2 \text { pílulas no outro dia, no horário de } \\
\text { sempre? }\end{array}$ & $\begin{array}{l}1 \text { [] Sim => Passe para } 5.10 f \\
2 \text { [] Não }\end{array}$ \\
\hline $5.10 \mathrm{e}$ & A Sra encerrou a cartela? & $\begin{array}{l}1 \text { [] Sim } \\
2 \text { [] Não }\end{array}$ \\
\hline $5.10 f$ & $\begin{array}{l}\text { A Sra tomou algum outro cuidado para não } \\
\text { engravidar? }\end{array}$ & $\begin{array}{ll}1 & \text { [] Sim } \\
2 & \text { [] Não => Passe para } 5.17 \\
3 & \text { [] Não foi necessário pois não } \\
\text { manteve relações sexuais no período } \\
=>\text { Passe para } 5.17 \\
9 \text { [] NS/NR => Passe para } 5.17\end{array}$ \\
\hline $5.10 \mathrm{~g}$ & Qual foi o cuidado que a Sra tomou? & $\begin{array}{l}1 \text { [] Pílula do dia seguinte => Passe } \\
\text { para } 5.17 \\
2 \text { [] Preservativo (camisinha) => } \\
\text { Passe para } 5.17 \\
3 \text { [] Diafragma => Passe para } 5.17 \\
4 \text { [] Evitou relações sexuais até vir a } \\
\text { menstruação => } \\
\text { Passe para } 5.17 \\
5 \text { [] Outro } \\
9 \text { [] NS/NR => Passe para } 5.17\end{array}$ \\
\hline $5.10 \mathrm{~h}$ & Se outro, anote o motivo: & $\Rightarrow>$ Passe para 5.17 \\
\hline
\end{tabular}

Contraceptivos injetáveis: 


\begin{tabular}{|c|c|c|}
\hline 5.11 & Quem Ihe indicou esta injeção? & $\begin{array}{l}1 \text { [] Médico } \\
2 \text { [] Enfermeiro } \\
3 \text { [] Farmacêutico } \\
4 \text { [] Outro profissional da saúde } \\
5 \text { [] Balconista da farmácia } \\
6 \text { [] Amigo(a) } \\
7 \text { [] Parceiro ou namorado } \\
8 \text { [] Tomou por conta própria } \\
9 \text { [] NS/NR }\end{array}$ \\
\hline 5.12 & Tem alguma receita, embalagem ou bula? & $\begin{array}{l}1 \text { [] } \operatorname{Sim} \\
2 \text { [] Não }\end{array}$ \\
\hline 5.13 & Qual o nome do contraceptivo? & \\
\hline 5.14 & $\begin{array}{l}\text { A Sra sabe a data em que tomou a injeção pela } \\
\text { última vez? }\end{array}$ & $\begin{array}{l}1 \text { [] Sim } \\
2 \text { [] Não => Passe para } 5.15 \\
9 \text { [] NS/NR => Passe para } 5.15\end{array}$ \\
\hline $5.14 a$ & $\begin{array}{l}\text { Anotar a data: } \\
{ }^{*} \text { Considerar data aproximada declarada* }\end{array}$ & I_l_l/I_l_l (dd/mm) \\
\hline 5.15 & $\begin{array}{l}\text { No último ano, a Sra deixou de tomar a injeção } \\
\text { por algum tempo? }\end{array}$ & $\begin{array}{l}1 \text { [] Sim } \\
2 \text { []Não => Passe para } 5.17\end{array}$ \\
\hline $5.15 a$ & Por quê? & $\begin{array}{l}1 \\
=>\text { Passe para } 5.16 \\
2 \quad \text { [] Porque ficou sem o } \\
\text { contraceptivo => Passe para } 5.16 \\
3 \quad \text { [] Porque esqueceu de } \\
\text { tomar => Passe para } 5.16 \\
4 \quad \text { [] Porque não teve } \\
\text { atividade sexual => Passe para } \\
5.16 \quad \text { [] Porque não é } \\
6 \quad \text { [] Porque não teve } \\
\text { necessário tomar todas os } \\
\text { meses, ou trimestres => Passe } \\
\text { para } 5.16 \\
7 \\
\text { dinheiro para comprar => Passe } \\
\text { para } 5.168 \text { []Outro }\end{array}$ \\
\hline $5.15 b$ & Se outro, anote o motivo: & \\
\hline 5.16 & $\begin{array}{l}\text { Quando deixou de tomar a injeção, a Sra tomou } \\
\text { algum outro cuidado para não engravidar? }\end{array}$ & $\begin{array}{ll}1 & \text { [] Sim } \\
2 & \text { [] Não => Passe para } 5.17 \\
3 & \text { [] Não foi necessário pois } \\
\text { não manteve relações sexuais no } \\
\text { período => Passe para } 5.17 \\
9 \text { [] NS/NR => Passe para } 5.17\end{array}$ \\
\hline
\end{tabular}




\begin{tabular}{|c|c|c|}
\hline $5.16 a$ & Qual foi o cuidado que a Sra tomou? & $\begin{array}{l}1 \text { [] Pílula do dia seguinte => } \\
\text { Passe para } 5.17 \\
2 \text { [] Preservativo (camisinha) => } \\
\text { Passe para } 5.17 \\
3 \text { [] Diafragma => Passe para } \\
5.17 \\
4 \text { [] Evitou relações sexuais até vir } \\
\text { a menstruação => } \\
\text { Passe para } 5.17 \\
5 \text { [] Outro } \\
9 \text { [] NS/NR => Passe para } 5.17\end{array}$ \\
\hline $5.16 \mathrm{~b}$ & Se outro, anote o cuidado: & \\
\hline
\end{tabular}

\begin{tabular}{|c|c|c|}
\hline & Pílula e Contraceptivos Injetáveis: & \\
\hline 5.17 & $\begin{array}{l}\text { Este anticoncepcional causa problemas de saúde } \\
\text { para a Sra? } \\
\text { `Ler as alternativas* }^{*}\end{array}$ & $\begin{array}{l}1 \text { [] Sim, muitos. } \\
2 \text { [] Sim, um pouco. } \\
3 \text { [] Sim, muito pouco. } \\
4 \text { [] Não, nada => Passe para } 5.18 \\
9 \text { [] NS/NR => Passe para } 5.18\end{array}$ \\
\hline $5.17 a$ & Qual(is) problema(s)? & \\
\hline 5.18 & $\begin{array}{l}\text { A Sra pagou por este anticoncepcional? } \\
\text { *Considerar "SIM" quando entrevistada relatar } \\
\text { pagamento com desconto* }\end{array}$ & $\begin{array}{l}1 \text { [] Não => Passe para } 5.22 \\
2 \text { [] Sim } \\
9 \text { [] NS/NR => Passe para } 5.20\end{array}$ \\
\hline 5.19 & Onde comprou? & $\begin{array}{lc}1 & \text { [] Programa Farmácia } \\
\text { Popular =>Passe para } 5.26 \\
2 \quad \text { [] Farmácia Comercial } \\
=>\text { Passe para } 5.203 \text { [] Outro } \\
9 \text { [] NS/NR => Passe para } 5.20\end{array}$ \\
\hline $5.19 a$ & Qual? & \\
\hline 5.20 & $\begin{array}{l}\text { Tentou obter este anticoncepcional no SUS sem } \\
\text { pagamento? }\end{array}$ & $\begin{array}{l}1 \text { [] Sim => Passe para } 5.21 \\
2 \text { [] Não } \\
9 \text { [] NS/NR => Passe para } 5.23\end{array}$ \\
\hline $5.20 a$ & Por quê? & $\begin{array}{l}\text { [] Porque nunca pensei } \\
\text { nisso => Passe para 5.23 } \\
-\quad[] \text { Porque não preciso/não } \\
\text { quero }=>\text { Passe para } 5.23 \\
-\quad \text { [] Porque tenho plano de } \\
\text { saúde }=>\text { Passe para } 5.23 \\
-\quad \text { [] Porque é longe=> Passe } \\
\text { para 5.23 } \\
-\quad \text { [] Porque é demorado=> } \\
\text { Passe para 5.23 } \\
-\quad \text { [] Porque o atendimento é } \\
\text { ruim=> Passe para } 5.23 \text { - [] Outro }\end{array}$ \\
\hline $5.20 b$ & Se outro, qual: & $\Rightarrow$ Passe para 5.23 \\
\hline
\end{tabular}




\begin{tabular}{|c|c|c|}
\hline 5.21 & Quando procurou o SUS, conseguiu obter? & $\begin{array}{l}1 \text { [] Sim, sempre => Passe para } \\
5.23 \\
2 \text { [] Sim, às vezes => Passe para } \\
5.23 \\
3 \text { [] Não conseguiu } \\
9 \text { [] NS/NR => Passe para } 5.23\end{array}$ \\
\hline $5.21 a$ & Por quê? & $\begin{array}{l}\text { - [] Estava em falta => Passe para } \\
5.23 \\
\text { - [] Não tinha a receita => Passe } \\
\text { para } 5.23 \\
\text { - [] Precisava de consulta => Passe } \\
\text { para } 5.23 \\
\text { - [] Foi na unidade/farmácia errada } \\
\text { => Passe para } 5.23 \\
\text { - [] Outro }\end{array}$ \\
\hline $5.21 b$ & Se outro, qual: & $\Rightarrow$ Passe para 5.23 \\
\hline 5.22 & Onde obteve? & $\begin{array}{l}1 \text { [] SUS => Passe para } 5.23 \\
2 \text { [] Programa Farmácia Popular } \\
\text { =>Passe para 5.26 } \\
3 \text { [] Amostra grátis => Passe para } \\
5.23 \\
4 \text { [] Instituição de caridade/Igreja => } \\
\text { Passe para } 5.23 \\
5 \text { [] Amigos, parentes ou vizinhos => } \\
\text { Passe para } 5.23 \\
6 \text { [] Outro } \\
9 \text { [] NS/NR => Passe para } 5.23\end{array}$ \\
\hline $5.22 \mathrm{a}$ & Se outro, anote qual: & \\
\hline 5.23 & $\begin{array}{l}\text { Alguma vez a Sra procurou por este } \\
\text { anticoncepcional na Farmácia Popular? }\end{array}$ & $\begin{array}{l}1 \text { [] Sim => Passe para } 5.24 \\
2 \text { [] Não } \\
9 \text { [] NS/NR => Passe para } 5.26 a\end{array}$ \\
\hline
\end{tabular}

\begin{tabular}{|c|c|c|}
\hline $5.23 a$ & Por quê? & 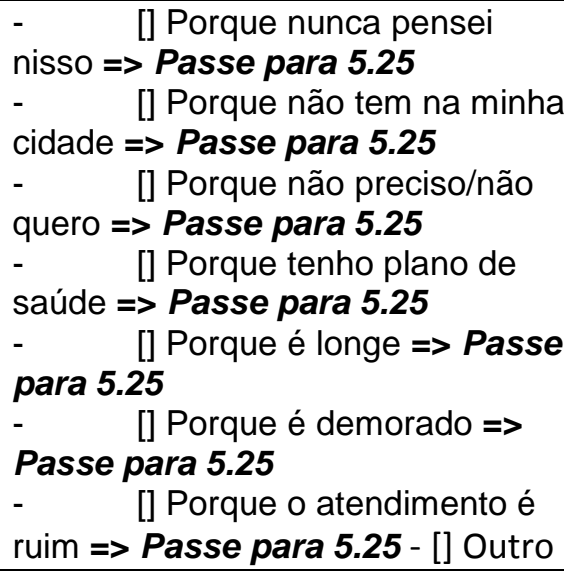 \\
\hline $5.23 b$ & Se outro, qual: & $=>$ Passe para 5.25 \\
\hline
\end{tabular}




\begin{tabular}{|c|c|c|}
\hline 5.24 & $\begin{array}{l}\text { Quando procurou a Farmácia Popular, conseguiu } \\
\text { obter? }\end{array}$ & $\begin{array}{l}1 \text { [] Sim, sempre => Passe para } \\
5.25 \\
2 \text { [] Sim, às vezes => Passe para } \\
5.25 \\
3 \text { [] Não conseguiu } \\
9 \text { [] NS/NR => Passe para } 5.25\end{array}$ \\
\hline $5.24 a$ & Por quê? & $\begin{array}{l}\text { - [] Porque não está na lista } \\
\text { de remédios oferecidos => Passe } \\
\text { para } 5.25 \\
\text { - [] Porque não tinha a } \\
\text { receita => Passe para } 5.25 \\
\text { - [] Porque a receita estava } \\
\text { vencida => Passe para } 5.25 \text { - [] Outro }\end{array}$ \\
\hline $5.24 b$ & Se outro, qual: & $\Rightarrow$ Passe para 5.25 \\
\hline 5.25 & $\begin{array}{l}\text { O quanto é difícil para a Sra conseguir } \\
\text { este anticoncepcional? * Ler as } \\
\text { alternativas* }\end{array}$ & $\begin{array}{l}1 \text { [] Muito difícil } \\
2 \text { [] Um pouco difícil } \\
3 \text { [] Não é difícil } \\
9 \text { [] NS/NR }\end{array}$ \\
\hline 5.26 & $\begin{array}{l}\text { Além deste contraceptivo, a Sra toma algum } \\
\text { outro cuidado para não engravidar? }\end{array}$ & $\begin{array}{l}1 \text { [] Sim } \\
2 \text { [] Não=> Encerre o bloco }\end{array}$ \\
\hline $5.26 a$ & Qual o outro cuidado que a Sra toma? & $\begin{array}{ll}- & \text { [] DIU => Passe para } 5.27 \\
- & \text { [] Diafragma => Passe para } \\
5.27 & \\
- & \text { [] Preservativo (camisinha) } \\
=>\text { Passe para } 5.27 \\
- & \text { [] Ligadura => Encerre o } \\
\text { bloco } & \\
- & \text { [] Pílula do dia seguinte }=> \\
\text { Encerre o bloco } \\
-\quad \text { [] Norplant (implante) => } \\
\text { Encerre o bloco } \\
-\quad \text { [] Adesivo transdérmico }=> \\
\text { Encerre o bloco }- \text { [] Outro }\end{array}$ \\
\hline $5.26 \mathrm{~b}$ & Se outro, anote qual: & => Encerre o bloco \\
\hline 5.27 & $\begin{array}{l}\text { A Sra pagou pelo __ (DIU, diafragma ou } \\
\text { preservativo)? } \\
\text { *Considerar "SIM" quando entrevistada relatar } \\
\text { pagamento com desconto* }\end{array}$ & $\begin{array}{l}1 \text { [] Não } \\
2 \text { [] Sim } \\
9 \text { [] NS/NR }\end{array}$ \\
\hline $5.27 a$ & Onde obteve? & $\begin{array}{l}1 \text { [] SUS => Passe para } \mathbf{5 . 3 0} \\
2 \text { [] Programa Farmácia Popular } \\
\mathbf{3} \text { [] Amostra grátis } \\
4 \text { [] Instituição de caridade/Igreja } \\
5 \text { [] Amigos, parentes ou vizinhos } \\
6 \text { [] Farmácia Comercial } \\
6 \text { [] Outro } \\
9 \text { [] NS/NR }\end{array}$ \\
\hline
\end{tabular}




\begin{tabular}{|c|c|c|}
\hline $5.27 \mathrm{~b}$ & Qual? & \\
\hline 5.28 & $\begin{array}{l}\text { Tentou obter o }(\text { DIU, diafragma e } \\
\text { preservativo) no SUS, sem pagamento? }\end{array}$ & $\begin{array}{l}1 \text { [] Sim => Passe para } 5.29 \\
2 \text { [] Não } \\
9 \text { [] NS/NR => Passe para } 5.30\end{array}$ \\
\hline $5.28 a$ & Por quê? & 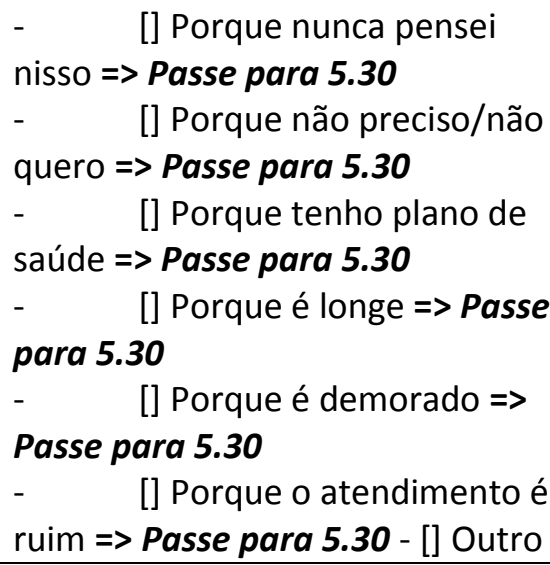 \\
\hline $5.28 b$ & Se outro, qual: & $\Rightarrow$ Passe para 5.30 \\
\hline 5.29 & Quando procurou o SUS, conseguiu obter? & $\begin{array}{l}1 \text { [] Sim, sempre => Passe para } \\
5.30 \\
2 \text { [] Sim, às vezes => Passe para } \\
5.30 \\
3 \text { [] Não } \\
9 \text { [] NS/NR => Passe para } 5.30\end{array}$ \\
\hline $5.29 a$ & Por quê? & $\begin{array}{l}\text { - [] Estava em falta => Passe } \\
\text { para } 5.30 \\
-\quad \text { [] Não tinha a receita => } \\
\text { Passe para } 5.30 \\
-\quad \text { [] Precisava de consulta => } \\
\text { Passe para } 5.30 \\
\text { - [] Foi na unidade/farmácia } \\
\text { errada => Passe para } 5.30 \text { - [] } \\
\text { Outro }\end{array}$ \\
\hline $5.29 b$ & Se outro, qual: & $\Rightarrow$ Passe para 5.30 \\
\hline 5.30 & $\begin{array}{l}\text { O quanto é difícil para a Sra conseguir o } \\
\text { * (DIU, diafragma e preservativo)? }\end{array}$ & $\begin{array}{l}1 \text { [] Muito difícil } \\
2 \text { [] Um pouco difícil } \\
3 \text { [] Não é difícil } \\
9 \text { [] NS/NR }\end{array}$ \\
\hline
\end{tabular}




\section{6 - SERVIÇOS DE FARMÁCIA \\ 106_A - FARMÁCIA DO SUS}

Agora, vamos falar um pouco sobre os locais onde o(a) $\mathrm{Sr}(\mathrm{a})$ consegue os seus remédios.

[As questões sobre serviços de farmácia do SUS devem ser respondidas nos casos em que pelo menos um remédio tenha sido obtido no SUS.]

\begin{tabular}{|c|c|c|}
\hline & FARMÁCIA DO SUS & \\
\hline 6.1 & $\begin{array}{l}\text { Em qual local o (a) Sr(a) consegue seus } \\
\text { remédios sem pagamento? }\end{array}$ & \\
\hline 6.2 & $\begin{array}{l}\text { Este local é o mesmo onde o (a) } \\
\text { Sr(a) é atendido(a) para tratar seus problemas } \\
\text { de saúde? }\end{array}$ & $\begin{array}{l}1 \text { [] Sim } \\
2 \text { [] Não } \\
3 \text { [] As vezes }\end{array}$ \\
\hline 6.3 & $\begin{array}{l}\text { Neste local o (a) Sr(a) consegue } \\
\text { todos os remédios que precisa? }\end{array}$ & $\begin{array}{l}1 \text { [] Sim } \\
2 \text { [] Não } \\
3 \text { [] As vezes }\end{array}$ \\
\hline 6.4 & Alguma vez faltou algum desses remédios? & $\begin{array}{l}1 \text { [] Sim } \\
2 \text { [] Não => Passe para } 6.6 \\
9 \text { [] NS/NR => Passe para } 6.6\end{array}$ \\
\hline $6.4 a$ & $\begin{array}{l}\text { Com que frequência? }{ }^{*} \text { Ler } \\
\text { as alternativas* }\end{array}$ & $\begin{array}{l}1 \text { [] Sempre falta } \\
2 \text { [] As vezes falta } \\
3 \text { [] Quase sempre falta } \\
9 \text { [] NS/NR => Passe para } 6.6\end{array}$ \\
\hline 6.5 & $\begin{array}{l}\text { Desses remédios, quais } \\
\text { costumam faltar? }\end{array}$ & $\begin{array}{c}\text { *Carregar lista de remédios que } \\
\text { o entrevistado disse que retira } \\
\text { neste local. (MC.16, MC.18, } \\
\text { ME.16 e ME.19 - Fichas de } \\
\text { remédios)* }\end{array}$ \\
\hline 6.6 & Este local entrega plantas e/ou chás? & $\begin{array}{l}1 \text { [] Sim } \\
2 \text { [] Não => Passe para } 6.7 \\
9 \text { [] NS/NR => Passe para } 6.7\end{array}$ \\
\hline $6.6 a$ & O(a) Sr(a) já retirou alguma planta e/ou chá? & $\begin{array}{l}1 \text { [] Sim } \\
2 \text { [] Não => Passe para } 6.7 \\
9 \text { [] NS/NR => Passe para } 6.7\end{array}$ \\
\hline $6.6 b$ & Qual(is)? & \\
\hline 6.7 & $\begin{array}{l}\text { Este local aceita receita de médico } \\
\text { particular ou do convênio para retirar os } \\
\text { remédios? }\end{array}$ & $\begin{array}{l}1 \text { [] Sim } \\
2 \text { [] Não } \\
9 \text { [] NS/NR }\end{array}$ \\
\hline 6.8 & $\begin{array}{l}\text { O remédio pode ser retirado em } \\
\text { qualquer dia da semana? }\end{array}$ & $\begin{array}{l}1 \text { [] } \mathrm{Sim} \\
2 \text { [] Não } \\
9 \text { [] NS/NR }\end{array}$ \\
\hline
\end{tabular}




\begin{tabular}{|c|c|c|}
\hline 6.9 & $\begin{array}{l}\text { Para retirar o(s) remédio(s) precisa participar de } \\
\text { algum grupo ou reunião? }\end{array}$ & $\begin{array}{l}1 \text { [] } \mathrm{Sim} \\
2 \text { [] Não } \\
9 \text { [] NS/NR }\end{array}$ \\
\hline \multirow[t]{2}{*}{6.10} & $\begin{array}{l}\text { Chegar neste local é: } \\
\text { *Ler as alternativas* }\end{array}$ & $\begin{array}{l}1 \text { [] Muito difícil } \\
2 \text { [] Um pouco difícil } \\
3 \text { [] Não é difícil }\end{array}$ \\
\hline & & 9 [] NS/NR \\
\hline 6.11 & $\begin{array}{l}\text { Como o(a) Sr(a) vai até este lugar? } \\
\text { *Considere o menor pulo* }\end{array}$ & $\begin{array}{l}\text { - [] Caminha => Passe para } 6.12 \\
\text { - [] Ônibus/transporte coletivo => } \\
\text { Passe para } 6.12 \\
\text { - [] Carro, moto ou barco => } \\
\text { Passe para } 6.12 \\
\text { - [] Outro } \\
\text { - [] NS/NR => Passe para } 6.12\end{array}$ \\
\hline $6.11 a$ & Se outro, qual: & \\
\hline 6.12 & Este lugar é longe? & $\begin{array}{l}1 \text { [] Sim } \\
2 \text { [] Mais ou menos } \\
3 \text { [] Não } \\
9 \text { [] NS/NR }\end{array}$ \\
\hline 6.13 & $\begin{array}{l}\text { Quanto tempo o(a) Sr(a) costuma ficar esperando até } \\
\text { ser atendido neste lugar? }\end{array}$ & $\begin{array}{l}1 \text { [] Não espera } \\
2 \text { [] Um pouco } \\
3 \text { [] Muito tempo } \\
4 \text { [] I_I Horas: I_l_l Minutos } \\
9 \text { [] NS/NR }\end{array}$ \\
\hline 6.14 & $\begin{array}{l}\text { O horário de funcionamento é: *Ler } \\
\text { as alternativas* }\end{array}$ & $\begin{array}{l}1 \text { [] Muito Bom } \\
2 \text { [] Bom } \\
3 \text { [] Regular } \\
4 \text { [] Ruim } \\
5 \text { [] Muito ruim }\end{array}$ \\
\hline 6.15 & $\begin{array}{l}\text { O atendimento nesse lugar para } \\
\text { retirar os remédios é: *Ler as } \\
\text { alternativas* }\end{array}$ & $\begin{array}{l}1 \text { [] Muito Bom } \\
2 \text { [] Bom } \\
3 \text { [] Regular } \\
4 \text { [] Ruim } \\
5 \text { [] Muito ruim }\end{array}$ \\
\hline
\end{tabular}




\section{6_B - FARMÁCIA PRIVADA}

[Estas questões devem ser respondidas pelos entrevistados que usam remédios obtidos em farmácia privada]

\begin{tabular}{|c|c|c|}
\hline & FARMÁCIA PRIVADA & \\
\hline 6.16 & $\begin{array}{l}\text { Neste local o (a) } \mathrm{Sr}(\mathrm{a}) \text { consegue todos os remédios } \\
\text { que precisa? }\end{array}$ & $\begin{array}{l}1 \text { [] Sim } \\
2 \text { [] Não } \\
3 \text { [] As vezes }\end{array}$ \\
\hline 6.17 & Alguma vez faltou algum desses remédios? & $\begin{array}{l}1 \text { [] Sim } \\
2 \text { [] Não => Passe para } 6.19 \\
9 \text { [] NS/NR => Passe para } 6.19\end{array}$ \\
\hline $6.17 a$ & $\begin{array}{l}\text { Com que frequência? } \\
\text { *Ler as alternativas* }\end{array}$ & $\begin{array}{l}1 \text { [] Sempre falta } \\
2 \text { [] As vezes falta } \\
3 \text { [] Quase sempre falta } \\
9 \text { [] NS/NR => Passe para } 6.19\end{array}$ \\
\hline 6.18 & $\begin{array}{l}\text { Desses remédios que utiliza, } \\
\text { quais costumam faltar? }\end{array}$ & $\begin{array}{l}\text { *Carregar lista de remédios que } \\
\text { o entrevistado disse que retira } \\
\text { neste local. (MC.16, MC.18, } \\
\text { ME.16 e ME.19 - Fichas de } \\
\text { remédios)* }\end{array}$ \\
\hline 6.19 & Tentou obter algum desses remédios no SUS? & $\begin{array}{l}1 \text { [] Sim } \\
2 \text { [] Não => Passe para } 6.21\end{array}$ \\
\hline 6.20 & $\begin{array}{l}\text { Por que não conseguiu? } \\
\text { *Considere o menor pulo* }\end{array}$ & $\begin{array}{l}\text { - [] Estava em falta => Passe } \\
\text { para } 6.22 \\
-\quad \text { [] Não tinha a receita => } \\
\text { Passe para } 6.22 \\
-\quad \text { [] Precisava de consulta => } \\
\text { Passe para } 6.22 \text { - [] Foi na } \\
\text { unidade/farmácia errada => Passe } \\
\text { para } 6.22 \\
-\quad \text { [] Outro }\end{array}$ \\
\hline $6.20 a$ & Se outro, qual: & $\Rightarrow>$ Passe para 6.22 \\
\hline
\end{tabular}




\begin{tabular}{|c|c|c|}
\hline 6.21 & Por que não tentou obter no SUS? & 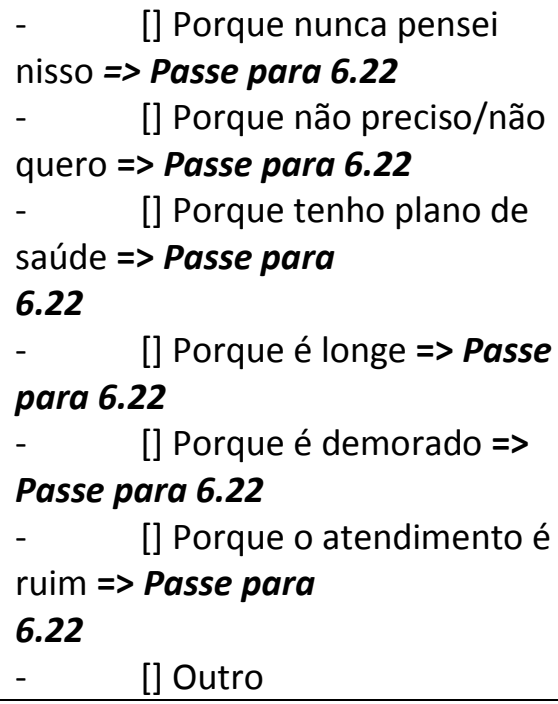 \\
\hline $6.21 a$ & Se outro, qual? & \\
\hline 6.22 & $\begin{array}{l}\text { Chegar neste local é: } \\
\text { *Ler as alternativas* }\end{array}$ & $\begin{array}{l}1 \text { [] Muito difícil } \\
2 \text { [] Um pouco difícil } \\
3 \text { [] Não é difícil } \\
9 \text { [] NS/NR }\end{array}$ \\
\hline \multirow[t]{2}{*}{6.23} & Como o(a) Sr(a) vai até este lugar? & $\begin{array}{l}\text { - [] Caminha => Passe para } 6.24 \\
\text { - [] Ônibus/transporte coletivo => } \\
\text { Passe para }\end{array}$ \\
\hline & *Considere o menor pulo* & $\begin{array}{l}6.24 \\
\text { - [] Carro, moto ou barco => Passe } \\
\text { para } 6.24 \\
\text { - [] Outro } \\
\text { - [] NS/NR => Passe para } 6.24\end{array}$ \\
\hline $6.23 a$ & Se outro, qual? & \\
\hline 6.24 & Este lugar é longe? & $\begin{array}{l}1 \text { [] Sim } \\
2 \text { [] Mais ou menos } \\
3 \text { [] Não } \\
9 \text { [] NS/NR }\end{array}$ \\
\hline 6.25 & $\begin{array}{l}\text { Quanto tempo o(a) } \mathrm{Sr}(\mathrm{a}) \text { costuma ficar esperando } \\
\text { até ser atendido neste lugar? }\end{array}$ & $\begin{array}{l}1 \text { [] Não espera } \\
2 \text { [] Um pouco } \\
3 \text { [] Muito tempo } \\
4 \text { [] I_I Horas: I_I_I Minutos } \\
9 \text { [] NS/NR }\end{array}$ \\
\hline 6.26 & $\begin{array}{l}\text { O horário de funcionamento é: } \\
\text { *Ler as alternativas* }\end{array}$ & $\begin{array}{l}1 \text { [] Muito Bom } \\
2 \text { [] Bom } \\
3 \text { [] Regular } \\
4 \text { [] Ruim } \\
5 \text { [] Muito ruim }\end{array}$ \\
\hline
\end{tabular}




\begin{tabular}{|l|l|l|}
\hline 6.27 & O atendimento nesse lugar & 1 [] Muito Bom \\
& para retirar os remédios é: & 2 [] Bom \\
& *Ler as alternativas* & 3 [] Regular \\
& & 4 [] Ruim \\
& & 5 [] Muito ruim \\
\hline
\end{tabular}

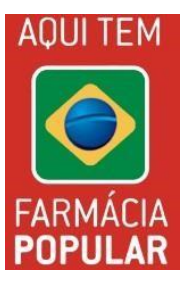

\section{6_C-FARMÁCIA POPULAR}

[Caso o uso da Farmácia Popular já tenha sido citado, passe para a questão 6.29.]

\begin{tabular}{|c|c|c|}
\hline 6.28 & $\begin{array}{l}\text { O(a) Sr(a) conhece o Programa Farmácia } \\
\text { Popular? }\end{array}$ & $\begin{array}{l}1 \text { [] Sim } \\
2 \text { [] Não => Encerre o bloco }\end{array}$ \\
\hline 6.29 & O(a) Sr(a) usa a Farmácia Popular? & $\begin{array}{l}1 \text { [] Sim } \\
2 \text { [] Não => Encerre o bloco }\end{array}$ \\
\hline 6.30 & $\begin{array}{l}\text { Qual o principal motivo que faz o(a) Sr(a) usar a Farmácia } \\
\text { Popular? } \\
\text { *Ler as alternativas. Em caso de resposta múltipla } \\
\text { por parte do respondente, perguntar qual o mais } \\
\text { importante. }\end{array}$ & $\begin{array}{l}1 \text { []O preço => Passe para } \\
6.31 \\
3 \text { []A localização => Passe } \\
\text { para } 6.31 \\
4 \text { []O atendimento => Passe } \\
\text { para } 6.31 \\
5 \text { []Porque tem os remédios } \\
\text { que faltam no } \\
\text { SUS => Passe para } 6.31 \\
7 \text { []Porque é mais perto do } \\
\text { que o posto do } \\
\text { SUS => Passe para } 6.31 \\
8 \text { [] Outros } \\
9 \text { [] NS/NR => Passe para } \\
6.31\end{array}$ \\
\hline $6.30 a$ & Se outro, qual? & \\
\hline 6.31 & $\begin{array}{l}\text { Neste local o (a) Sr(a) consegue todos os remédios que } \\
\text { precisa? }\end{array}$ & $\begin{array}{l}1 \text { [] Sim } \\
2 \text { [] Não } \\
3 \text { [] Às vezes }\end{array}$ \\
\hline 6.32 & Alguma vez faltou algum desses remédios? & $\begin{array}{l}1 \text { [] Sim } \\
2 \text { [] Não => Passe para } 6.34 \\
9 \text { [] NS/NR => Passe para } \\
6.34\end{array}$ \\
\hline
\end{tabular}




\begin{tabular}{|c|c|c|}
\hline $6.32 a$ & $\begin{array}{l}\text { Com que frequência? }{ }^{*} \text { Ler } \\
\text { as alternativas* }\end{array}$ & $\begin{array}{l}1 \text { [] Sempre falta } \\
2 \text { [] As vezes falta } \\
3 \text { [] Quase sempre falta } \\
9 \text { [] NS/NR => Passe para } \\
6.34\end{array}$ \\
\hline 6.33 & $\begin{array}{l}\text { Desses remédios que utiliza, quais } \\
\text { costumam faltar? }\end{array}$ & $\begin{array}{l}\text { *Carregar lista de remédios } \\
\text { que o entrevistado disse } \\
\text { que retira neste local. } \\
\text { (MC.16, MC.18, ME.16 e } \\
\text { ME.19 - Fichas de } \\
\text { remédios)* }\end{array}$ \\
\hline 6.34 & $\begin{array}{l}\text { Se estes remédios não estivessem disponíveis na } \\
\text { Farmácia Popular, o(a) Sr(a) procuraria por eles } \\
\text { no SUS? }\end{array}$ & $\begin{array}{l}1 \text { [] Sim } \\
2 \text { [] Não => Passe para } 6.34 c\end{array}$ \\
\hline $6.34 a$ & Por quê? & $\begin{array}{l}1 \text { [] Porque é grátis => } \\
\text { Passe para } 6.352 \text { [] } \\
\text { Porque preciso do } \\
\text { remédio => Passe para } \\
6.35 \\
3 \text { [] Porque é perto => } \\
\text { Passe para } 6.354 \text { [] } \\
\text { outro }\end{array}$ \\
\hline $6.34 b$ & Se outro, qual: & $\Rightarrow$ Passe para 6.35 \\
\hline \multirow[t]{2}{*}{$6.34 c$} & Por quê? & $\begin{array}{l}1 \quad \text { []Porque nunca } \\
\text { pensei nisso => Passe para } \\
6.35 \\
2 \quad \text { [] Porque o posto é } \\
\text { longe => Passe para } \\
6.35 \\
3 \quad \text { [] Porque demora => } \\
\begin{array}{l}\text { Passe } \\
\text { para } 6.35\end{array}\end{array}$ \\
\hline & & $\begin{array}{l}4 \quad \text { [] Porque o horário } \\
\text { de atendimento é ruim } \\
\Rightarrow>\text { Passe para } 6.35 \\
5 \quad \text { [] Porque o } \\
\text { atendimento é ruim => Passe } \\
\text { para } 6.35 \\
6 \quad \text { []Porque sempre } \\
\text { falta remédio => Passe para } \\
6.357 \text { [] Outro }\end{array}$ \\
\hline $6.34 d$ & Se outro, qual: & \\
\hline
\end{tabular}




\begin{tabular}{|c|c|c|}
\hline 6.35 & $\begin{array}{l}\text { Chegar neste local é: } \\
\text { *Ler as alternativas* }\end{array}$ & $\begin{array}{l}1 \text { [] Muito difícil } \\
2 \text { [] Um pouco difícil } \\
3 \text { [] Não é difícil } \\
9 \text { [] NS/NR }\end{array}$ \\
\hline 6.36 & $\begin{array}{l}\text { Como o(a) Sr(a) vai até este lugar? } \\
\text { *Considere o menor pulo* }\end{array}$ & $\begin{array}{l}- \\
\text { para } 6.37 \\
- \\
\text { coletivo }=>\text { Passe para } 6.37 \\
\text { [ Ônibus/transporte } \\
\text { barco }=>\text { Passe para } 6.37 \\
-\quad \text { [] Outro } \\
-\quad \text { [] NS/NR => Passe } \\
\text { para 6.37 }\end{array}$ \\
\hline $6.36 a$ & Se outro, qual? & \\
\hline 6.37 & Este lugar é longe? & $\begin{array}{l}1 \text { [] Muito longe } \\
2 \text { [] Mais ou menos longe } \\
3 \text { [] Não é longe } \\
9 \text { [] NS/NR }\end{array}$ \\
\hline 6.38 & $\begin{array}{l}\text { Quanto tempo o(a) Sr(a) costuma ficar esperando até } \\
\text { ser atendido neste lugar? }\end{array}$ & $\begin{array}{l}1 \text { [] Não espera } \\
2 \text { [] Um pouco } \\
3 \text { [] Muito tempo } \\
4 \text { [] I__ I Horas: I___l } \\
\text { Minutos } \\
9 \text { [] NS/NR }\end{array}$ \\
\hline 6.39 & $\begin{array}{l}\text { O horário de funcionamento é: } \\
\text { *Ler as alternativas* }\end{array}$ & $\begin{array}{l}1 \text { [] Muito Bom } \\
2 \text { [] Bom } \\
3 \text { [] Regular } \\
4 \text { [] Ruim } \\
5 \text { [] Muito ruim }\end{array}$ \\
\hline 6.40 & $\begin{array}{l}\text { O atendimento nesse lugar para retirar os remédios é: } \\
\text { *Ler as alternativas* }\end{array}$ & $\begin{array}{l}1 \text { [] Muito Bom } \\
2 \text { [] Bom } \\
3 \text { [] Regular } \\
4 \text { [] Ruim } \\
5 \text { [] Muito ruim }\end{array}$ \\
\hline 6.41 & $\begin{array}{l}\text { Onde o(a) Sr(a) consegue a receita para retirar os } \\
\text { remédios pela Farmácia Popular? }\end{array}$ & 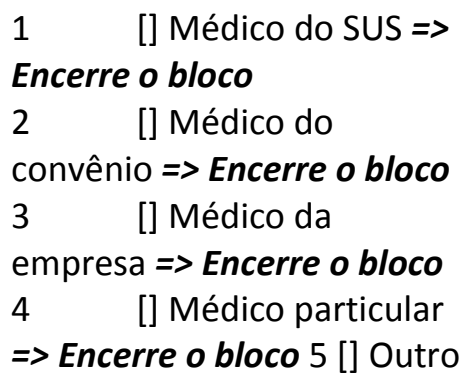 \\
\hline $6.41 a$ & Se outro, qual? & \\
\hline
\end{tabular}


I07 - COMPORTAMENTOS NO USO DOS REMÉDIOS

Agora vou fazer mais algumas perguntas sobre remédios. Para responder a estas perguntas, gostaria que o(a) $\mathrm{Sr}(\mathrm{a})$ considerasse todas as vezes em que fez o uso de remédios, de uma maneira geral.

\begin{tabular}{|c|c|c|}
\hline 7.1 & $\begin{array}{l}\text { Em quem o(a) Sr(a) confia para lhe indicar } \\
\text { remédios? Responda com "sim", "mais ou } \\
\text { menos" ou "não". }\end{array}$ & \\
\hline $7.1 \mathrm{a}$ & Mãe & $\begin{array}{l}\text { 1[] Sim } \\
\text { 2[] Mais ou menos } \\
\text { 3[] Não } \\
\text { 9[] NS/NR, não se aplica ou falecido/ausente }\end{array}$ \\
\hline $7.1 b$ & Pai & $\begin{array}{l}\text { 1[] Sim } \\
\text { 2[] Mais ou menos } \\
\text { 3[] Não } \\
\text { 9[] NS/NR, não se aplica ou falecido/ausente }\end{array}$ \\
\hline $7.1 \mathrm{c}$ & $\begin{array}{l}\text { Outros familiares como esposa(o), } \\
\text { filho(a)... }\end{array}$ & $\begin{array}{l}\text { 1[] Sim } \\
\text { 2[] Mais ou menos } \\
\text { 3[] Não } \\
\text { 9[] NS/NR, não se aplica ou falecido/ausente }\end{array}$ \\
\hline $7.1 d$ & Amigos, colegas, vizinhos & $\begin{array}{l}\text { 1[] Sim } \\
\text { 2[] Mais ou menos } \\
\text { 3[] Não } \\
\text { 9[] NS/NR, não se aplica ou falecido/ausente }\end{array}$ \\
\hline 7.1e & Médico & $\begin{array}{l}\text { 1[] Sim } \\
\text { 2[] Mais ou menos } \\
\text { 3[] Não } \\
\text { 9[] NS/NR, não se aplica ou falecido/ausente }\end{array}$ \\
\hline $7.1 f$ & Dentista & $\begin{array}{l}\text { 1[] Sim } \\
\text { 2[] Mais ou menos } \\
\text { 3[] Não } \\
\text { 9[] NS/NR, não se aplica ou falecido/ausente }\end{array}$ \\
\hline $7.1 \mathrm{~g}$ & Farmacêutico & $\begin{array}{l}\text { 1[] Sim } \\
\text { 2[] Mais ou menos } \\
\text { 3[] Não } \\
\text { 9[] NS/NR, não se aplica ou falecido/ausente }\end{array}$ \\
\hline $7.1 \mathrm{~h}$ & Atendente de Farmácia & $\begin{array}{l}\text { 1[] Sim } \\
\text { 2[] Mais ou menos } \\
\text { 3[] Não } \\
\text { 9[] NS/NR, não se aplica ou falecido/ausente }\end{array}$ \\
\hline $7.1 \mathrm{i}$ & Enfermeiro & $\begin{array}{l}\text { 1[] Sim } \\
\text { 2[] Mais ou menos } \\
\text { 3[] Não } \\
\text { 9[] NS/NR, não se aplica ou falecido/ausente }\end{array}$ \\
\hline
\end{tabular}




\begin{tabular}{|c|c|c|}
\hline $7.1 \mathrm{j}$ & Técnico de enfermagem & $\begin{array}{l}\text { 1[] Sim } \\
\text { 2[] Mais ou menos } \\
\text { 3[] Não } \\
\text { 9[] NS/NR, não se aplica ou falecido/ausente }\end{array}$ \\
\hline 7.11 & Agente comunitário de saúde & $\begin{array}{l}\text { 1[] Sim } \\
\text { 2[] Mais ou menos } \\
\text { 3[] Não } \\
\text { 9[] NS/NR, não se aplica ou falecido/ausente }\end{array}$ \\
\hline $7.1 \mathrm{~m}$ & $\begin{array}{l}\text { Alguém que o(a) Sr(a) conhece pouco, } \\
\text { mas que usa remédio }\end{array}$ & $\begin{array}{l}\text { 1[] Sim } \\
\text { 2[] Mais ou menos } \\
\text { 3[] Não } \\
\text { 9[] NS/NR, não se aplica ou falecido/ausente }\end{array}$ \\
\hline 7.2 & $\begin{array}{l}\mathrm{O}(\mathrm{a}) \mathrm{Sr}(\mathrm{a}) \text { confia em propaganda na TV, } \\
\text { rádio ou outros meios de comunicação } \\
\text { para indicar remédios? }\end{array}$ & $\begin{array}{l}1 \text { [] Sim } \\
2 \text { [] Mais ou menos } \\
3 \text { [] Não } \\
9 \text { [] NS/NR }\end{array}$ \\
\hline 7.3 & $\begin{array}{l}\text { *Caso o entrevistado cite alguma outra } \\
\text { pessoa em quem confia, anote aqui* }\end{array}$ & \\
\hline
\end{tabular}

\begin{tabular}{|c|c|c|}
\hline 7.4 & $\begin{array}{l}\text { Quando tem alguma dúvida sobre o uso de } \\
\text { remédios, onde ou com quem o(a) } \operatorname{Sr}(\text { a) } \\
\text { costuma buscar informação? } \\
\text { *Se outro, preencha 7.4a* }\end{array}$ & 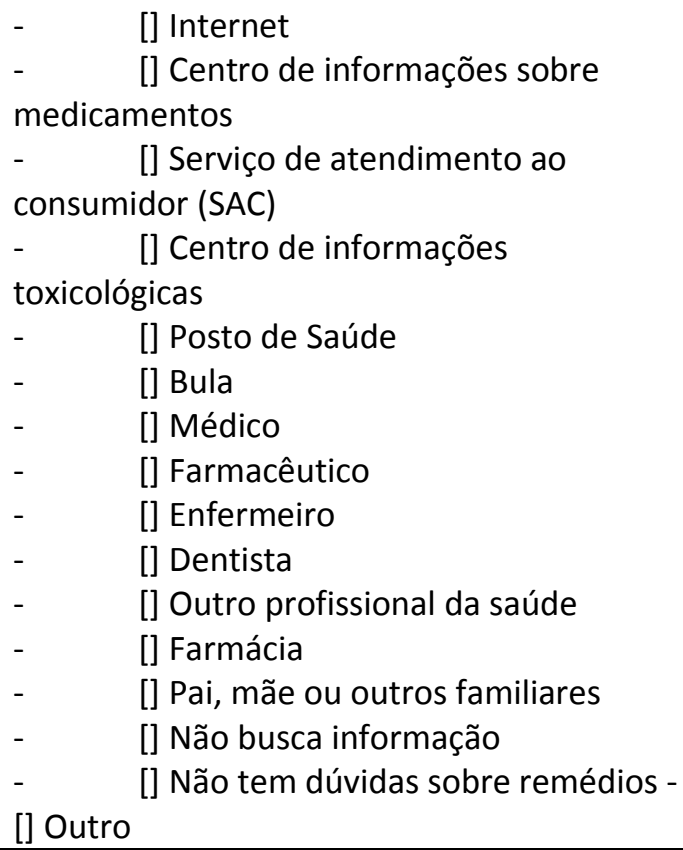 \\
\hline $7.4 a$ & Se outro, qual: & \\
\hline
\end{tabular}

\begin{tabular}{l|l}
7.5 & $\begin{array}{l}\mathrm{O}(\mathrm{a}) \mathrm{Sr}(\mathrm{a}) \text { toma um remédio sem receita } \\
\text { quando... }\end{array}$
\end{tabular}




\begin{tabular}{|c|c|c|}
\hline 7.5a & Já tem o remédio em casa? & $\begin{array}{l}\text { 1[]Sim } \\
\text { 2[]Não } \\
\text { 8[]Entrevistado declarou } \\
\text { espontaneamente } \\
\text { que não toma remédio sem receita => } \\
\text { Passe para a } 7.69[] \text { NS/NR }\end{array}$ \\
\hline $7.5 b$ & Quando conhece alguém que já tomou? & $\begin{array}{l}\text { 1[]Sim } \\
\text { 2[]Não } \\
\text { 8[]Entrevistado declarou } \\
\text { espontaneamente } \\
\text { que não toma remédio sem receita => } \\
\text { Passe para a } 7.69[] \text { NS/NR }\end{array}$ \\
\hline $7.5 \mathrm{c}$ & Quando já tomou este remédio antes? & $\begin{array}{l}\text { 1[]Sim } \\
\text { 2[]Não } \\
\text { 8[]Entrevistado declarou } \\
\text { espontaneamente } \\
\text { que não toma remédio sem receita => } \\
\text { Passe para } a \text { } 7.69[] \text { NS/NR }\end{array}$ \\
\hline $7.5 d$ & Quando leu a bula ou outra informação? & $\begin{array}{l}\text { 1[]Sim } \\
\text { 2[]Não } \\
\text { 8[]Entrevistado declarou } \\
\text { espontaneamente } \\
\text { que não toma remédio sem receita => } \\
\text { Passe para } a \text { } 7.69[] \text { NS/NR }\end{array}$ \\
\hline 7.5e & Quando consegue o remédio fácil? & $\begin{array}{l}\text { 1[]Sim } \\
\text { 2[]Não } \\
\text { 8[]Entrevistado declarou } \\
\text { espontaneamente } \\
\text { que não toma remédio sem receita => } \\
\text { Passe para a } 7.69[] \text { NS/NR }\end{array}$ \\
\hline $7.5 f$ & $\begin{array}{l}\text { *Caso o entrevistado cite algum outro } \\
\text { motivo que o faça tomar remédio sem } \\
\text { receita anote aqui* }\end{array}$ & \\
\hline
\end{tabular}

\begin{tabular}{|c|l|l|}
\hline 7.6 & $\begin{array}{l}\text { O(a) Sr(a) deixa de tomar algum remédio } \\
\text { receitado pelo médico quando... }\end{array}$ & \\
\hline $7.6 a$ & Acha que o remédio é muito forte ou & $\begin{array}{l}\text { 1[]Sim } \\
\text { 2[]Não } \\
\text { muito fraco? }\end{array}$ \\
& $\begin{array}{l}\text { 8[]Entrevistado declarou espontaneamente } \\
\text { que não deixa de tomar remédio receitado } \\
\text { pelo médico OU que neste caso procura o } \\
\text { médico ou outro serviço de saúde => Passe } \\
\text { para a } 7.7 \\
\text { 9[] NS/NR }\end{array}$ \\
\hline
\end{tabular}




\begin{tabular}{|c|c|c|}
\hline $7.6 b$ & $\begin{array}{l}\text { Quando acha que o remédio não é o certo } \\
\text { ou não funciona? }\end{array}$ & $\begin{array}{l}\text { 1[]Sim } \\
\text { 2[]Não } \\
\text { 8[]Entrevistado declarou espontaneamente } \\
\text { que não deixa de tomar remédio receitado } \\
\text { pelo médico oU que neste caso procura o } \\
\text { médico ou outro serviço de saúde => Passe } \\
\text { para a } 7.7 \\
\text { 9[] NS/NR }\end{array}$ \\
\hline $7.6 \mathrm{c}$ & Quando acha que não precisa do remédio? & $\begin{array}{l}\text { 1[]Sim } \\
\text { 2[]Não } \\
\text { 8[]Entrevistado declarou espontaneamente } \\
\text { que não deixa de tomar remédio receitado } \\
\text { pelo médico oU que neste caso procura o } \\
\text { médico ou outro serviço de saúde => Passe } \\
\text { para a } 7.7 \\
\text { 9[] NS/NR }\end{array}$ \\
\hline $7.6 \mathrm{~d}$ & Quando já usou o remédio e passou mal? & $\begin{array}{l}\text { 1[]Sim } \\
2[] \text { Não } \\
\text { 8[]Entrevistado declarou espontaneamente } \\
\text { que não deixa de tomar remédio receitado } \\
\text { pelo médico ou que neste caso procura o } \\
\text { médico ou outro serviço de saúde => Passe } \\
\text { para } a \text { } 7.7 \\
\text { 9[] NS/NR }\end{array}$ \\
\hline $7.6 e$ & $\begin{array}{l}\text { Quando lê alguma coisa que acha ruim na } \\
\text { bula? }\end{array}$ & $\begin{array}{l}\text { 1[]Sim } \\
\text { 2[]Não } \\
\text { 8[]Entrevistado declarou espontaneamente } \\
\text { que não deixa de tomar remédio receitado } \\
\text { pelo médico ou que neste caso procura o } \\
\text { médico ou outro serviço de saúde => Passe } \\
\text { para } a \text { } 7.7 \\
\text { 9[] NS/NR }\end{array}$ \\
\hline $7.6 f$ & $\begin{array}{l}\text { *Caso o entrevistado cite algum outro } \\
\text { motivo que o faça deixar de tomar algum } \\
\text { remédio receitado pelo médico, anote aqui* }\end{array}$ & \\
\hline 7.7 & $\begin{array}{l}\mathrm{O}(\mathrm{a}) \mathrm{Sr}(\mathrm{a}) \text { aumenta a dose de algum } \\
\text { remédio, receitado pelo médico, quando... }\end{array}$ & \\
\hline $7.7 a$ & Quer começar o tratamento com mais força? & $\begin{array}{l}1 \text { [] Sim } \\
2 \text { [] Não } \\
8 \text { [] Entrevistado declarou } \\
\text { espontaneamente que não aumenta a dose } \\
\text { sem falar com o médico OU que neste caso } \\
\text { procura o médico ou outro serviço de } \\
\text { saúde => Passe para a } 7.89 \text { [] NS/NR }\end{array}$ \\
\hline
\end{tabular}




\begin{tabular}{|c|c|c|}
\hline $7.7 \mathrm{~b}$ & $\begin{array}{l}\text { Quando o(a) Sr(a) percebe que não está } \\
\text { melhorando? }\end{array}$ & $\begin{array}{l}1 \text { [] Sim } \\
2 \text { [] Não } \\
8 \text { [] Entrevistado declarou } \\
\text { espontaneamente que não aumenta a dose } \\
\text { sem falar com o médico OU que neste caso } \\
\text { procura o médico ou outro serviço de } \\
\text { saúde => Passe para a } 7.89 \text { [] NS/NR }\end{array}$ \\
\hline 7.7c & Quando o(a) Sr(a) acha que está piorando? & $\begin{array}{l}1 \text { [] Sim } \\
2 \text { [] Não } \\
8 \text { [] Entrevistado declarou } \\
\text { espontaneamente que não aumenta a dose } \\
\text { sem falar com o médico OU que neste caso } \\
\text { procura o médico ou outro serviço de } \\
\text { saúde => Passe para a } 7.89 \text { [] NS/NR }\end{array}$ \\
\hline $7.7 d$ & $\begin{array}{l}\text { *Caso o entrevistado cite algum outro } \\
\text { motivo que o faça aumentar a dose de } \\
\text { algum remédio receitado pelo médico, } \\
\text { anote aqui* }\end{array}$ & \\
\hline
\end{tabular}

\begin{tabular}{|l|l|l|}
\hline 7.8 & $\begin{array}{l}\text { O(a) Sr(a) diminui a dose de algum remédio, } \\
\text { receitado pelo médico, quando... }\end{array}$ & \\
\hline $7.8 \mathrm{a}$ & Acha que a doença já está controlada? & 1 [] Sim \\
& & 2 [] Não \\
8 [] Entrevistado declarou \\
espontaneamente que não dimunui a \\
\end{tabular}




\begin{tabular}{|l|l|l|}
\hline $7.8 \mathrm{~d}$ & Quando o remédio é muito caro? & $\begin{array}{l}1[] \mathrm{Sim} \\
2[] \mathrm{Não} \\
8[] \text { Entrevistado declarou } \\
\text { espontaneamente que não dimunui a } \\
\text { dose sem falar com o médico OU que } \\
\text { neste caso procura o médico ou outro } \\
\text { serviço de saúde => Passe para a } 7.99[] \\
\text { NS/NR }\end{array}$ \\
\hline $7.8 \mathrm{e}$ & $\begin{array}{l}\text { *Caso o entrevistado cite algum outro } \\
\text { motivo que o faça diminuir a dose de algum } \\
\text { remédio receitado pelo médico, anote } \\
\text { aqui* }\end{array}$ \\
\hline
\end{tabular}

\begin{tabular}{|l|l|l|}
\hline 7.9 & O(a) Sr(a) já recebeu informação sobre... & \\
\hline $7.9 a$ & $\begin{array}{l}\text { Onde devem ser guardados os remédios em } \\
\text { casa? }\end{array}$ & $\begin{array}{l}1 \text { [] Sim } \\
2[] \text { Não } \\
9[] \text { NS/NR }\end{array}$ \\
\hline $7.9 b$ & $\begin{array}{l}\text { Sobre o melhor horário para tomar os } \\
\text { remédios? }\end{array}$ & $\begin{array}{l}1 \text { [] Sim } \\
2[] \text { Não } \\
9[] \text { NS/NR }\end{array}$ \\
\hline
\end{tabular}

\begin{tabular}{|c|c|c|}
\hline 7.10 & $\begin{array}{l}\text { O(a) Sr(a) costuma retirar os comprimidos } \\
\text { da cartela/vidro no mesmo momento em } \\
\text { que vai tomar o remédio? }\end{array}$ & $\begin{array}{l}1 \text { [] Sim =>Encerer } 0 \text { bloco } \\
2 \text { [] Não } \\
9 \text { [] NS/NR =>Encerer o bloco }\end{array}$ \\
\hline $7.10 \mathrm{a}$ & $\begin{array}{l}\text { Quanto tempo antes de tomar o remédio } \\
\text { o(a) Sr(a) retira os comprimidos da } \\
\text { cartela/vidro? }\end{array}$ & $\begin{array}{l}1 \text { [] I____ hora(s) } \\
2 \text { [] I____ dia(s) } \\
3 \text { [] I___ } \operatorname{semana(s)} \\
4 \text { [] I_I_I mês(s) } \\
9 \text { [] NS/NR }\end{array}$ \\
\hline
\end{tabular}


108 - BULAS E EMBALAGENS

Agora, vamos falar sobre as bulas e embalagens que acompanham os remédios.

[Se entrevistado analfabeto, passe para a questão 8.6]

\begin{tabular}{|c|c|c|}
\hline 8.0 & O(a) Sr(a) costuma ler as bulas dos remédios que usa? & $\begin{array}{l}1 \text { [] Sim => Passe } \\
\text { para } 8.1 \\
2 \text { [] Não }\end{array}$ \\
\hline $8.0 a$ & $\begin{array}{l}\text { Por quê? } \\
\text { *Considere o menor pulo* }\end{array}$ & 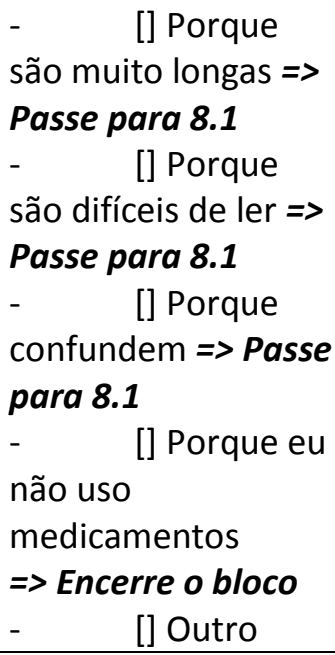 \\
\hline \multirow[t]{2}{*}{$8.0 \mathrm{~b}$} & Se outro, qual: & \\
\hline & Considerando as bulas de uma maneira geral: & \\
\hline 8.1 & $\begin{array}{l}\text { Enxergar o que está escrito nas bulas é: } \\
\text { *Ler as alternativas* }\end{array}$ & $\begin{array}{l}1 \text { [] Muito difícil } \\
2 \text { [] Um pouco difícil } \\
3 \text { [] Não é difícil } \\
9 \text { [] NS/NR }\end{array}$ \\
\hline 8.2 & $\begin{array}{l}\text { Entender o que está escrito nas bulas é: *Ler } \\
\text { as alternativas* }\end{array}$ & $\begin{array}{l}1 \text { [] Muito difícil } \\
2 \text { [] Um pouco difícil } \\
3 \text { [] Não é difícil } \\
9 \text { [] NS/NR }\end{array}$ \\
\hline 8.3 & O(a) Sr(a) já deixou de tomar algum remédio após ter lido a bula? & $\begin{array}{l}1 \text { [] Sim } \\
2 \text { [] Não }\end{array}$ \\
\hline 8.4 & $\begin{array}{l}\text { O(a) Sr(a) acha que as bulas que acompanham os remédios são } \\
\text { necessárias? }\end{array}$ & $\begin{array}{l}1 \text { [] Sim } \\
2 \text { [] Não =>Passe } \\
\text { para } 8.5 c \\
9 \text { [] NS/NR =>Passe } \\
\text { para } 8.6\end{array}$ \\
\hline
\end{tabular}




\begin{tabular}{|c|c|c|}
\hline 8.5 & $\begin{array}{l}\text { Por quê? } \\
\text { *Considere o menor pulo* }\end{array}$ & $\begin{array}{l}\text { - [] Traz } \\
\text { informações sobre a } \\
\text { composição do } \\
\text { remédio => Passe } \\
\text { para } 8.6 \\
\text { - [] Traz } \\
\text { informações sobre a } \\
\text { posologia e forma de } \\
\text { administração } \\
\text { => Passe para } 8.6 \\
\text { - [] Traz as } \\
\text { contra-indicações } \\
\text { do remédio => Passe } \\
\text { para } 8.6 \text { - [] Traz as } \\
\text { indicações de uso do } \\
\text { remédio => Passe } \\
\text { para } 8.6 \\
\text { - [] Outro }\end{array}$ \\
\hline $8.5 a$ & Se outro, qual: & $\Rightarrow$ Passe para 8.6 \\
\hline $8.5 c$ & $\begin{array}{l}\text { Por quê? } \\
\text { *Considere o menor pulo* }\end{array}$ & 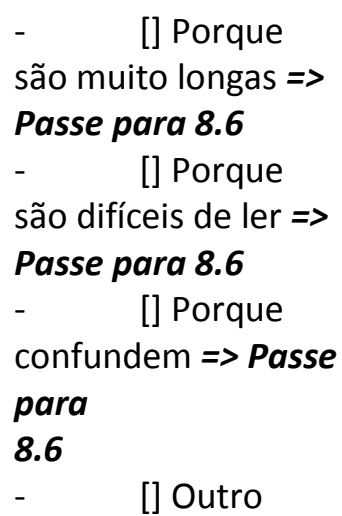 \\
\hline $8.5 d$ & Se outro, qual: & \\
\hline
\end{tabular}

\begin{tabular}{|c|c|c|}
\hline \multicolumn{3}{|c|}{$\begin{array}{l}\text { Agora, vamos falar sobre alguns problemas que as pessoas, às vezes, têm com } \\
\text { seus remédios. O quanto é difícil para o(a) } \operatorname{Sr}(a) \text { : }\end{array}$} \\
\hline 8.6 & $\begin{array}{l}\text { Abrir ou fechar as embalagens * Ler } \\
\text { as alternativas* }\end{array}$ & $\begin{array}{l}1 \text { [] Muito difícil } \\
2 \text { [] Um pouco } \\
\text { difícil } \\
3 \text { [] Não é difícil } \\
9 \text { [] NS/NR }\end{array}$ \\
\hline 8.7 & $\begin{array}{l}\text { Lembrar-se de tomar todos os remédios } \\
\text { *Ler as alternativas* }\end{array}$ & $\begin{array}{l}1 \text { [] Muito difícil } \\
2 \text { [] Um pouco } \\
\text { difícil } \\
3 \text { [] Não é difícil } \\
9 \text { [] NS/NR }\end{array}$ \\
\hline
\end{tabular}




\begin{tabular}{|l|l|l|}
\hline 8.8 & $\begin{array}{l}\text { Tomar vários comprimidos ao mesmo tempo *Ler } \\
\text { as alternativas* }\end{array}$ & 1 [] Muito difícil \\
& & $\begin{array}{l}\text { [] Um pouco } \\
\text { difícil } \\
\end{array}$ \\
& 3 [] Não é difícil \\
9 [] NS/NR
\end{tabular}

109 - ESTILO DE VIDA

Agora, vou fazer algumas perguntas sobre o seu dia-a-dia.

\begin{tabular}{|l|l|l|}
\hline 9.1 & $\begin{array}{l}\text { Com que frequência o(a) Sr(a) costuma consumir bebida } \\
\text { alcoólica? }\end{array}$ & $\begin{array}{l}1 \text { [] Não bebo nunca => Passe } \\
\text { para 9.8 } \\
2 \text { [] Menos de uma vez por } \\
\text { mês => Passe para } \\
9.3\end{array}$ \\
3 [] Uma vez ou mais por mês
\end{tabular}




\begin{tabular}{|c|c|c|}
\hline \multicolumn{3}{|c|}{$\begin{array}{l}\text { Prática de atividade física: } \\
\text { Agora falaremos sobre atividades físicas. Primeiro vamos falar das atividades físicas no trabalho. }\end{array}$} \\
\hline 9.8 & $\begin{array}{l}\text { O seu trabalho envolve atividades físicas intensas, como } \\
\text { carregar grandes pesos, capinar, trabalhar com enxada ou } \\
\text { trabalhar com construção, fazer serviços domésticos } \\
\text { dentro de casa ou no quintal por pelo menos } 10 \text { minutos } \\
\text { seguidos? }\end{array}$ & $\begin{array}{l}1 \text { [] Sim } \\
2 \text { [] Não =>Passe para } 9.11\end{array}$ \\
\hline 9.9 & $\begin{array}{l}\text { Em uma semana normal, em quantos dias o(a) } \mathrm{Sr}(\mathrm{a}) \\
\text { realiza atividades físicas intensas como parte do seu } \\
\text { trabalho? }\end{array}$ & I_l_l dias \\
\hline 9.10 & $\begin{array}{l}\text { Quanto tempo o(a) } \mathrm{Sr}(\mathrm{a}) \text { passa realizando atividades } \\
\text { físicas intensas em um dia normal de trabalho? }\end{array}$ & I_l_l:|_l_l horas \\
\hline 9.11 & $\begin{array}{l}\text { O seu trabalho envolve atividades de intensidade média } \\
\text { como caminhar em ritmo rápido ou carregar pesos leves, } \\
\text { atividades domésticas dentro de casa ou no quintal como } \\
\text { varrer, aspirar, ou cortar a grama por pelo menos } 10 \\
\text { minutos seguidos? }\end{array}$ & $\begin{array}{l}1 \text { [] Sim } \\
2 \text { [] Não =>Passe para } 9.14\end{array}$ \\
\hline 9.12 & $\begin{array}{l}\text { Em uma semana normal, quantos dias o(a) Sr(a) realiza } \\
\text { atividades de intensidade moderada como parte do seu } \\
\text { trabalho? }\end{array}$ & I_I_l dias \\
\hline 9.13 & $\begin{array}{l}\text { Quanto tempo o(a) Sr(a) passa realizando atividades } \\
\text { físicas de intensidade moderada em um dia normal de } \\
\text { trabalho? }\end{array}$ & $\left|\_\right| \_|:| \_\left|\_\right|$horas \\
\hline \multicolumn{3}{|c|}{$\begin{array}{l}\text { Atividade Física no Deslocamento } \\
\text { Agora vamos falar sobre atividades físicas que você faz no seu deslocamento de um lugar para o } \\
\text { outro. Por favor, não repita as atividades que você já mencionou anteriormente. }\end{array}$} \\
\hline 9.14 & $\begin{array}{l}\mathrm{O}(\mathrm{a}) \mathrm{Sr}(\mathrm{a}) \text { caminha ou utiliza bicicleta por pelo menos } 10 \\
\text { minutos seguidos para ir de um lugar para outro? }\end{array}$ & $\begin{array}{l}1 \text { [] Sim } \\
2 \text { [] Não =>Passe para } 9.17\end{array}$ \\
\hline 9.15 & $\begin{array}{l}\text { Em uma semana normal, em quantos dias o(a) } \mathrm{Sr}(\mathrm{a}) \\
\text { caminha ou anda de bicicleta por pelo menos } 10 \text { minutos } \\
\text { seguidos para ir de um lugar a outro? }\end{array}$ & I_I_l dias \\
\hline 9.16 & $\begin{array}{l}\text { Quanto tempo o(a) } \mathrm{Sr}(\mathrm{a}) \text { passa caminhando ou andando } \\
\text { de bicicleta para ir de um lugar a outro em um dia } \\
\text { normal? }\end{array}$ & $\left|\_\right| \_|:| \_\left|\_\right|$horas \\
\hline \multicolumn{3}{|c|}{$\begin{array}{l}\text { Atividades Físicas Intensas no Lazer } \\
\text { Agora vamos falar sobre atividades físicas que você realiza no seu tempo livre. Novamente, por } \\
\text { favor, não repita o que você já mencionou nas questões anteriores. }\end{array}$} \\
\hline 9.17 & $\begin{array}{l}\text { O(a) Sr(a) realiza algum esporte, exercício físico ou } \\
\text { atividade recreativa intensa como correr ou praticar } \\
\text { esportes intensos como ginástica aeróbica, futebol, } \\
\text { pedalar rápido de bicicleta, basquete, vôlei, musculação, } \\
\text { lutas por pelo menos } 10 \text { minutos seguidos? }\end{array}$ & $\begin{array}{l}1 \text { [] Sim } \\
2 \text { [] Não =>Passe para } 9.20\end{array}$ \\
\hline
\end{tabular}




\begin{tabular}{|c|c|c|}
\hline 9.18 & $\begin{array}{l}\text { Em uma semana normal, em quantos dias o(a) } \mathrm{Sr}(\mathrm{a}) \\
\text { realiza esportes, exercícios físicos ou atividades } \\
\text { recreativas intensas? }\end{array}$ & I_I_l dias \\
\hline 9.19 & $\begin{array}{l}\text { Quanto tempo o(a) } \mathrm{Sr}(\mathrm{a}) \text { passa realizando esportes, } \\
\text { exercícios físicos ou atividades recreativas intensas em } \\
\text { um dia normal? }\end{array}$ & I_l_l:|_l_l horas \\
\hline \multicolumn{3}{|c|}{ Atividades Físicas Médias no Lazer } \\
\hline 9.20 & $\begin{array}{l}\text { O(a) Sr(a) realiza algum esporte, exercício físico ou } \\
\text { atividade recreativa de intensidade média como caminhar } \\
\text { rápido, pedalar devagar a bicicleta, nadar, ginástica, yôga, } \\
\text { pilates, jogar esportes recreativos por pelo menos } 10 \\
\text { minutos seguidos? }\end{array}$ & $\begin{array}{l}1 \text { [] Sim } \\
2 \text { [] Não =>Passe para } 9.23\end{array}$ \\
\hline 9.21 & $\begin{array}{l}\text { Em uma semana normal, em quantos dias o(a) } \mathrm{Sr}(\mathrm{a}) \\
\text { realiza esportes, exercícios físico ou atividades recreativas } \\
\text { de intensidade média? }\end{array}$ & I_I_l dias \\
\hline 9.22 & $\begin{array}{l}\text { Quanto tempo o(a) Sr(a) passa realizando esportes, } \\
\text { exercícios físicos ou atividades recreativas de intensidade } \\
\text { média em um dia normal? }\end{array}$ & I_l_l:|_l_l horas \\
\hline \multicolumn{3}{|c|}{$\begin{array}{l}\text { Comportamento sedentário } \\
\text { Agora falaremos sobre o tempo que você passa sentado ou deitado, mas sem contar o tempo em } \\
\text { que você está dormindo. }\end{array}$} \\
\hline 9.23 & $\begin{array}{l}\text { Quanto tempo o(a) Sr(a) costuma ficar sentado ou } \\
\text { reclinado em um dia habitual? }\end{array}$ & I_l_l:I_l_l horas \\
\hline
\end{tabular}

Agora vou fazer algumas perguntas para o senhor relacionadas ao uso de cigarro.

\begin{tabular}{|c|c|c|}
\hline & Fumo: & \\
\hline 9.24 & $\mathrm{O}(\mathrm{a}) \mathrm{Sr}(\mathrm{a})$ fuma? & $\begin{array}{l}1 \text { [] Sim } \\
2 \text { []Não => Passe para } 9.27\end{array}$ \\
\hline $9.24 a$ & $\mathrm{O}(\mathrm{a}) \mathrm{Sr}(\mathrm{a})$ fuma todos os dias? & $\begin{array}{l}1 \text { [] Sim } \\
2 \text { []Não => Passe para } 9.26\end{array}$ \\
\hline 9.25 & Quantos cigarros o(a) Sr(a) fuma por dia? & $\begin{array}{l}I \_I-I \text { cigarros por dia } \\
99=\text { NS/NR }\end{array}$ \\
\hline 9.26 & $\begin{array}{l}\text { Que idade o(a) Sr(a) tinha quando começou a fumar } \\
\text { regularmente? } \\
\text { *Caso o entrevistado relate uma idade aproximada, anote } \\
\text { a idade aproximada declarada por ele* }\end{array}$ & $\begin{array}{l}\left|\_\right| \_\mid \text {anos =>Passe para } \\
9.30 \\
99=\mathrm{NS} / \mathrm{NR}=>\text { Passe para } 9.30\end{array}$ \\
\hline 9.27 & O(a) Sr(a) já fumou regularmente? & $\begin{array}{l}1 \text { [] Sim } \\
2 \text { [] Não => Passe para } 9.31\end{array}$ \\
\hline 9.28 & $\begin{array}{l}\text { Que idade o(a) Sr(a) tinha quando começou a fumar } \\
\text { regularmente? } \\
\text { *Caso o entrevistado relate uma idade aproximada, anote } \\
\text { a idade aproximada declarada por ele* }\end{array}$ & $\left.I_{-1} I_{-N S / N R}\right|^{\prime}$ \\
\hline
\end{tabular}




\begin{tabular}{|l|l|l|}
\hline 9.29 & $\begin{array}{l}\text { Que idade o(a) Sr(a) tinha quando parou de fumar? } \\
\text { o entrevistado relate uma idade aproximada, anote a } \\
\text { idade aproximada declarada por ele* }\end{array}$ & $\begin{array}{l}\text { I__ I__ I => Passe para 9.31 } \\
99=\mathrm{NS} / \mathrm{NR}\end{array}$ \\
\hline 9.30 & $\begin{array}{l}\text { Algum médico já lhe recomendou parar de fumar? } \\
1 \text { [] Sim } \\
2 \text { [] Não } \\
9 \text { [] NS/NR }\end{array}$ \\
\hline
\end{tabular}

Agora vou fazer algumas perguntas relacionadas a sua dieta alimentar.

\begin{tabular}{|c|c|c|}
\hline & Dieta & \\
\hline 9.31 & O(a) Sr(a) está fazendo alguma dieta para perder peso? & $\begin{array}{l}1 \text { [] Sim } \\
2 \text { [] Não }\end{array}$ \\
\hline 9.32 & $\begin{array}{l}\text { O(a) Sr(a) faz alguma dieta para reduzir o consumo de } \\
\text { sal? }\end{array}$ & $\begin{array}{l}1 \text { [] Sim } \\
2 \text { [] Não }\end{array}$ \\
\hline 9.33 & $\begin{array}{l}\text { O(a) Sr(a) faz alguma dieta para reduzir o consumo de } \\
\text { gordura? }\end{array}$ & $\begin{array}{l}1 \text { [] Sim } \\
2 \text { [] Não }\end{array}$ \\
\hline 9.34 & O(a) Sr(a) faz alguma dieta para reduzir o açúcar? & $\begin{array}{l}1 \text { [] Sim } \\
2 \text { [] Não }\end{array}$ \\
\hline 9.35 & $\mathrm{O}(\mathrm{a}) \mathrm{Sr}(\mathrm{a})$ faz uso de algum adoçante na sua dieta? & $\begin{array}{l}1 \text { [] Sim } \\
2 \text { [] Não => Passe para } 9.36\end{array}$ \\
\hline $9.35 a$ & Qual? & $\begin{aligned} 1 & \text { [] Zero-Cal => Passe para } \\
& 9.36 \\
2 & \text { [] Assugrin => Passe para } \\
& 9.36 \\
3 & \text { [] Finn => Passe para } 9.36 \\
4 & \text { [] Linea => Passe para } \\
& 9.36 \\
5 & \text { [] Magro => Passe para } \\
& 9.36 \\
6 & \text { [] Stevita => Passe para } \\
& 9.36 \\
7 & \text { [] Lowçucar => Passe para } \\
& 9.36 \\
8 & \text { [] Gold => Passe para } 9.36 \\
9 & \text { [] União => Passe para } \\
& 9.36 \\
10 & \text { [] Outro }\end{aligned}$ \\
\hline \multirow[t]{2}{*}{$9.35 b$} & Se outro, qual: & \\
\hline & Se sim para alguma das 5 perguntas acima: & \\
\hline 9.36 & $\begin{array}{l}\text { Qual o principal motivo que levou o(a) } \operatorname{Sr}(a) \text { a fazer esta } \\
\text { dieta? }\end{array}$ & $\begin{array}{l}1 \quad \text { [] Por } \\
\text { aconselhamento médico => } \\
\text { Passe para } 9.37 \\
2 \quad \text { [] Por decisão } \\
\text { própria => Encerre o bloco } \\
3 \text { [] Outro }\end{array}$ \\
\hline
\end{tabular}




\begin{tabular}{|c|c|c|}
\hline $9.36 a$ & Se outro, qual: & $\Rightarrow>$ Encerre o bloco \\
\hline 9.37 & $\begin{array}{l}\text { Para qual problema de saúde recebeu esta recomendação } \\
\text { médica? }\end{array}$ & 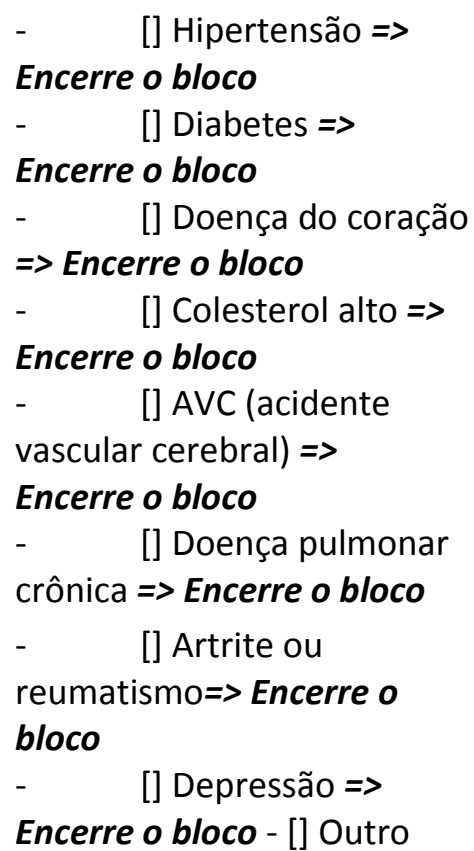 \\
\hline 9.37 & Se outro, qual: & $\Rightarrow$ Encerre o bloco \\
\hline
\end{tabular}




\section{I10 - PLANO DE SAÚDE}

Agora, vou fazer algumas perguntas referentes a planos de saúde.

\begin{tabular}{|c|c|c|}
\hline 10.1 & $\begin{array}{l}\text { O(a) Sr(a) tem plano de saúde ou convênio } \\
\text { médico? }\end{array}$ & $\begin{array}{l}1 \text { [] Sim } \\
2 \text { [] Não => Encerre o bloco } \\
3 \text { [] Não sabe => Encerre o bloco }\end{array}$ \\
\hline 10.2 & $\begin{array}{l}\text { Qual o nome do(s) plano(s) de saúde ou } \\
\text { convênio(s)? }\end{array}$ & \\
\hline \multirow[t]{2}{*}{10.3} & O(a) Sr(a) é o titular deste plano? & $\begin{array}{l}1 \text { [] Sim } \\
2 \text { [] Não }\end{array}$ \\
\hline & O(s) plano(s) ou convênio(s) cobre(m): & \\
\hline 10.4 & $\begin{array}{l}\text { Consulta médica? } \\
{ }^{*} \text { COPAGAMENTO: O entrevistado paga } \\
\text { apenas uma parte da consulta* }\end{array}$ & $\begin{array}{l}1 \text { [] Não } \\
2 \text { [] Tenho desconto no preço } \\
3 \text { [] O plano cobre, mas tem copagamento } \\
4 \text { [] O plano cobre integral } \\
5 \text { [] Eu pago e o plano reembolsa } \\
9 \text { [] NS/NR }\end{array}$ \\
\hline 10.5 & $\begin{array}{l}\text { Internação? } \\
\text { *COPAGAMENTO: O entrevistado paga } \\
\text { apenas uma parte da internação* }\end{array}$ & $\begin{array}{ll}1 & \text { [] Não } \\
2 & \text { [] Tenho desconto no preço } \\
3 & \text { [] O plano cobre, mas tem } \\
\text { copagamento } \\
4 \quad \text { [] O plano cobre integral } 5 \text { [] Eu } \\
\text { pago e o plano reembolsa } \\
9 \text { [] NS/NR }\end{array}$ \\
\hline 10.6 & $\begin{array}{l}\text { Exames? } \\
{ }^{*} \text { COPAGAMENTO: O entrevistado paga } \\
\text { apenas uma parte do exame* }\end{array}$ & $\begin{array}{ll}1 & \text { [] Não } \\
2 & \text { [] Tenho desconto no preço } \\
3 & \text { [] O plano cobre, mas tem } \\
\text { copagamento } \\
4 \quad \text { [] O plano cobre integral } 5 \text { [] Eu } \\
\text { pago e o plano reembolsa } \\
9 \text { [] NS/NR }\end{array}$ \\
\hline 10.7 & $\begin{array}{l}\text { Medicamentos (fora da internação)? } \\
{ }^{*} \text { COPAGAMENTO: O entrevistado paga } \\
\text { apenas uma parte do medicamento* }\end{array}$ & $\begin{array}{ll}1 & \text { [] Não => Encerre o bloco } \\
2 & \text { [] Alguns medicamentos } \\
3 & \text { [] Tenho desconto no preço => } \\
\text { Encerre o bloco } \\
4 \quad \text { [] O plano cobre, mas tem } \\
\text { copagamento => } \\
\text { Encerre o bloco } \\
5 \quad \text { [] O plano cobre integral => } \\
\text { Encerre o bloco } 6 \text { [] Eu pago e o plano } \\
\text { reembolsa => Encerre o bloco } \\
9 \text { [] NS/NR => Encerre o bloco }\end{array}$ \\
\hline $10.7 \mathrm{a}$ & $\begin{array}{l}\text { Para quais doenças são os medicamentos que } \\
\text { o(s) plano(s) ou convênio(s) cobre }(\mathrm{m}) \text { ? }\end{array}$ & $\Rightarrow$ Encerre o bloco \\
\hline
\end{tabular}




\section{I11 - INFORMAÇÕES SOBRE O DOMICÍLIO E DA PESSOA DE REFERÊNCIA}

Agora, preciso de algumas informações sobre este domicílio.

\begin{tabular}{|c|c|c|c|c|c|c|}
\hline \multicolumn{7}{|c|}{ INFORMAÇÕES SOBRE O DOMICÍLIO } \\
\hline \multicolumn{7}{|c|}{ BENS DOMÉSTICOS } \\
\hline \multirow{3}{*}{$\begin{array}{l}1.1 \\
\end{array}$} & \multicolumn{6}{|c|}{$\begin{array}{l}\text { Vou Ihe apresentar um conjunto de itens e gostaria de saber quais existem em seu } \\
\text { domicílio. Para cada item que o(a) } \operatorname{Sr}(a) \text { responder sim, vou lhe perguntar a } \\
\text { quantidade. }\end{array}$} \\
\hline & Neste domicílio o(a) Sr(a) tem: & & & & & \\
\hline & Quantidade & 0 & 1 & 2 & 3 & 4+ \\
\hline 11.2 & Televisão em cores & & & & & \\
\hline 11.3 & Rádio (não considerar rádio de automóvel) & & & & & \\
\hline 11.4 & $\begin{array}{l}\text { Banheiro (não considerar se servirem a mais de uma } \\
\text { habitação, nem lavabos) }\end{array}$ & & & & & \\
\hline 11.5 & Automóvel (de uso particular) & & & & & \\
\hline 11.6 & $\begin{array}{l}\text { Empregada mensalista (trabalhar pelo menos } 5 \text { dias por } \\
\text { semana) }\end{array}$ & & & & & \\
\hline 11.7 & Máquina de lavar roupa (não considerar o tanquinho) & & & & & \\
\hline 11.8 & Videocassete / DVD & & & & & \\
\hline 11.9 & Geladeira & & & & & \\
\hline 11.10 & $\begin{array}{l}\text { Freezer (aparelho independente ou parte da geladeira } \\
\text { duplex) }\end{array}$ & & & & & \\
\hline 11.11 & Microcomputador & & & & & \\
\hline 11.12 & Micoondas & & & & & \\
\hline 11.13 & Motocicleta & & & & & \\
\hline 11.14 & Secadora de roupa & & & & & \\
\hline
\end{tabular}

\begin{tabular}{|c|c|c|}
\hline 11.15 & $\begin{array}{l}\text { Quantos cômodos existem neste domicílio? } \\
\text { (incluindo banheiro, área de serviço e demais } \\
\text { divisões) }\end{array}$ & $I_{99=N S / N R}$ \\
\hline 11.16 & $\begin{array}{l}\text { Quantos cômodos (peças da casa) servem } \\
\text { como dormitório (quartos) no seu domicílio? }\end{array}$ & $I_{99}=I_{N S / N R}$ \\
\hline 11.17 & $\begin{array}{l}\text { Qual é a renda mensal total dos moradores } \\
\text { deste domicílio? }\end{array}$ & 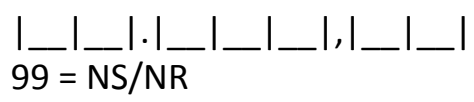 \\
\hline 11.18 & O domicílio possui agua encanada? & $\begin{array}{l}1 \text { [] Sim } \\
2 \text { [] Não } \\
9 \text { [] NS/NR }\end{array}$ \\
\hline
\end{tabular}




\begin{tabular}{|c|c|c|}
\hline 11.19 & A rua é pavimentada? & $\begin{array}{l}1 \text { [] Sim } \\
2 \text { [] Não } \\
9 \text { [] NS/NR }\end{array}$ \\
\hline 11.20 & Quantas pessoas dependem desta renda? & $I_{-} I_{-} \mid$ \\
\hline 11.21 & Recebe auxílio do governo como: & \\
\hline 11.22 & Bolsa família? & $\begin{array}{l}1 \text { [] } \mathrm{Sim} \\
2 \text { [] Não } \\
9 \text { [] NS/NR }\end{array}$ \\
\hline 11.23 & Seguro desemprego? & $\begin{array}{l}1 \text { [] } \mathrm{Sim} \\
2 \text { [] Não } \\
9 \text { [] NS/NR }\end{array}$ \\
\hline 11.24 & $\begin{array}{l}\text { Outro auxílio? } \\
\text { *A aposentadoria deve ser considerada na } \\
\text { renda mensal, e não como auxílio* }\end{array}$ & $\begin{array}{l}1 \text { [] Sim } \\
2 \text { [] Não => Passe para } 11.25 \\
9 \text { [] NS/NR => Passe para } 11.25\end{array}$ \\
\hline $11.24 a$ & Qual ? & \\
\hline 11.25 & $\begin{array}{l}\text { No último ano, a família deixou de comprar } \\
\text { algo importante para o seu dia a dia, } \\
\text { precisou fazer algum empréstimo, ou } \\
\text { vendeu algo para pagar gastos com algum } \\
\text { problema de saúde? }\end{array}$ & $\begin{array}{l}1 \text { [] Sim } \\
2 \text { [] Não => Passe para } 11.28 \\
9 \text { [] NS/NR => Passe para } 11.28\end{array}$ \\
\hline 11.26 & Que tipo de problema ocasionou este gasto? & $\begin{array}{l}1 \text { [] Remédios => Passe para } 11.27 \\
2 \text { [] Consulta médica => Passe para } \\
\mathbf{1 1 . 2 7} \\
3 \text { [] Exame de laboratório ou } \\
\text { imagem => } \\
\text { Passe para } \mathbf{1 1 . 2 7} \\
4 \text { [] Internação clínica => Passe } \\
\text { para } \mathbf{1 1 . 2 7} \\
5 \text { [] Cirurgia => Passe para } 11.27 \\
6 \text { [] Outro } \\
9 \text { [] NS/NR => Passe para } 11.27\end{array}$ \\
\hline $11.26 a$ & Se outro, qual: & \\
\hline 11.27 & Como foi que a família lidou com esse gasto? & $\begin{array}{l}1 \quad \text { [] Deixou de comprar } \\
\text { alimento => Passe para } \mathbf{1 1 . 2 8} \\
2 \quad \text { [] Deixou de pagar contas } \\
=>\text { Passe para } \\
\mathbf{1 1 . 2 8} \\
3 \quad \text { [] Fez empréstimo de } \\
\text { amigo ou familiar } \\
=>\text { Passe para } 11.28 \\
4 \quad \text { [] Fez empréstimo de } \\
\text { banco ou financeira => Passe para } \\
11.285 \text { [] Vendeu algum bem }=> \\
\text { Passe para } \\
\mathbf{1 1 . 2 8}\end{array}$ \\
\hline
\end{tabular}




\begin{tabular}{|l|l|l|}
\hline \multicolumn{1}{|l|}{} & & 6 [] Outro \\
9 [] NS/NR => Passe para 11.28 \\
\end{tabular}

Agora, gostaria de obter algumas informações sobre a pessoa de referência. [A pessoa de referência é aquela que o entrevistado identifica como tal. Caso o entrevistado não consiga apontar claramente quem é, deve ser indicada a pessoa de maior renda ou de maior idade]

\begin{tabular}{|c|c|c|}
\hline \multicolumn{3}{|c|}{ INFORMAÇÕES SOBRE A PESSOA DE REFERÊNCIA } \\
\hline 11.28 & $\begin{array}{l}\text { Quem é a pessoa de referência da } \\
\text { família? }\end{array}$ & $\begin{array}{l}\text { I____ I Número na lista de dos } \\
\text { moradores *Se o entrevistado se } \\
\text { declarar ser a pessoa de } \\
\text { referência, encerre o bloco.* }\end{array}$ \\
\hline 11.29 & $\begin{array}{l}\text { A pessoa de referência da família vive } \\
\text { em companhia de cônjuge ou } \\
\text { companheiro(a)? }\end{array}$ & $\begin{array}{l}1 \text { [] Sim } \\
2 \text { [] Não, mas já viveu antes } \\
3 \text { [] Nunca viveu }\end{array}$ \\
\hline 11.30 & $\begin{array}{l}\text { A cor ou raça da pessoa de referência é: } \\
\text { * Ler as alternativas* }\end{array}$ & $\begin{array}{l}1 \text { [] Branca } \\
2 \text { [] Preta } \\
3 \text { [] Amarela } \\
4 \text { [] Parda } \\
5 \text { [] Indígena } \\
\end{array}$ \\
\hline 11.31 & $\begin{array}{l}\text { Até que série a pessoa de referência } \\
\text { completou na escola? }\end{array}$ & 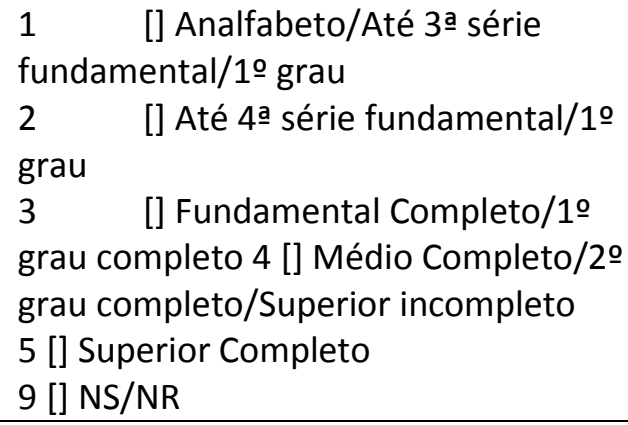 \\
\hline
\end{tabular}

Para concluir, gostaria de fazer uma última pergunta: 


\begin{tabular}{|l|l|l|}
\hline 11.32 & Em geral, como o(a) Sr(a) avalia sua & 1 [] Muito boa \\
& saúde? & 2 [] Boa \\
& & 3 [] Regular \\
& & 4 [] Ruim \\
& 5 [] Muito ruim \\
\hline
\end{tabular}

\section{PARA O PREENCHIMENTO DO ENTREVISTADOR}

*Preencher sem perguntar*

\begin{tabular}{|c|c|c|}
\hline 11.33 & O questionário foi respondido: & $\begin{array}{l}1 \text { [] Todo pelo(a) } \\
\text { entrevistado(a), sem ajuda } \\
2 \quad \text { [] Todo pelo(a) } \\
\text { entrevistado(a), com ajuda } 3 \text { [] Maior } \\
\text { parte das respostas foi dada por outra } \\
\text { pessoa } \\
5 \text { [] Todas as respostas foram dadas por } \\
\text { outra pessoa (proxy) }\end{array}$ \\
\hline
\end{tabular}

O nosso trabalho é supervisionado pela Datamétrica, assim, pode ser que outro pesquisador entre em contato com o(a) $\mathrm{Sr}(\mathrm{a})$ por telefone para confirmar apenas alguns dados para avaliação do meu trabalho. Agradeço a sua participação, colaboração e paciência.

Horário do final da entrevista $\mid \_l[\mid$ ____ 